Masters' Degree in Informatics Engineering Dissertation

Final Report

$2014 / 2015$

\title{
A serious game with virtual reality for travel training with Autism Spectrum Disorder
}

Miguel Rasteiro Simões Bernardes mrsimoes@student.dei.uc.pt

Advisors:

Fernando Barros

Department of Informatics Engineering

Marco Simões

Institute for Biomedical Imaging and Life Sciences

July 6, 2015

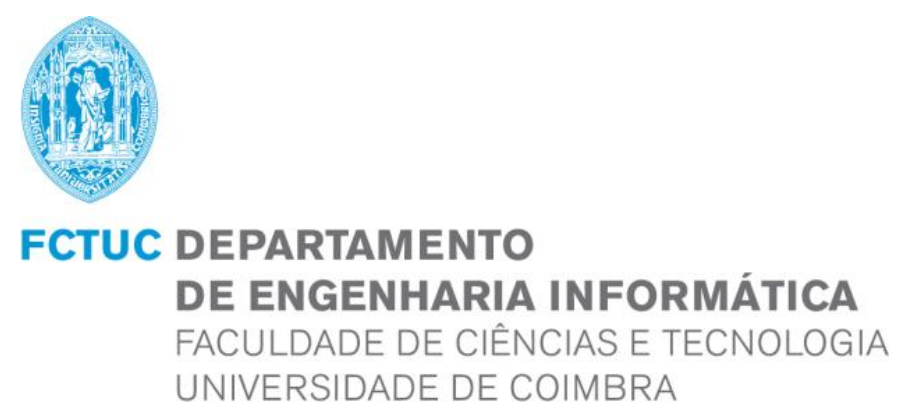


Masters' Degree in Informatics Engineering Dissertation

Final Report

$2014 / 2015$

\section{A serious game with virtual reality for travel training with Autism Spectrum Disorder}

Miguel Rasteiro Simões Bernardes

mrsimoes@student.dei.uc.pt

Advisors:

Fernando Barros

Department of Informatics Engineering

Marco Simões

Institute for Biomedical Imaging and Life Sciences

Jury:

Pedro Abreu

Department of Informatics Engineering

Alexandre Miguel Pinto

Department of Informatics Engineering

Fernando Barros

Department of Informatics Engineering

July 6, 2015

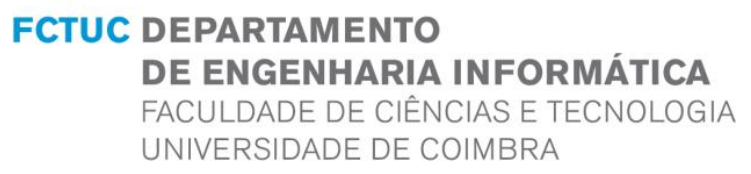





\section{Acknowledgements}

I would like to thank my advisers, Marco Simões and Professor Fernando Barros, for all the assistance provided during this project. Their guidance and knowledge were crucial to the success of this study.

I would also like to express my gratitude to Professor Miguel Castelo-Branco, for welcoming me in IBILI, for all the support offered, and for making sure that all my needs were met.

Also essential to this project, was the support of APPDA-Viseu and APPDACoimbra, more specifically of Prazeres Domingues and Tânia Morais, who established the connection between me and all the participants that were a part of this study. To these participants, thank you for your time and dedication.

Susana Mouga was my connection to Autism Spectrum Disorder, without whom I would not have been able to properly understand this disorder.

Hélio Gonçalves was the 3D modeller from the development team, who was always there for me whenever I needed a new, optimized model to replace the heavy ones, downloaded from the internet.

To all my friends in IBILI, for all the unforgettable moments, and for making sure that my stay in IBILI is a memory to be fond of.

To my family, for always being there for me, everyday, making sure I would come home to a warm and welcoming environment.

Last but not least, to my friends Catarina Parente, João Leal, Mariana Moutinho, Mariana Seiça, and Paulo Fernandes, for their kindness and support. 



\section{Abstract}

Autism Spectrum Disorder (ASD) is a neurodevelopmental disorder characterised by impairments in social interaction and repetitive patterns of behaviour which can lead to deficits in adaptive behaviour. This project involves the creation of a serious game that prepares individuals with ASD to use buses as a mean of transportation. The aim is to use the game as a safe environment where the players become familiar with the process of taking a bus. By adding virtual reality support, the feeling of presence in the scene is increased and the experience becomes more realistic, thus increasing its potential as a learning tool. More specifically, the game consists of placing the player in a three-dimensional city and setting a task which involves taking a bus to reach a specific destination. This includes activities such as planning a route, waiting for the right bus, choosing a place to sit and deciding when to press the STOP button to leave. In order to measure the player's performance, two different methods were used: a score system which focuses on the player's actions, and a biofeedback system based on Electrodermal Activity (EDA), which measures the anxiety level of the player throughout the task. With these systems, it is possible to analyse the impact of practice on both task performance and anxiety reduction. The game was developed using the Unity game engine and used the Oculus Rift as virtual reality headset. Following the development of the application, a validation phase took place in which its rehabilitation potential was evaluated throughout three therapy sessions. The results obtained revealed a major reduction in anxiety experienced when exposed to bus environments, statistically significant improvements in the knowledge of the bus process and norms, and a high success rate of their application within the game. In conclusion, the results of this project were useful in understanding how games and virtual reality can help individuals with ASD become more independent, specifically regarding to the task of taking the bus.

Keywords: Autism Spectrum Disorder, Serious Game, Virtual Reality, Virtual Reality Therapy 



\section{Resumo}

A Perturbação do Espetro do Autismo (PEA) é um distúrbio do neurodesenvolvimento caracterizado por incapacidades ao nível da interação social e por padrões de comportamentos repetitivos que podem levar a défices no comportamento adaptativo. Este projeto visa a criação de um serious game que prepare indivíduos com PEA para a utilização de autocarros como meio de transporte. O objetivo é disponibilizar, sob a forma de um jogo, um ambiente seguro onde os jogadores possam ficar familiarizados com o processo de apanhar um autocarro. Através da utilização de tecnologias de realidade virtual, a sensação de presença no jogo é aumentada, tornando-se a experiência mais realista e, consequentemente, aumentando o seu potencial como ferramenta de aprendizagem. O jogador é colocado numa cidade em três dimensões, sendo-lhe atribuída uma tarefa que consiste em apanhar um autocarro para chegar a um determinado destino, implicando atividades como o planeamento do percurso, esperar pelo autocarro certo, escolher um lugar para sentar, e decidir quando carregar no botão de STOP para sair. De forma a medir o desempenho do jogador, foram utilizados dois métodos: um sistema de pontuação que se foca nas ações do jogador e um sistema de biofeedback que utiliza a condutância galvânica da pele para avaliar os níveis de ansiedade do jogador ao longo da tarefa. Estes sistemas permitem avaliar o impacto da prática tanto ao nível do desempenho como na redução da ansiedade. O jogo foi desenvolvido utilizando a plataforma de desenvolvimento de jogos Unity e o capacete de realidade virtual Oculus Rift. Após o desenvolvimento da aplicação, foi feita uma fase de validação na qual o potencial de reabilitação do jogo foi avaliado ao longo de três sessões de terapia. Os resultados obtidos demonstraram uma forte redução da ansiedade sentida por parte dos jogadores, quando expostos ao ambiente do autocarro. Foram também registados melhoramentos estatisticamente significativos ao nível dos conhecimentos demonstrados em relação ao processo de andar de autocarro e normas envolvidas, assim como uma elevada taxa de sucesso na aplicação destes conhecimentos dentro do jogo. Os resultados deste projeto foram úteis na compreensão do contributo dos jogos e da realidade virtual para tornar indivíduos com PEA mais independentes, especialmente no que toca à utilização de autocarros como meio de transporte.

Keywords: Perturbação do Espetro do Autismo, Serious Games, Realidade Virtual, Terapia de Exposição à Realidade Virtual 



\section{Contents}

1 Introduction 1

1.1 Background ....................... 1

1.2 Purpose .............................. 1

1.3 Work done and contributions . . . . . . . . . . . . . 2

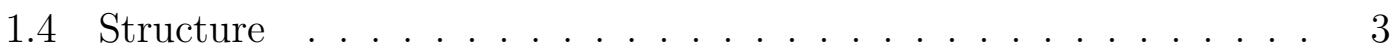

2 Background $\quad 4$

2.1 Autism Spectrum Disorder . . . . . . . . . . . . . . . . . . 4

2.1.1 Symptoms . . . . . . . . . . . . . . . . 4

2.1 .2 Diagnosis . . . . . . . . . . . . . . . 5

2.1 .3 Causes . . . . . . . . . . . . . . . . . 5

2.1.4 Prevalence . . . . . . . . . . . . . . . . 6

2.1.5 Treatment . . . . . . . . . . . . . . 6

2.2 Virtual Reality . . . . . . . . . . . . . . . . . . 7

2.3 Head Mounted Displays . . . . . . . . . . . . . . . . . . . 9

2.4 Electrodermal Activity . . . . . . . . . . . . . . . . . 11

3 State of the Art $\quad 12$

3.1 Virtual Reality Therapy . . . . . . . . . . . . . . . . . 12

3.1.1 Phobias . . . . . . . . . . . . . . . . . . 12

3.1.2 Posttraumatic Stress Disorder . . . . . . . . . . . . . 13

3.1.3 Pain distraction . . . . . . . . . . . . . . . . . . . 14

3.1.4 Autism Spectrum Disorder . . . . . . . . . . . . . . . . . 14

3.1.5 Conclusion . . . . . . . . . . . . . . . . . . 14

3.2 Serious Games . . . . . . . . . . . . . . . . . 16

3.3 Biofeedback . . . . . . . . . . . . . . . . . 19

3.3.1 Anxiety and stress . . . . . . . . . . . . . . . . 19

3.3 .2 Other purposes . . . . . . . . . . . . . . . 20

4 Objectives and Planning $\quad 21$

4.1 Objectives . . . . . . . . . . . . . . . . . . . . . . . 21

4.2 Requirements . . . . . . . . . . . . . . . . . 22

4.3 Development Methodology . . . . . . . . . . . . . . . . . . . 24

4.4 Work Plan . . . . . . . . . . . . . . . . . . . . . 24 
5 Game development $\quad \mathbf{2 6}$

5.1 Choosing a Game Engine . . . . . . . . . . . . . . . . . . . . 26

5.1 Primary requirements evaluation . . . . . . . . . 27

5.1.2 Documentation and community size evaluation . . . . . . . 28

5.1.3 Self-experimentation and Secondary Requirements . . . . . . 29

5.1 .4 Conclusion . . . . . . . . . . . . . . . . 30

5.2 Development of Stage 1 . . . . . . . . . . . . . . . . . . 30

5.2.1 Specification . . . . . . . . . . . . . . . 31

5.2 .2 Implementation . . . . . . . . . . . . . . . . . . . 34

5.2 .3 Testing. . . . . . . . . . . . . . . . . 37

5.3 Development of Stage 2 . . . . . . . . . . . . . . . . . . . . . . . . . . . . . . . 45

5.3 .1 Specification . . . . . . . . . . . . . . 45

5.3 .2 Implementation . . . . . . . . . . . . . . . . . . . 47

5.3 .3 Testing. . . . . . . . . . . . . . . . 53

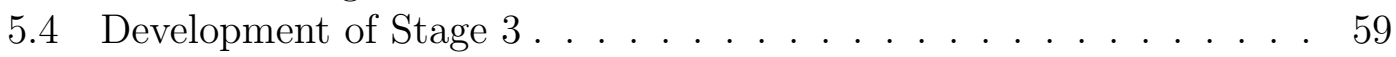

5.4 Specification . . . . . . . . . . . . . . 59

5.4 .2 Implementation . . . . . . . . . . . . . . . . . . 60

5.4 .3 Testing. . . . . . . . . . . . . . . . . 74

5.5 Conclusion . . . . . . . . . . . . . . . . . . . . . 78

$\begin{array}{llr}6 & \text { Therapy and Results } & \mathbf{7 9}\end{array}$

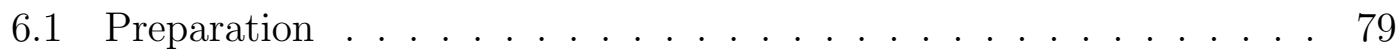

6.2 Design and Procedure . . . . . . . . . . . . . . . . . 80

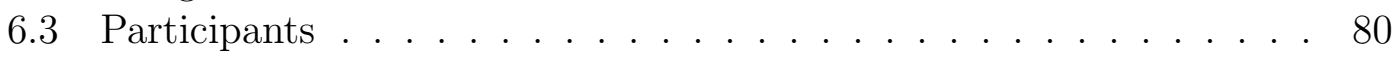

6.4 Materials . . . . . . . . . . . . . . . . . 82

6.5 Results. . . . . . . . . . . . . . . . . . . 82

6.5.1 Performance changes . . . . . . . . . . . . . . . 82

6.5.2 Anxiety Changes . . . . . . . . . . . . . . . . . . 84

6.5.3 Knowledge Retention . . . . . . . . . . . . . . . . 87

6.6 Conclusions . . . . . . . . . . . . . . . . . . . . . . . . . . 93

7 Conclusion and Future Work $\quad 95$

$\begin{array}{ll}\text { Bibliography } & 96\end{array}$

$\begin{array}{ll}\text { A Poster presented at IBILI Meeting 2014 } & 107\end{array}$

$\begin{array}{ll}\text { B Poster presented at ICVR2015 } & 109\end{array}$

$\begin{array}{ll}\text { C Unity development } & 113\end{array}$ 


\section{Glossary}

ADI-R Autism Diagnosis Interview - Revised.

ADOS Autism Diagnostic Observation Schedule.

APPDA Associação Portuguesa para as Perturbações do Desenvolvimento e Autismo.

ASD Autism Spectrum Disorder.

CV Consumer Version.

DK Development Kit.

DSM-5 Diagnostic and Statistical Manual of Mental Disorders, 5th edition.

EDA Electrodermal Activity.

GUI Graphical User Interface.

HMD Head-mounted display.

HUD Heads-up Display.

IBILI Institute for Biomedical Imaging and Life Sciences.

ICVR International Conference on Virtual Rehabilitation.

IQ Intelligence Quotient.

OLED Organic Light-emitting Diode.

OS Operating System.

PTSD Posttraumatic Stress Disorder.

VE Virtual Environment.

VR Virtual Reality.

VRT Virtual Reality Therapy. 



\section{List of Figures}

2.1 Oculus Rift, a fully immersive VR system. . . . . . . . . . . . . . . 8

2.2 CAVE, a semi-immersive VR system. . . . . . . . . . . . 8

2.3 Oculus Rift DK1. . . . . . . . . . . . . . . . . . . . 10

2.4 Oculus Rift's display, with one image for each eye. . . . . . . . . . . 10

2.5 Example of an increase in Electrodermal Activity (EDA) level. . . . 11

3.1 Zakari et al. [1] serious game platforms. . . . . . . . . . . . 16

3.2 Zakari et al. [1] serious game computer graphics style. . . . . . . . . 17

3.3 Zakari et al. [1] serious game purposes. . . . . . . . . . . . . . . . 17

3.4 Zakari et al. [1] serious game user interaction style. . . . . . . . . . 17

4.1 Work plan schedule. . . . . . . . . . . . . . . 25

5.1 First version of city map. . . . . . . . . . . . . . . . . . . . . . . 32

5.2 First version of city map with bus stops. . . . . . . . . . . . . 32

5.3 Second version of city map. . . . . . . . . . . . . . . . . . . . . . . . . . . . 33

5.4 Complete version of city map. . . . . . . . . . . . . . . . . . . . . . . . . . . . . . 33

5.5 Stage 1 petri net representation. . . . . . . . . . . . . . 34

5.6 Player waiting for the bus. . . . . . . . . . . . . . . . . 35

5.7 A task's current objective can be viewed at any time by pressing a key. . . . . . . . . . . . . . . . . 35

5.8 Player viewing the map. . . . . . . . . . . . . . . . . . . . 36

5.9 In order to complete a task the player should move over the red X painted on the floor. . . . . . . . . . . . . 36

5.10 Player inside the bus. . . . . . . . . . . . . . . . . . . 37

5.11 Testing setup. . . . . . . . . . . . . . . . . . . 40

5.12 Stage 1 task performance comparison between ASD group and control group. . . . . . . . . . . . . . . . . . . 44

5.13 Stage 2 petri net representation with full map access. . . . . . . . . 46

5.14 Stage 2 petri net representation with blocked map access. . . . . . . 47

5.15 Comparison between the objective panel used in stage 1 (left) and stage 2 (right) . . . . . . . . . . . . . . . . 48

5.16 Comparison between the map used in stage 1 (left) and stage 2 (right). 48 5.17 New bus model - outside view. . . . . . . . . . . . . . . . . . . . . 49 
5.18 New bus model - inside view (with reserved seat sign and validating machine). . . . . . . . . . . . . . . . . . . 49

5.19 New bus model - inside view (with stop button and doors open). . . 50

5.20 Examples of the interaction system - "Validar", "Sentar" and "Parar" ("Validate", "Sit" and "Stop", respectively). . . . . . . . . . . . . . 50

5.21 Menu system, screen 1 - "Jogar" and "Sair" ("Play" and "Leave", respectively). . . . . . . . . . . . . . . . . 51

5.22 Menu system, screen 2 - "Iniciar", "Tarefa", "Dificuldade", "Mapa" and "Voltar" ("Begin", "Task", "Difficulty", "Map" and "Return", respectively). . . . . . . . . . . . . . . . . .

5.23 Two maps of two different play sessions. The blue lines represent walking courses and yellow lines bus courses. The red circles represent idle time (the longer the player stood, the bigger the radius). . 53

5.24 Stage 2 task performance comparison between ASD group and control group. . . . . . . . . . . . . . . . . 57

5.25 Course followed by participant A for the easy task. . . . . . . . 58

5.26 Player starting position in stage 2 and 3 represented in orange and blue, respectively. . . . . . . . . . . . . . . 60

5.27 Bus with new number panels, added to the side and back. . . . . . 61

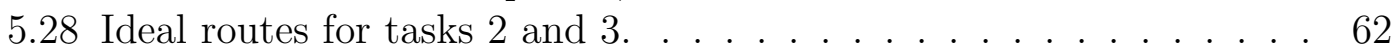

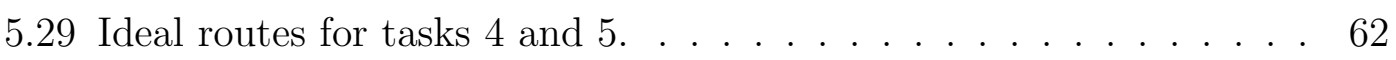

5.30 Ideal routes for tasks 6 and $7 \ldots \ldots . \ldots . \ldots . . \ldots 63$

5.31 A car stopped in front of a traffic light with the red light lit. . . . . 64

5.32 Cars driving in the city. . . . . . . . . . . . . . . . . . . 64

5.33 Car driving route. . . . . . . . . . . . . . . . . . . . . . . . . . . . . . . . . . 65

5.34 People idle, in the bus stop. . . . . . . . . . . . . . . . . 65

5.35 People interacting in the street. . . . . . . . . . . . . . 66

5.36 People in the bus. . . . . . . . . . . . . . . . . . . 66

5.37 Dog near the bus stop. . . . . . . . . . . . . . . . . . 67

5.38 Score menu with the "Action" component. In order: "Validate ticket", "Not validate ticket", "Enter through the front door", "Enter through the back door", "Leave through the front door", "Leave through the back door", "Sit in a reserved seat", "Sit in an unreserved seat", "Final score". . . . . . . . . . . . . . . . . . . . 68

5.39 Score menu with the "Route" component. In order: "Number of buses to take", "Number of buses taken", "Take a wrong bus", "Take a right bus", "Enter in the right stop", "Enter in the wrong stop", "Leave in the right stop", "Leave in the wrong stop", "Final score". . 69

5.40 Data flow for the biofeedback system. . . . . . . . . . . . . . 70

5.41 Graph of a normal standard deviation distribution. . . . . . . . . 71 
5.42 City rendered with and without fog (with fog, the farther buildings are grayed out). . . . . . . . . . . . . . . . . 72

5.43 Fire Station model replacement (before on the left and after on the right). . . . . . . . . . . . . . . . . 72

5.44 Office model replacement (before on the left and after on the right). 73

5.45 Bus stop model replacement (before on the left and after on the right). 73

5.46 Map modifications (before on the left and after on the right). . . . . 74

5.47 Stage 3 task performance comparison between ASD group and control group. . . . . . . . . . . . . . . . . . . 77

6.1 Task performance graph. . . . . . . . . . . . . . . . . 83

6.2 Heat maps created with the EDA values, from the street, obtained from all participants that completed the therapy. Data from the tutorial and tasks. Sessions 1, 2 and 3 from left to right. . . . . . . 85

6.3 Heat maps created with the EDA values, from inside the bus, obtained from all participants that completed the therapy. Data from the tutorial and tasks. Sessions 1, 2 and 3 from left to right. . . . . 86

6.4 Average of the standard deviations of the EDA values from all the participants that completed the study, from the tasks in session 1

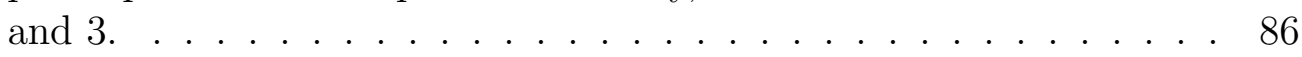

6.5 Score results for "Actions". . . . . . . . . . . . . . . . . . . . . . 91

6.6 Score results for "Route". . . . . . . . . . . . . . . . . . . . . . . . . 92

A.1 Poster presented. . . . . . . . . . . . . . . . . . 108

B.1 International Conference on Virtual Rehabilitation (ICVR)2015 award.112

C.1 Unity screen. . . . . . . . . . . . . . . . . . . . . . 114

C.2 Unity Animator. . . . . . . . . . . . . . . . . . . . . . . 115

C.3 Bus environment in Unity. . . . . . . . . . . . . . . . . 115

C.4 Bus in Unity. . . . . . . . . . . . . . . . . . . . 116

C.5 C\# code segment with the creation of a delegate. . . . . . . . . 117

C.6 C\# code segment with the creation of the interaction functions. . . 117

C.7 C\# code segment with the attribution of the interaction functions to the delegates. . . . . . . . . . . . . . . . . 118 


\section{List of Tables}

4.1 Application requirements. . . . . . . . . . . . . . 23

5.1 Primary game engine requirements evaluation. . . . . . . . . . . . 28

5.2 Game engine community evaluation. . . . . . . . . . . . . . . 29

5.3 Game engine documentation evaluation. . . . . . . . . . . . . 29

5.4 Characteristics of participants with ASD. . . . . . . . . . . 38

5.5 Characteristics of control participants. . . . . . . . . . . . 39

5.6 Interface test results from participants with ASD. . . . . . . . . . . 42

5.7 Interface test results for control participants. . . . . . . . . . . . . . 42

5.8 Tutorial and task results for participants with ASD. . . . . . . . . . 43

5.9 Tutorial and task results from control participants. . . . . . . . . . 43

5.10 Interface test results from participants with ASD . . . . . . . . . 55

5.11 Interface test results from control participants. . . . . . . . . . . . 55

5.12 Tutorial and task results from participants with ASD. . . . . . . . 56

5.13 Tutorial and task results from control participants. . . . . . . . . . 56

5.14 Characteristics of participants with Autism Spectrum Disorder (ASD). 74

5.15 Characteristics of control participants. . . . . . . . . . . . . 75

5.16 Tutorial and task results from participants with ASD. . . . . . . 76

5.17 Tutorial and task results from control participants. . . . . . . . . . 76

6.1 Characteristics of participants. . . . . . . . . . . . . . . 81

6.2 Assiduity of participants in sessions. . . . . . . . . . . . . . . . 81

6.3 Task performance table. . . . . . . . . . . . . . . 83

6.4 Process description accuracy in session 1 (Partic. = participant, valdn. = validation, $\mathrm{r}$. seats $=$ reserved seats, $\mathrm{STOP}$ btn. $=\mathrm{STOP}$ button). . . . . . . . . . . . . . . . . 88

6.5 Process description accuracy in session 2 (Partic. = participant, valdn. = validation, $\mathrm{r}$. seats $=$ reserved seats, $\mathrm{STOP}$ btn. $=\mathrm{STOP}$ button). . . . . . . . . . . . . . . . . 88

6.6 Process description accuracy in session 3 (Partic. = participant, valdn. = validation, $\mathrm{r}$. seats $=$ reserved seats, $\mathrm{STOP}$ btn. $=\mathrm{STOP}$ button). . . . . . . . . . . . . . . . . . 89

6.7 Score percentage results for "Actions". . . . . . . . . . . . . . . . . . . . . 90

6.8 Score percentage results for "Route". . . . . . . . . . . . . . . . . . 92 


\section{Chapter 1}

\section{Introduction}

This chapter contains an overview of the report. It starts by summarizing some of the core concepts related to this project. Then, the objectives set and the work done are presented. Finally, the structure of the report is detailed.

\subsection{Background}

Autism Spectrum Disorder (ASD) is a neurodevelopmental disorder responsible for impairments in social communication and interaction and restricted repetitive patterns of behaviour, interests, or activities. Currently ASD affects 1\% of the population, worldwide [2], and, with a cure yet to be found, individuals rely on therapies and interventions to improve and overcome their impairments. Further increasing the relevance of therapies and interventions is the fact that only a minority of individuals with ASD are able to live independently in adulthood [2].

Immersive Virtual Reality (VR) technologies available nowadays are able to present users with experiences realistic enough to trick the mind and create a feeling of presence within the environment [3]. These technologies have already been used and proven effective in the therapies for Posttraumatic Stress Disorder (PTSD) [4], phobias [5], and also ASD [6], for providing safe and controlled environments where these can be conducted [7], as further explained in section 3.1.

Serious games (games whose objective is learning rather than entertainment) have also been proven effective in ASD therapies, not only for including game design techniques to keep the players motivated, but also because individuals with ASD are often interested in computer-based activities [8].

\subsection{Purpose}

The aim of this project was to create a serious game which uses a VR headset (Oculus Rift) to rehabilitate individuals with autism. Teaching a person with 
ASD to use public transports requires parents or therapists to practice with them, until they are ready and comfortable enough to do it alone (basically, the same process used with people with typical development, but with all the obstacles set by ASD). In fact, being able to efficiently use public transports can be particularly challenging for people with ASD due to deficits in adaptive behaviour [9] and anxiety [10]. This project intended to ease this process by creating a game that prepares the players to use, in this case, buses for transportation, not only teaching the required skills but also making them comfortable with the procedures and environments involved. Furthermore, in the game, players are placed in a city and must go to a specific location, which, naturally, involves taking buses. This will require planning the trip in advance, waiting for the right bus, validating the ticket, choosing a place to sit and knowing when to press the stop button to leave. These are skills that not only apply to travelling in other means of transport but are also important for the independent living of oneself. With the recent release of Oculus Rift, immersive virtual reality is more accessible, and more realistic environments can be created, which can increase the rehabilitating potential of these tools. During and after the development, the application was uploaded to Neurohab [11], a serious game platform. This project had a duration of nine months during which the application was developed and its effectiveness validated with individuals with ASD.

\subsection{Work done and contributions}

During nine months, a serious game was planned, developed, tested, and validated. The tests identified a higher task performance in control participants (individuals without ASD), compared to participants with ASD, revealing a window of opportunity for improvement. In the validation phase, participants with ASD were submitted to three therapy sessions, after which they showed significant improvements, especially in anxiety reduction, in learning the bus taking process, and in applying the norms in practical contexts. Additionally, an abstract of this project was submitted to the VI Annual Meeting of the Institute for Biomedical Imaging and Life Sciences (IBILI), and an extended abstract submitted to International Conference on Virtual Rehabilitation (ICVR)2015. Both were and accepted, leading to posterior poster presentations during the conferences (please see Appendix $\mathrm{A}$ and B). The poster presented in ICVR2015 received an honourable mention for the ICVR2015 Best Student Poster category. This project was developed in IBILI, a research institution of the Faculty of Medicine of the University of Coimbra, Portugal, as the final project for the Master of Science degree in Informatics Engineering from the University of Coimbra. This study was supported by the AAC SI/2011/HomeTech/QREN Compete, co-financed by FEDER and Por- 
tuguese Foundation for Science and Technology and also the European Project BRAINTRAIN (FP7-HEALTH-2013-Innovation-1-602186BrainTrain).

\subsection{Structure}

This report contains seven chapters. After this chapter, chapter 2, "Background", explains the core concepts of this project: Autism Spectrum Disorder, Virtual Reality and Head Mounted Displays. Chapter 3, "State of the Art", describes several research projects which used Virtual Environment exposure to treat particular disorders or conditions, used Serious Games to rehabilitate individuals with Autism Spectrum Disorder, or used of Biofeedback approaches in therapies. Chapter 4, "Objectives and Planning", describes the purpose of the project and the game developed. It also includes a list of the identified requirements and a schedule of the tasks distributed over the duration of the project. The work done throughout seven of the nine months of the project is then described in the fifth chapter, "Game development", from the choice of a game engine, to the features implemented in each development stage and the results obtained in the testing phases. Chapter 6 , "Therapy and Results", includes the process of validating the potential of the game developed as a therapy tool, and the results obtained from the therapy sessions conducted. Finally, chapter 7, "Conclusion and Future Work", includes a summary of what was done, results obtained, and describes the work that could be done in the future of the project. Contributions from this project are included at the end of the report, in the appendix section. 


\section{Chapter 2}

\section{Background}

This chapter presents the basic concepts required to understand the work done. It starts by describing what Autism Spectrum Disorder is, which symptoms can be used to identify it, how the diagnosis is made, what causes it, prevalence, and how it is treated. Then, Virtual Reality is described, focusing on the concepts of immersion and presence. Finally, an overview of the current market situation of Head Mounted Displays is presented, along with an explanation of the core hardware components of Oculus Rift Virtual Reality Headset.

\subsection{Autism Spectrum Disorder}

Autism Spectrum Disorder (ASD) refers to a neurodevelopmental disorder which causes impairments in social communication and interaction and leads to restricted, repetitive patterns of behaviour, interests, or activities. This section covers the symptoms of an individual with ASD, how the diagnosis is made, known causes, prevalence and treatment.

\subsubsection{Symptoms}

The symptoms of ASD comprise the characteristics that are common in autism and indicate the existence of the disorder. The Diagnostic and Statistical Manual of Mental Disorders, 5th edition (DSM-5) [2] divides them into two different groups: impairments in social communication and interaction, and restricted or repetitive patterns of behaviour, interests or activities. Examples of the symptomatology from each group are presented below.

Impairments in social communication and interaction:

- Lack of initiation of social interaction and sharing of emotions

- Insufficiency or inadequacy of nonverbal communicative behaviours such as eye contact, pointing, instrumental gestures or facial expressions 
- Difficulties in understanding appropriacy of specific behaviours in different scenarios.

Restricted or repetitive patterns of behaviour, interests or activities:

- Presence of motor stereotypes (e.g. flapping - moving arms up and down), repetitive use of objects (e.g. lining up toys) and repetitive speech (e.g. echolalia - repetition of sounds)

- Resistance to change

- Fascination with lights or spinning objects.

These symptoms can vary depending on the individual, environment, severity, developmental level and chronological age (thus the term spectrum) [2]. Moreover, individuals with autism may also show other features such as intellectual and/or language impairment and motor deficits.

\subsubsection{Diagnosis}

The diagnosis process consists of collecting a detailed developmental history, performing a systematic and clinical examination [12]. There are no biological tests that confirm the presence of ASD. Therefore, the evaluation of individuals who show symptoms of ASD should be preformed by a multidisciplinary team, including paediatricians/psychiatrists, psychologists, and speech therapists [12] [13]. There are several tools which can be used to screen and diagnose ASD such as Autism Diagnosis Interview - Revised (ADI-R), a parental or caregiver interview [14], and Autism Diagnostic Observation Schedule (ADOS), a "semistructured, standardized assessment of social interaction, communication, play, and imaginative use of materials" [12] [15] [16]. Finally, for ASD to be diagnosed, symptoms must be present in the early developmental period and must not be better explained by the presence of global developmental delay or intellectual developmental disorder [2].

\subsubsection{Causes}

Even though there is no known single cause for ASD, researchers have identified several factors associated with the disorder, such as genetic, environmental and immunological. Some examples of the latter include inheritance and genetic mutations (genetic factors), advanced parental age and certain types of medication and chemicals (environmental factors), maternal viral infection and bacterial infection during pregnancy (immunological factors) [17]. 


\subsubsection{Prevalence}

The first survey of autism was in 1966 in the United Kingdom and the estimated prevalence rate of autism, in children from eight to ten years old, was of 4.1 per 10,000 [18]. According to DSM-5 [2], the worldwide frequency for ASD has approached $1 \%$ of the population. However, higher rates can result not only from the increase in autism frequency, but also from the expansion of diagnostic criteria and increased awareness. Moreover, different studies can use different methods to estimate prevalence which can also affect the results.

\subsubsection{Treatment}

Currently there is no cure for autism and DSM-5 [2] states that, in adulthood, only a minority of individuals with autism spectrum disorder live and work independently. Nevertheless, therapies and interventions can result in substantial improvement and, with all the possible differences between individuals with ASD, these interventions should be tailored according to their particular needs [19].

Johnson and Myers [20] emphasized the importance of an early diagnosis, which allows "early intervention, etiologic investigation, and counseling regarding recurrence risk". More specifically, studies show that exposing ASD children to intensive intervention can result in a higher Intelligence Quotient (IQ) increase [21] [22].

Treatments can be divided into medical and nonmedical interventions and are ideally used together rather than separately [13]. Medical interventions consist of using medication to treat anxiety, depression, and other autism-related symptoms. Nonmedical interventions include educational and behavioural therapies to develop social and language skills.

Finally, parents also play an important role in the treatment of ASD. Besides becoming knowledgeable about ASD and the possible treatments, parents need to learn teaching strategies to help their child acquire new skills or generalize the ones already learned [23]. 


\subsection{Virtual Reality}

Virtual Reality (VR) consists of artificial, 3D, computer-generated environments which the user can explore and interact with [24]. VR usually takes advantage of different types of devices such as Head-mounted displays (HMDs) and controllers to deliver the stimulation and provide means of interaction that lead to immersive experiences [25]. In fact, Bimber [3] reported that "immersive VR has the capacity to trick the mind by providing sufficiently realistic (mainly visual) illusions".

According to Slater [26], immersion is objective, measurable and depends only on the technology used by the VR system. It measures the level of fidelity, in all sensory modalities, a VR system is able to provide. Presence is defined as the "human reaction to immersion" [26]. Different definitions of presence include "the (psychological) sense of being in the Virtual Environment (VE)" [27] and "phenomenon of behaving and feeling as if we are in the virtual world created by computer displays" [28]. Sanchez-Vives and Slater [28] emphasized the factors listed below as having an impact on the presence in a VE:

- Display parameters - graphics frame-rate, latency, head tracking, stereopsis (stereoscopic vision), geometric field of view

- Visual realism

- Sound

- Haptics (technology with tactile feedback (e.g. game controller vibration)).

- Visual body representation

- Body engagement - using body motion as input.

Gutierrez [24] points immersion and presence as the two main factors of VR experiences and divides VR systems, immersion-wise, in three different groups, depending on how much the player can "perceive the real world during the simulation". Thus, a VR system can be:

- fully immersive - systems using HMDs (e.g. Oculus Rift (Figure 2.1))

- semi-immersive - systems using large projection screens (e.g. CAVE (Figure 2.2))

- nonimmersive - systems using desktop-based VR (e.g. video games). 


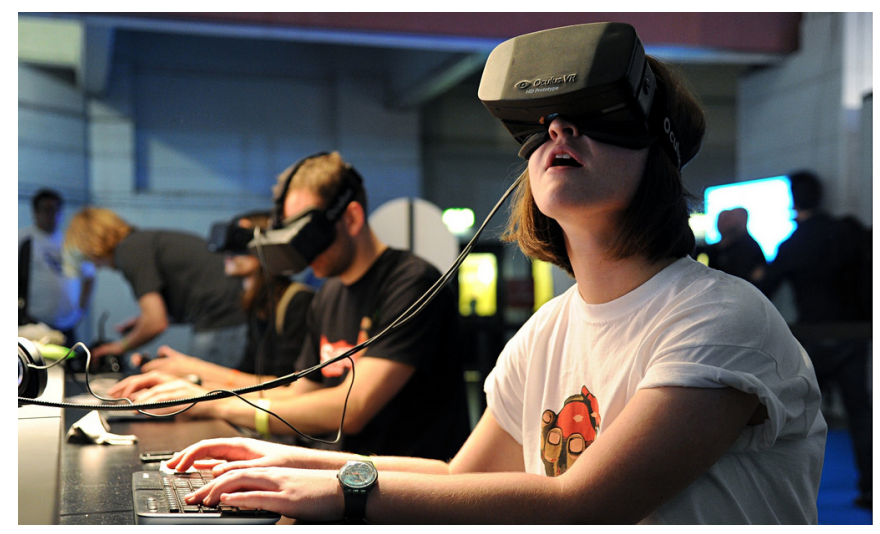

Figure 2.1: Oculus Rift, a fully immersive VR system.

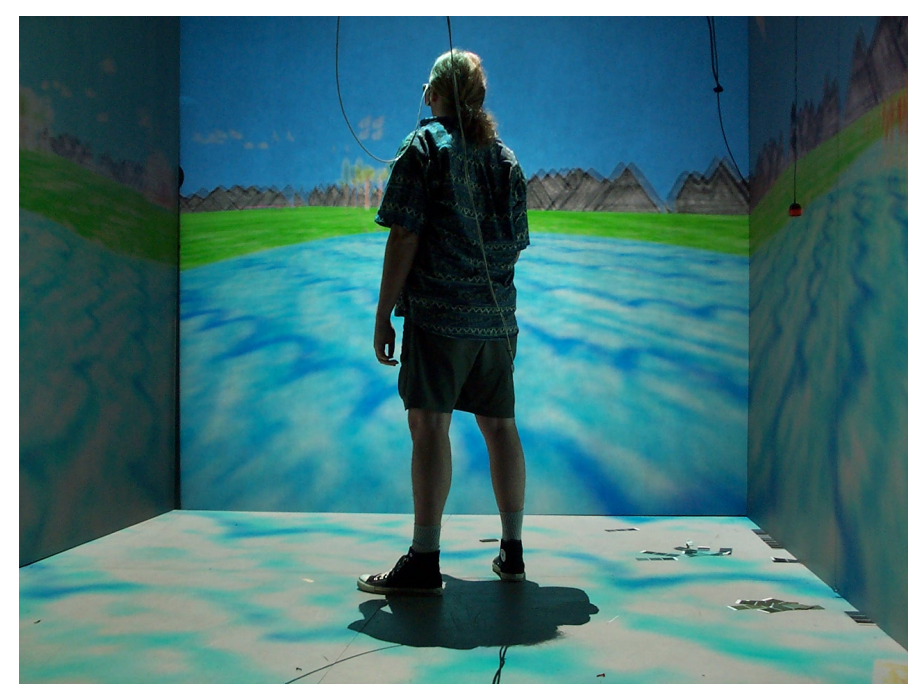

Figure 2.2: CAVE, a semi-immersive VR system. 


\subsection{Head Mounted Displays}

HMDs are display devices worn on the head, whose primary aim is to provide immersive virtual reality experiences. The latter can be achieved by including features such as displaying stereoscopic images, which create the illusion of depth, and head-based rendering which consists of translating head movements from the "real world" into the game. The Sword of Damocles, created in 1968 by Ivan Sutherland is considered to be the first HMD [29]. However, few HMDs have been released so far and only recently has the VR market started to grow. Accordingly, a report, released by KZero Worldswide, forecasted the penetration rates of consumers purchasing HMDs to be of 1\% in 2014 and described the HMD market in 2014 as being driven by Oculus Development Kit (DK)1 [30](Figure 2.3) owners, DK2 [31] and Durovis Dive [32], but predicted a further penetration in 2015, when more HMDs will be released [33]. Nevertheless, according to another report, released by MarketsandMarkets, the VR market is expected to reach US $\$ 407.51$ million by 2018 , mostly due to hardware advances and improvements in internet connectivity [34].

Since 2012, some HMDs were announced or released, including:

- Oculus Rift DK1 and 2 for Windows, OS X and Linux

- Sony's Poject Morpheus for PlayStation 4 [35]

- Oculus VR's Samsung Gear [36] and Google's Cardboard [37], headsets for smartphones.

Oculus Rift started as a Kickstarter [38] campaign which raised US\$2.4 million. Oculus VR, the company behind Oculus Rift and founded by Palmer Luckey, was, later, bought by Facebook [39] for US $\$ 2$ billion [40]. 


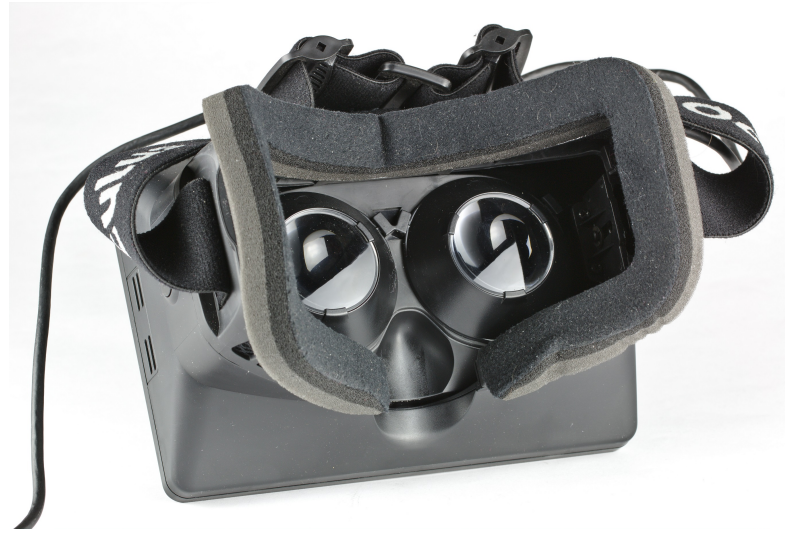

Figure 2.3: Oculus Rift DK1.

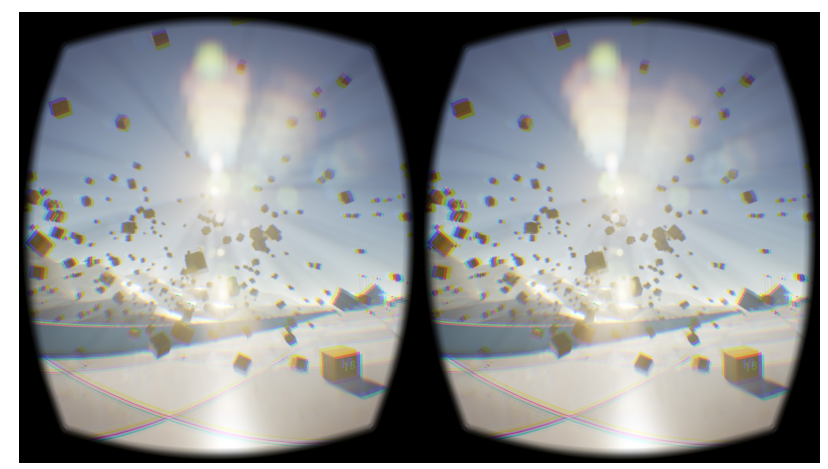

Figure 2.4: Oculus Rift's display, with one image for each eye.

Oculus Rift HMD contains a screen where two parallel images are displayed, one for each eye. A set of lenses reshape the image seen by each eye (Figure 2.4), creating the stereoscopic 3D view. Sensors (gyroscope, accelerometer and magnetometer) are used to detect head motion and translate it into the game. Oculus Rift DK2 also includes:

- An external positional tracking device which helps tracking head movements

- A display resolution of 960x1080 per eye

- $100^{\circ}$ field of view

- Low persistence Organic Light-emitting Diode (OLED) display to reduce motion blur and judder, known to contribute to motion sickness.

So far, Oculus VR only released the DK1 and DK2 headsets. However, the Consumer Version (CV)1 will launch in 2016 [41]. 


\subsection{Electrodermal Activity}

Electrodermal activity is a term used to describe changes in the electrical properties of the skin. When exposed to external stimuli that provoke arousal, the sympathetic system (part of the autonomic nervous system) increases the activity of the sweat glands in the skin and, consequently, improves its conductance [42] [43]. In order to measure Electrodermal Activity (EDA) levels, two electrodes are placed in contact with the skin, which pass a small current, at a constant voltage. Since sweat reduces the electrical resistance of the skin, changes in the current will be noticed whenever the sweat glands are stimulated [42]. An example of this can be seen in Figure 2.5.

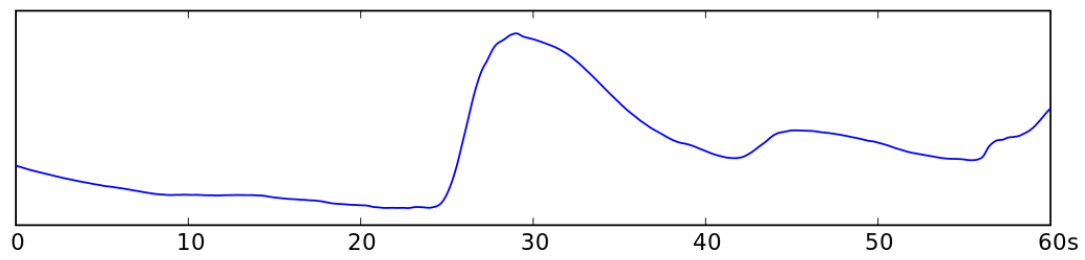

Figure 2.5: Example of an increase in EDA level.

There are two types skin conductance: tonic and phasic [44]. Tonic skin conductance represents the baseline, the level of skin conductance in the absence of arousal. The phasic skin conductance, on the other hand, changes in the presence of environmental stimuli, such as sights and sounds. Accordingly, exposing the player to stress-inducing stimuli will lead to high arousal levels and, consequently, increase the skin secretion rates, which will be detected by the EDA measuring system [45].

There are several factors which can influence the EDA of a person, both internal and external, such as climatic conditions (e.g. temperature and humidity) and physiological influences (e.g. skin temperature, skin blood flow, skin moisture), which are connected with thermoregulation, and also demographic characteristics (e.g. age, gender, ethnic differences and heritability) [45]. Boucsein [45] also reviews several studies which have used EDA in the assessment of disorders such as phobias, depression of schizophrenia. 


\section{Chapter 3}

\section{State of the Art}

This chapter presents some of the research done in topics also covered by this project. First, several therapies that took advantage of the potential of Virtual Reality are described. Then the concept of Serious Games is presented, along with various examples of how it was used with ASD. Finally, the term Biofeedback is also explained, followed by some examples of its use.

\subsection{Virtual Reality Therapy}

Virtual Reality Therapy (VRT) is conducted by exposing individuals to particular Virtual Environments (VEs) which might trigger or ease specific aspects of their condition. For example, people who suffer from anxiety would be exposed to a VE representing the situations that cause the anxiety. This section presents examples of how immersive Virtual Reality (VR) has been used to explore phobias (acrophobia and arachnophobia), Posttraumatic Stress Disorder (PTSD), and pain distraction.

\subsubsection{Phobias}

The standard treatment for phobias is exposure in vivo: gradually exposing a person to his/her fear. Due to its immersive potential, virtual reality has been used effectively as an alternative to the in vivo approach, resulting in similar or equal progress in patients [5].

Emmelkamp et al. [5] compared the use of VRT and exposure in vivo for the treatment of acrophobia (fear of heights). In this study, 33 participants, suffering from acrophobia, went through three one-hour, weekly, therapy sessions, in which patients were exposed to different heights-related environments. The participants were divided into two groups: one which received exposure in vivo and another which received exposure via immersive VR (VR environments were designed to be as similar to the in vivo exposure environments as possible). The results, which 
maintained six months after the last session, showed that VR exposure was as effective as in vivo exposure in the treatment of acrophobia.

Similar research was also done by Garcia-Palacios et al. [46] and Hoffman et al. [47] which used VR to treat arachnophobia (fear of spiders and other arachnids). In Garcia-Palacios et al. [46], 23 participants were divided into two groups, one which received VR exposure and another which received no exposure. Instead of defining a specific number of sessions, each participant underwent the number of sessions needed (one hour per session) until he/she could hold a big virtual spider, with tactile augmentation (real plastic spider), while reporting low levels of anxiety. After an average of four therapy sessions, the fear and avoidance of spiders experienced by the participants was significantly reduced. Furthermore, the VR group showed improvement on all treatment measures considered while the control group showed no improvement.

Hoffman et al. [47] also used VR with tactile augmentation to treat arachnophobia. In this study, 36 participants were divided into three groups: no treatment, VRT without tactile augmentation, and VRT with tactile augmentation. Both VRT groups underwent three, one-hour exposure therapy sessions which significantly reduced the fear of spiders, being the VRT with tactile augmentation group the one with greatest progress.

\subsubsection{Posttraumatic Stress Disorder}

PTSD is a disorder that develops after the exposure to one or more traumatic events. It causes persistent avoidance of stimuli associated with the event(s) (e.g. memories, thoughts, people, and places) and, in some cases, inability to remember important aspects of the traumatic event(s) [2]. One of the effective approaches to treat PTSD is prolonged exposure therapy, which involves asking the patient to relive the traumatic event by means of imagination and narrative [4]. However, the stimuli avoidance and potential inability to remember parts of the event(s) can cause the therapy to fail [4]. VR has thus been explored as an alternative and immersive way to simulate the traumatic event(s).

Rizzo et al. [4] describes the use of Virtual Iraq/Afghanistan [48] exposure therapy system, which includes four different, customizable scenarios and is currently being used in over 60 early-adopter sites (e.g. medical centres, universities and private clinics). Two different clinical trials: Rizzo et al. [49] and Reger et al. [50], were able to treat some of the participants using this VRT system. In Rizzo et al. [49], 20 active-duty service members diagnosed with PTSD, which had previously engaged in PTSD treatment without benefit, used this system in 11 sessions (two sessions per week, between 90 and 120 minutes per session). After all the therapy sessions, 
16 of the 20 completers no longer met the criteria for PTSD. Similarly, Reger et al. [50] applied the same system, over an average of seven sessions, to 24 active-duty service members. As a result, $45 \%$ of the completers no longer met the criteria for PTSD.

\subsubsection{Pain distraction}

VR has also been proven effective in reducing the pain felt during certain medical procedures. Hoffman et al. [51] created SnowWorld, a virtual environment, delivered using immersive VR and designed to reduce pain. In this study participated 12 people whose total body surface area burned corresponded to an average of $21 \%$. Each of these 12 participants spent three minutes of physical therapy with and without VR exposure. According to the results, the distraction caused by the VR exposure resulted in statistically significant pain reduction. It is also important to highlight that $86 \%$ of the burn patients interviewed (approximately 40 people) reported to feeling severe to excruciating pain, even when under the effects of opioids, during wound care, without the pain distraction system.

\subsubsection{Autism Spectrum Disorder}

Bellani et al. [52] reviews eight studies in which VRT was used to rehabilitate individuals with Autism Spectrum Disorder (ASD). From these studies, only two used Head-mounted display (HMD) (the others used desktops or touch screens): Strickland et al. [6] and Strickland [53]. Both studies used a street environment to teach two children with ASD to identify cars within the VE. In the former, they were asked to name the colour of the car, while in the latter, they also had to find a stop sign within the scene and move to it. Both obtained successful results. Despite the amount of studies focused on VRT, there are still few which use immersive VR to rehabilitate individuals with ASD.

\subsubsection{Conclusion}

According to Bimber [3], a possible reason for the success and potential value of VRTs is the VR's "capacity to trick the mind". Furthermore, Emmelkamp et al. [5] proved that VR exposure, using low-budget hardware and software, can be as effective as exposure in vivo, in patients suffering from acrophobia. Finally, VR has several advantages which enhance its potential in therapeutic approaches. VR can provide safe, realistic and controlled environments for therapies to be conducted, which can be used by people who due to physical (e.g. paralyzation) or psychological (e.g. anxiety) reasons can not undergo exposure in vivo. Moreover, 
VRTs can be applied without the need to go to a location where the exposure can take place, as happens with exposure in vivo. 


\subsection{Serious Games}

Serious games are applications whose primary aim is not entertainment, enjoyment or fun [54], but to promote the acquisition of skills that are difficult or not directly rewarding [55]. According to Chen and Bernard-Opitz [8], people with ASD tend to find computer-based activities interesting and motivating, increasing the potential of using serious games for therapy.

Zakari et al. [1] reviews 40 serious games and case studies, developed between 2004 and 2014 and designed to rehabilitate individuals with ASD. This study classified each game in terms of technology platform, computer graphics, purposes/objectives, and user interaction. The data gathered showed that $70 \%$ of the games were developed for desktops/laptops, $22 \%$ for mobile/tablets, $3 \%$ for large screens, $3 \%$ for consoles, and $2 \%$ for tabletops (Figure 3.1). Furthermore, $67.5 \%$ were in 2D, $20 \%$ were in 3D, and $12.5 \%$ were both in 2D and 3D (Figure 3.2). As for purposes/objectives, $54 \%$ aimed at improving social and communication skills, $26 \%$ for conversation skills and speech therapy, $5 \%$ for learning accounting, $5 \%$ for imaginative skills, $3 \%$ for first aid, $2 \%$ for sensory integration, and $5 \%$ for others (Figure 3.3). Finally, in terms of user interaction, $45 \%$ of the games used ordinary IO (keyboard and mouse), 27\% used a touch screen, $13 \%$ had camera-based IO, $10 \%$ had more than one interaction tool, and 5\% used Electroencephalography (Figure 3.4).

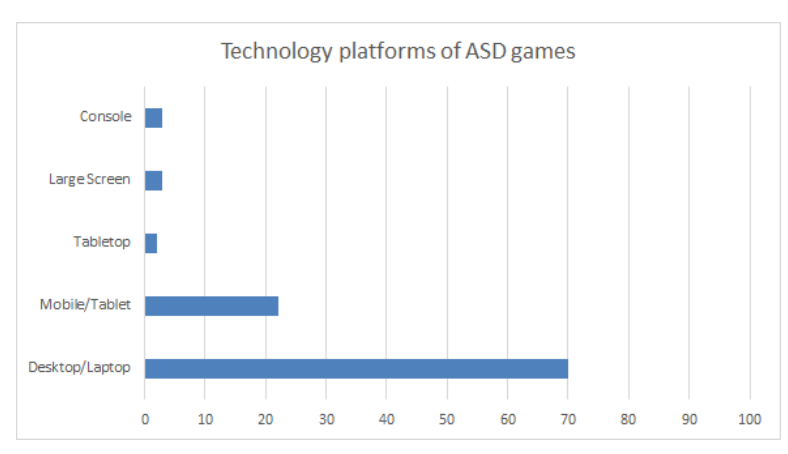

Figure 3.1: Zakari et al. [1] serious game platforms. 


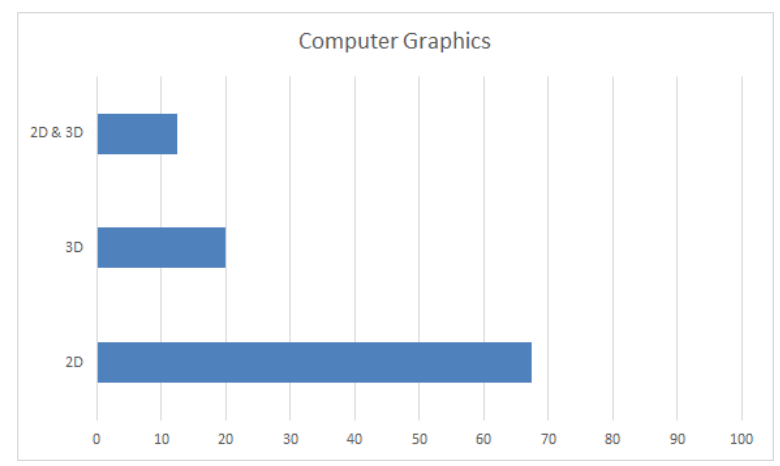

Figure 3.2: Zakari et al. [1] serious game computer graphics style.

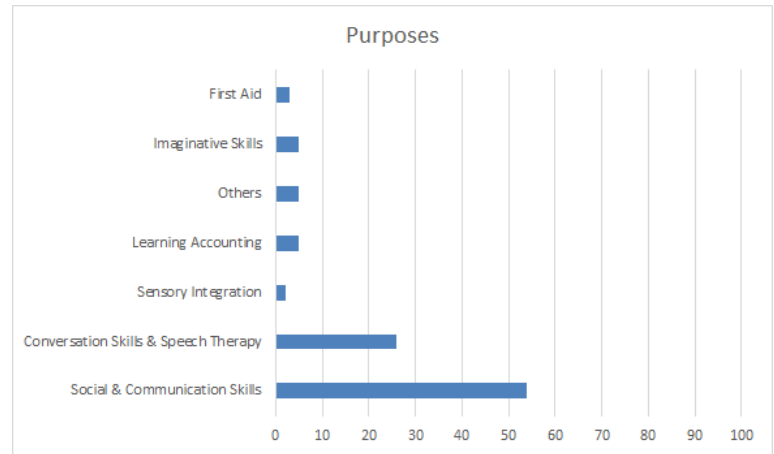

Figure 3.3: Zakari et al. [1] serious game purposes.

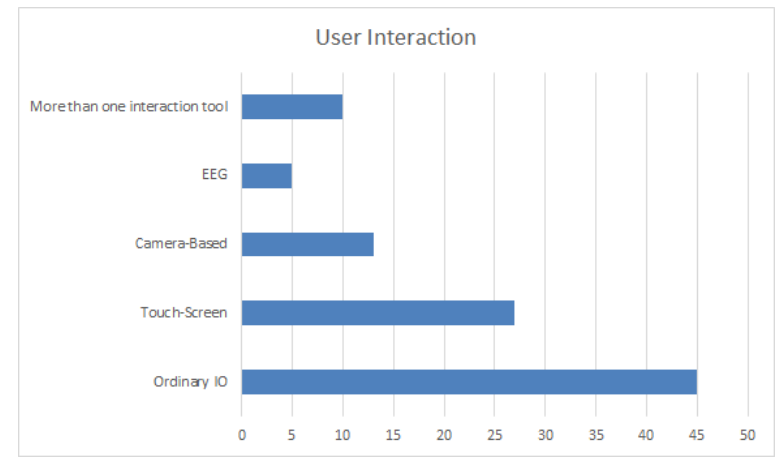

Figure 3.4: Zakari et al. [1] serious game user interaction style.

In Parsons and Cobb [7], case studies published after 2000, including the ones of Parsons et al. [56] and Mitchell et al. [57] were also reviewed. Parsons et al. [56] used café and bus environments to train the social skills of two adolescents with 
ASD whose task was to find an appropriate place to sit within the environment. After three weekly, non-immersive VR exposure sessions (between thirty and fifty minutes each), both adolescents were able to identify specific real life situations in which the therapy had helped them. Mitchell et al. [57], similarly, used a café environment to teach social skills to six adolescents with ASD which, after two non-immersive VR exposure sessions (on successive days, between thirty and fifty minutes each), were able to generalize the learned skills and apply them to another context (bus environment).

In a technologically different approach, Maskey et al. [58] used the Blue Room technology, a semi-immersive VR technology which creates the environment by projecting images onto walls and ceilings, instead of showing them on a display. The aim of this study was to use this technology to reduce specific phobias in young people with ASD (e.g. pigeons, crowded buses). According to the results reported, after four VR exposure sessions (between 20 and 30 minutes each), eight of the nine children were able to confront their phobia situations and four of the nine children were able to completely overcome the phobia.

Finally, Lopresti [59] followed a cross-over design in which two groups, one with three participants (two with ASD, two with learning disabilities, two with Attention Deficit Hyperactivity Disorder, and one with anxiety disorder) and another with six participants (three with ASD, one with Borderline Intellectual Functioning, two with learning disabilities, and two with Attention Deficit Hyperactivity Disorder), played The Sims 3 [60], a life simulation game. In this game, participants created and played with avatars that represented them (similar physical characteristics, personality traits and preferences). After the fifteen weeks, reports indicated an increase in self-awareness, and improved mood and social skills. 


\subsection{Biofeedback}

Biofeedback consists of gathering information regarding the physiological state of an individual and translating it into a form that he/she can understand [61]. This information is collected through the use monitoring devices, which detect signals such as Heart Rate Variability and Electrodermal Activity (EDA). By having access to this kind of information, individuals can be trained to change these signals and improve their condition [62]. Even though biofeedback is often used to change habitual reactions to stress [61] or anxiety [63], evidence shows that it can be applied to different areas such as sports [64] or in drug rehabilitation [61].

\subsubsection{Anxiety and stress}

Anxiety is the anticipation of future threat, and can result from the overestimation of the danger in specific situations that are feared or avoided [2]. Studies such as McKinney and Gatchel [65] and Moraend et al. [66] took advantage of this fact and used some of these specific situations to evaluate the biofeedback therapies designed. More specifically, Moraend et al. [66] and McKinney and Gatchel [65] aimed at alleviating the anxiety felt by individuals towards visiting dental offices and giving public speeches, respectively.

In McKinney and Gatchel [65], 42 were divided into three groups: one that received heart rate biofeedback training, one that received speech skills training, and another that received both. According to the results obtained, after eight sessions, the heart rate increase of individuals while speaking before an audience was significantly less only for both groups that received biofeedback training.

Moraend et al. [66] created a biofeedback device that trains the users to slow their breathing rate and, consequently, their blood pressure. By using this device patients would reduce their anxiety levels when visiting a dental office and, as a result, decrease the pain of dental injections. To prove the effectiveness of the device, 81 subjects were divided into two groups: an experimental group that used the biofeedback device, and a control group whose subjects were not exposed to any biofeedback. The results obtained show that, for the subjects that belonged to the experimental group, there was a significant reduction of negative feelings regarding the overall injection experience.

Henriques et al. [63] followed a more general approach by not focusing on any specific anxiety-provoking situation. Instead, the effectiveness of a heart-rate variability biofeedback program was evaluated based on the reduction of anxiety and negative mood assessed through the completion of weekly Mood and Anxiety Symptom Questionnaire. The program included four different challenge levels which the user 
could complete by gathering points, earned by maintaining coherent heat rate intervals. This study was conducted primarily as a pilot, using only nine subjects, and only then as a second study with 35 subjects. According to the results, there were sizeable decreases in anxiety and negative mood in both studies.

Besides anxiety, biofeedback has also proven effective in reducing stress. Weinman et al. [67] divided 20 anxious individuals, experiencing stressful life events, into two groups: a high stress group and a low stress group. After ten sessions of biofeedback-assisted relaxation (two sessions per week, approximately 40 minutes per session) the high stress group showed significant changes on anxiety, depression and on symptoms of anxiety and tension. The low stress group, however, showed no change from pre to post treatment.

\subsubsection{Other purposes}

As previously said, despite the many projects that focus on reducing anxiety, biofeedback has also been used successfully on other areas such as sports and drug rehabilitation. In fact, Alahakone and Senanayake, [64] created a system using wearable sensors and a stimulation device with vibration feedback, which activated as users fell from a drop vertical jump, whenever proper knee angle had been achieved. The purpose of this system was to improve jump landing techniques and reduce the risk of injuries. The two subjects that participated in this study did drop vertical jumps first without, and later with the biofeedback system. As a result, the landing technique of both subjects improved when they started using the biofeedback system. This study proves the usefulness and potential of biofeedback systems on sports.

Finally, Du et al. [61] tested the possibility of reducing craving and physiological reactivity to drug-related cues in heroin dependents, when using biofeedback therapy, combined with cue-exposure therapy. In this project participated 45 individuals which were divided into two groups: an experimental group which received the cue-exposure therapy and the biofeedback therapy, and a control group which did not receive the therapies. After twelve sessions of treatment (between one and two sessions per week, approximately 60 minutes per session, during eight weeks) the experimental group had experienced a greater decrease in craving and physiological reactivity when compared to the control group. 


\section{Chapter 4}

\section{Objectives and Planning}

The purpose of this project was to create a serious game that uses Virtual Reality (VR) to rehabilitate individuals with Autism Spectrum Disorder (ASD). More specifically, it aimed at preparing individuals with ASD to use buses for transportation by placing them in a three-dimensional city and setting tasks which involve taking buses to reach specific destinations. The addition of virtual reality support increases the feeling of presence in the game environment, thus making the experience more immersive and increasing its potential as a learning tool. Collaborations with ASD associations eased the access to individuals with ASD, with whom the application was tested and validated. The duration of this project was nine months: in the first four months a fully functional prototype of the game was created and, in the following five months, the development of the application was concluded and its rehabilitation potential validated. The project was uploaded to Neurohab [11], a platform containing several other serious games whose aim is to rehabilitate social skills and executive functioning. This chapter further describes the objectives of the project, the requirements gathered and the work plan created for both semesters.

\subsection{Objectives}

More than a learning tool, the developed game should provide a safe environment where the players can become comfortable with the process of taking a bus, training activities such as planning a route, waiting for the right bus, choosing a place to sit and deciding when to press the stop button to leave. These activities can represent complex challenges for individuals with ASD due to deficits in adaptive behaviour [9] or anxiety, common in individuals with ASD [10].

The target audience of this game are individuals with high-functioning ASD, i.e without intellectual disability (IQ equal to 70 or higher) [68]), or with mild intellectual disability (IQ between 50 and 69 [69]). This includes people within a broad age range and from different backgrounds, who might have experience with using 
public transportation systems. In order to cover different complexity levels, for people with different capabilities, tasks are available in two different difficulties: easy and hard. The easy mode guides the player through all the steps required to go from the starting point to the destination. The hard mode, aimed at more experienced individuals, only informs the players of their final destination, being the players responsible for creating a plan for reaching the destination. Additionally, there are tasks of different complexity. More complex tasks can involve taking more than one bus to reach the destination or having more than one possible route and having to choose the fastest one.

In order keep a record of the player's progression, in each session his/her performance is measured using two different methods: a score system and a biofeedback system. The score system takes into consideration several details regarding the task execution and uses them to evaluate the overall performance. Examples include:

- Which buses are taken and in which bus stops

- In which bus stops does the player leave the bus

- Does the player validate the ticket upon entering the bus.

The biofeedback system, on the other hand, uses Electrodermal Activity (EDA) (changes in electrical resistance across two regions of the skin [70]), which can be used to measure stress levels [71]. With this information, the game can adapt based on how anxious the player is. For instance, if the player is experiencing more anxiety than intended, the amount of stimuli delivered is reduced. Accordingly, if the player is feeling comfortable in the environment, the amount of stimuli delivered is increased.

With these metrics, it is possible to analyse the impact of practice on both task performance and anxiety reduction.

\subsection{Requirements}

In meetings arranged between the development team and a therapist from Associação Portuguesa para as Perturbações do Desenvolvimento e Autismo (APPDA) of Coimbra, a portuguese association for people with ASD, the objectives were discussed and the requirements were identified. After listing all the requirements identified for this project, they were validated in another meeting with the same participants. For each requirement, its complexity (high, medium or low) and priority (necessary or desirable) were defined. Table 4.1 contains the final list of requirements. 


\begin{tabular}{|c|c|c|c|}
\hline Number & Description & Complexity & Priority \\
\hline 1 & $\begin{array}{l}\text { The game environment must be a 3D city } \\
\text { model }\end{array}$ & High & Necessary \\
\hline 2 & The city must have bus stops & Low & Necessary \\
\hline 3 & $\begin{array}{l}\text { The player must be controllable with the } \\
\text { keyboard }\end{array}$ & Low & Necessary \\
\hline 4 & $\begin{array}{l}\text { There must be buses driving around the } \\
\text { city in pre-defined routes }\end{array}$ & High & Necessary \\
\hline 5 & $\begin{array}{l}\text { The player must be able to enter/leave the } \\
\text { bus }\end{array}$ & Medium & Necessary \\
\hline 6 & $\begin{array}{l}\text { There must be a task available in different } \\
\text { difficulty levels for the player to choose }\end{array}$ & Medium & Necessary \\
\hline 7 & $\begin{array}{l}\text { The Oculus Rift must be integrated in the } \\
\text { project }\end{array}$ & Low & Necessary \\
\hline 8 & $\begin{array}{l}\text { The bus must stop and honk if the player } \\
\text { stands in front of it }\end{array}$ & Low & Necessary \\
\hline 9 & $\begin{array}{l}\text { The player must have access to a map of } \\
\text { the city }\end{array}$ & High & Necessary \\
\hline 10 & $\begin{array}{l}\text { The player must be controllable using a } \\
\text { gamepad }\end{array}$ & Low & Necessary \\
\hline 11 & $\begin{array}{l}\text { The player must be able to validate the } \\
\text { ticket }\end{array}$ & Low & Necessary \\
\hline 12 & $\begin{array}{l}\text { The player must be able to press the } \\
\text { "STOP" button inside the bus }\end{array}$ & Low & Necessary \\
\hline 13 & $\begin{array}{l}\text { The player must be able to sit inside the } \\
\text { bus }\end{array}$ & Low & Necessary \\
\hline 14 & The game must have a menu & High & Necessary \\
\hline 15 & $\begin{array}{l}\text { The game must be uploaded to the Neuro- } \\
\text { Hab platform }\end{array}$ & Medium & Necessary \\
\hline 16 & A score system must be implemented & Medium & Necessary \\
\hline 17 & There must be multiple tasks available & Medium & Necessary \\
\hline 18 & The game must incorporate biofeedback & Medium & Desirable \\
\hline 19 & The city must have traffic (e.g. cars) & High & Desirable \\
\hline 20 & The city must have people in it & High & Desirable \\
\hline
\end{tabular}

Table 4.1: Application requirements. 


\subsection{Development Methodology}

This project followed a methodology based on Agile development standards, which features a more flexible development approach, accepting higher rates of change and the need to adapt [72]. Agile values were originally described in the "Manifesto for Agile Software Development" [73] and include:

- Individuals and interactions over processes and tools

- Working software over comprehensive documentation

- Customer collaboration over contract negotiation

- Responding to change over following a plan.

More specifically, this project adopted an adaptive software development methodology [74], which encourages exploration, experimentation and flexibility by dividing the project into short iterations, after which tests are conducted and customer feedback is collected. This methodology has been used by Microsoft, whose process has been described by Highsmith [75] as an example of an adaptive development approach.

Highsmith [74] [75] described Adaptive Software Development's three-step cycle: Speculate - Collaborate - Learn. Speculate involves planning but without a high degree of certainty, thus embracing the concept that not everything can be predicted at the beginning of the project, and unexpected factors might appear, that require the project to adapt to them. Collaborate refers to team management and feature development. Since the features of the project were be implemented by one person only, most principles of Collaborate did not apply to this project. At the end of each iteration, on the Learn step, tests are conducted and feedback is gathered. By examining all the collected information and assumptions previously made, the next cycle is replanned and the project adapted. This methodology is particularly adequate for this project, whose target audience can be unpredictable and potential difficulties might be harder to anticipate.

\subsection{Work Plan}

The work done in this project was divided in three main phases. The first phase is called "context analysis, game engine evaluation and therapy requirements" and consisted of creating a solid knowledge base for the project. This included analyzing the context of the project (understanding ASD, how virtual reality works, finding other projects in this area, etc.), determining the most suitable game engine to use and identifying the requirements. In the second phase, "implementation", 
features which fulfilled the requirements identified were implemented. Finally, in the third phase, "validation", tests were conducted to evaluate the effectiveness of the application as a therapy tool. During the course of the project, the tasks performed were documented and two reports were written, an intermediate and a final one.

According to the methodology followed, the "implementation" phase was divided in three stages, with the first being a fully functional prototype and the last one the complete game. Thus, in each development stage, the complexity of the game was increased. Each of the development stages were also divided into three phases: "specification", "implementation" and "testing". In the "specification" phases, decisions involving the features to be implemented were made, which were then implemented in the "implementation" phases. The "testing" phases were small-scale validations at the end of each stage, in which potential problems identified became features of the following stage. The time allocated to each stage was based on the requirements assigned to each. Furthermore, to the first stage were assigned the first ten requirements; the second stage was assigned from the 11th requirement to the 15 th; and the rest (16th to 20 th) were assigned to the third stage.

Figure 4.1 represents a schedule with the time allocated for each task.

\begin{tabular}{|c|c|c|c|c|c|c|c|c|c|c|}
\hline \multirow{3}{*}{ Name } & \multirow{3}{*}{ Duration } & \multicolumn{9}{|c|}{ Time } \\
\hline & & \multicolumn{3}{|c|}{2014} & \multicolumn{6}{|c|}{2015} \\
\hline & & 0 & $\mathrm{~N}$ & $\mathrm{D}$ & J & $\mathrm{F}$ & M & A & M & $\mathrm{J}$ \\
\hline Context analysis, game engine evaluation and therapy requirements & 2 months & & & & & & & & & \\
\hline Context analysis & 4 weeks & & & & & & & & & \\
\hline Game engines evaluation & 4 weeks & & & & & & & & & \\
\hline Therapy requirements & 4 weeks & & & & & & & & & \\
\hline Development Stage 1 & 2 months & & & & & & & & & \\
\hline Specification & 1 week & & & & & & & & & \\
\hline Implementation & 7 weeks & & & & & & & & & \\
\hline Testing & 2 weeks & & & & & & & & & \\
\hline Development Stage 2 & 2 months & & & & & & & & & \\
\hline Specification & 1 week & & & & & & & & & \\
\hline \begin{tabular}{|l|} 
Implementation \\
\end{tabular} & 7 weeks & & & & & & & & & \\
\hline Testing & 2 weeks & & & & & & & & & \\
\hline Development Stage 3 & 1 month & & & & & & & & & \\
\hline Specification & 1 week & & & & & & & & & \\
\hline Implementation & 4 weeks & & & & & & & & & \\
\hline Testing & 1 week & & & & & & & & & \\
\hline Project Validation & 2 months & & & & & & & & & \\
\hline Documentation and Report & 8 months & & & & & & & & & \\
\hline
\end{tabular}

Figure 4.1: Work plan schedule. 


\section{Chapter 5}

\section{Game development}

This chapter describes the work done in the first seven months of this project. After analysing the project context and concluding the project's specification, both described in the previous chapter, several game engines were considered for this project and, after evaluating them based on eligibility, documentation, community and self-experimentation, one was chosen. Afterwards began the development of the game, composed of three stages, each with three phases: planning, implementation and testing. The planning phase consisted mostly of detailing the features that would be implemented. In the implementation phase, the requirements defined were addressed and, in the testing phase, participants with and without Autism Spectrum Disorder (ASD) were given in-game tasks to evaluate the current state of the application.

\subsection{Choosing a Game Engine}

A game engine is a software designed to ease the development of games by including features often required for most games, allowing the development team to focus on game content. These features include: rendering engine, physics engine, sound engine, networking, etc. Some game engines allow the developers to export the same game to several platforms such as personal computers, mobile devices or game consoles. The most popular game engines include Unity [76], Cry Engine 3 [77], Source [78], Unreal Engine 4 [79] and GameMaker: Studio [80] [81].

Choosing a game engine is an important decision which affects the course of the project, thus, a thorough evaluation was conducted in order to find the most suiting one for this project. In this section is presented a list of game engines. Their eligibility for this project is tested based on four primary requirements: Oculus Rift, 3D, OS, and mobile and web support. An engine short list is then evaluated according to the documentation and community size. Finally, self-experimentation results are reported and the game engine to be used in this project is chosen. 


\subsubsection{Primary requirements evaluation}

Given the large amount of game engines available nowadays [82] and to narrow the number of options, two lists were considered: "The top 16 game engines for 2014" [83] and "Comparison and evaluation of 3D mobile game engines" [84]. A short list containing the engines preset on both lists was then used as a starting point. In order to check the eligibility of these engines, four primary requirements were established:

\section{Oculus Rift support}

Since Oculus Rift is the virtual reality headset used in this project, the chosen game engine must support its integration in the project.

\section{$3 \mathrm{D}$ support}

In order to develop games that allow the navigation through scenarios that simulate real life situations in virtual reality environments, from a first person perspective, it is important to develop these games in $3 \mathrm{D}$.

\section{Operating System (OS) support}

Since desktop/laptop computers are the target platforms for the game developed in this project, it is important to use a game engine that is able to export it to most popular OS in the market (Windows, Linux and Mac OS X) [85].

\section{Mobile and Web support}

The game engine chosen for this project is intended to be used on future projects by the development team with the purpose of reusing developed assets. Furthermore, the team also plans to develop some of these future projects for mobile platforms and the web. Taking that into consideration, the chosen engine should support the development for web players, as well as for both Android and iOS, which cover the majority of the smartphone OS market share [86].

The following table presents an analysis of the chosen game engines according to the requirements previously identified. Despite not being in the game engine lists used as reference, Vizard [87] was also considered as it was the product used by the development team in previous projects. The corresponding data was collected on 13-10-2014. 


\begin{tabular}{|c|c|c|c|c|c|}
\hline $\begin{array}{c}\text { Game } \\
\text { Engine }\end{array}$ & $\begin{array}{c}\text { 3D } \\
\text { Support }\end{array}$ & $\begin{array}{c}\text { Mobile } \\
\text { Support } \\
\text { (Android } \\
\text { \& iOS) }\end{array}$ & $\begin{array}{c}\text { Web } \\
\text { Support }\end{array}$ & $\begin{array}{c}\text { Oculus } \\
\text { Support }\end{array}$ & $\begin{array}{c}\text { Windows } \\
\text { \& Linux \& } \\
\text { Mac } \\
\text { Support }\end{array}$ \\
\hline $\begin{array}{c}\text { Unreal } \\
\text { Engine } 4\end{array}$ & Yes & Yes & Yes & Yes & Yes \\
\hline Unity & Yes & Yes & Yes & Yes & Yes \\
\hline ShiVa & Yes & Yes & Yes & Yes & Yes \\
\hline $\begin{array}{c}\text { Marmalade } \\
{[88]}\end{array}$ & Yes & Yes & No & No & No \\
\hline Vizard & Yes & No & No & Yes & No \\
\hline
\end{tabular}

Table 5.1: Primary game engine requirements evaluation.

According to this first analysis, from the five game engines considered, three met the identified requirements: Unreal Engine 4, Unity and ShiVa [89]. Consequently, they were submitted to a more detailed and thorough evaluation to understand which would be more suited for this project.

\subsubsection{Documentation and community size evaluation}

The documentation available and the support given by a community are two important factors that can ease the development process of a project. In this subsection both were evaluated according to the following indicators:

- The number of questions in Game Development Stack Exchange [90], Stack Overflow [91] and in dedicated answer hubs was used to measure the size and support of the community

- The number of books written about development using the game engine, published after 01/01/2014. This indicator measures the amount of documentation available according to information present on Amazon.com [92], pointed by Reuters as the "most satisfying website to shop" [93].

The data was collected on 14-10-2014 and is presented in the following tables. 


\begin{tabular}{|c|c|c|c|}
\hline Game Engine & $\begin{array}{c}\text { Tags and } \\
\text { questions in } \\
\text { Game } \\
\text { Development } \\
\text { Stack Exchange }\end{array}$ & $\begin{array}{c}\text { Tags and } \\
\text { questions in } \\
\text { Stack Overflow }\end{array}$ & $\begin{array}{c}\text { Dedicated } \\
\text { Answer Hub }\end{array}$ \\
\hline Unreal Engine 4 & $\begin{array}{c}\text { tag, } 73 \\
\text { questions }\end{array}$ & $\begin{array}{c}1 \text { tag, } 32 \\
\text { questions }\end{array}$ & 21.213 questions \\
\hline Unity & 2 tags, 1578 & 8 tags, 7736 & 158.860 questions \\
questions & questions & 13.786 questions \\
\hline ShiVa & $\begin{array}{c}\text { (tags, } 0 \\
\text { questions }\end{array}$ & questions & \\
\hline
\end{tabular}

Table 5.2: Game engine community evaluation.

\begin{tabular}{|c|c|}
\hline Game Engine & $\begin{array}{c}\text { Number of books written about } \\
\text { development using the game engine, } \\
\text { published after } 01 / 01 / 2014\end{array}$ \\
\hline Unreal Engine 4 & 7 \\
\hline Unity & 31 \\
\hline ShiVa & 0 \\
\hline
\end{tabular}

Table 5.3: Game engine documentation evaluation.

This evaluation demonstrates that both Unity and Unreal Engine 4 feature a more extensive documentation and a wider community than ShiVa. For this reason, Unity and Unreal Engine 4 were further compared and one of them was chosen for this project.

\subsubsection{Self-experimentation and Secondary Requirements}

This subsection focuses on a more practical approach with hands-on experimentation. More specifically, four secondary requirements were identified as necessary for the project and implemented in both engines. The requirements were:

- The support of 3D models created in 3DS MAX, as there is already a group of models available which could be useful in this project

- Socket communication via TCP/IP can be a requirement for the developed game to be able to communicate with the technologies used, in case direct integration with the engine is not possible 
- Successful Oculus Rift integration

- Creation of experimental Heads-up Display (HUD) and Graphical User Interface (GUI) compatible with the Oculus Rift which is crucial to any application. However, designing user interfaces for Oculus Rift can represent challenges such as:

- The user can not see the keyboard with the Oculus Rift on

- There should not be a mouse or HUD floating in the screen as they could break the immersion.

These goals are crucial for the success of the project and provided some feedback on what working with each engine is like. All the goals were achieved in both engines.

\subsubsection{Conclusion}

In this section, a list of five game engines, defined as starting point, was continuously filtered and evaluated. The first evaluation focused on four primary eligibility requirements and reduced the list to three game engines: Unreal Engine 4, Unity and ShiVa. Afterwards, the documentation and community of these engines were analysed. The results showed that Unity features a more complete documentation and community than its counterparts, followed by Unreal Engine 4. Finally, as a self-experimentation process, four crucial features for the project were identified and successfully implemented with the two engines.

In conclusion, and considering the evaluation conducted and the information gathered, the chosen game engine to be used in this project, which fulfils all the requirements identified, is Unity. Further backing this decision is not only the fact that the development team already had experience in using Unity, but also the statistics that point Unity as the leading global game industry software, with $45 \%$ of the global game engine market share [94]. For more information on Unity development, please refer to Appendix C.

\subsection{Development of Stage 1}

As indicated in the work plan, the first stage of development was divided into three phases: specification, implementation and testing. According to the requirements identified, this stage allows the player to freely explore the city. He/She can take buses, which travel in pre-defined routes, with the interaction with them being limited to entering and leaving operations. The task available can be executed in two levels of difficulty: easy and hard. To help the player navigate in the city, there 
is a map with all the bus routes, bus stops, buildings, as well as the player's current position and the task's destination. In terms of hardware, Oculus Rift support was implemented in this stage and the player is controllable using, at least, a keyboard.

\subsubsection{Specification}

The stage 1 had an important yet complex requirement: "The game environment must be a 3D city model". The city is the base of game and everything that happens in the game, also happens in the city. Furthermore, modeled cities tend to be extremely complex as they consist of several individual models, such as buildings, streets, trees, etc. Accordingly, considering this is an academic project, the first approach was to try and find a modeled city, free to use. However, most of the cities found were either too small or built with low quality models. Additionally, since this game uses a first person view and the player navigates close to the models, in order to provide a more realistic experience, the models should also be realistic. Consequently, it was decided that a city would be built by gathering and using free models available online. Although modeling part of a real city rather than creating a new one was considered, the use of an original city could lead to better results regarding the generalization of the process of taking a bus and would avoid the creation of patterns or routines associated with the real version of the city. Thus, inspired in a region of a city in google maps, a first version of the city's architecture was created. Figure 5.1 contains the architecture built on top of google maps and Figure 5.2 the same map with the bus stops represented. 


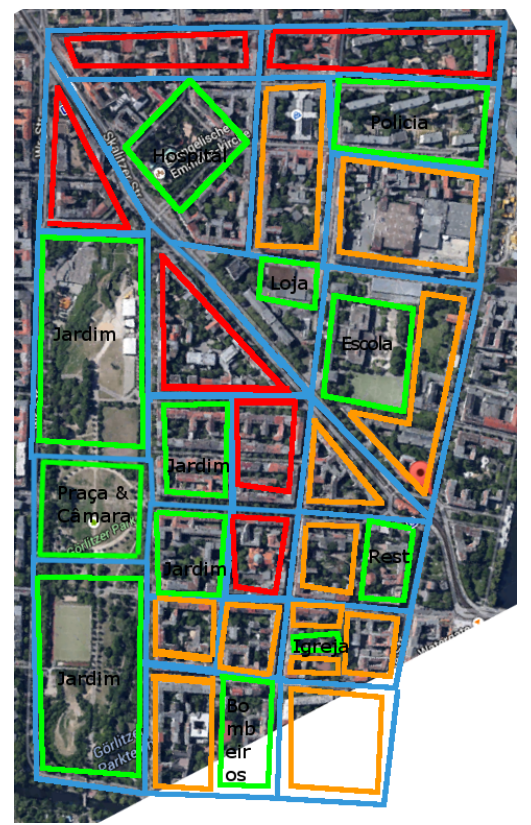

Figure 5.1: First version of city map.

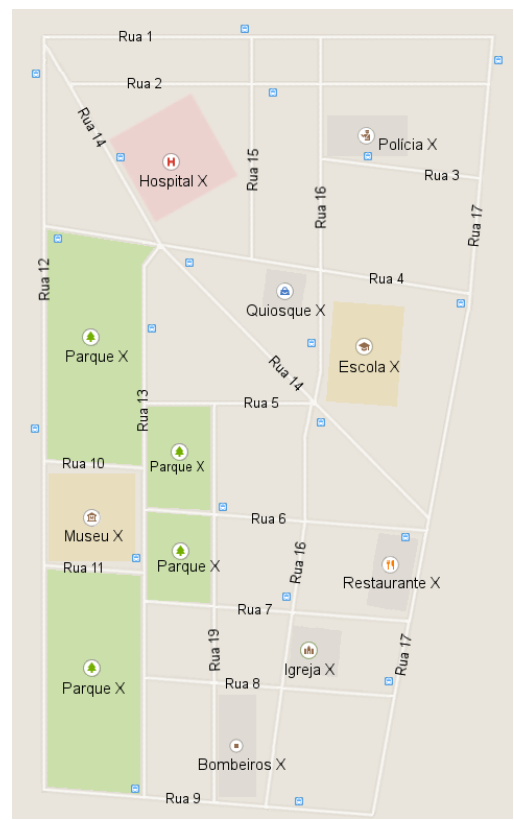

Figure 5.2: First version of city map with bus stops.

When implementing the first version of the city, the architecture went through some changes to ease the development, resulting in the map represented in Figure 5.3. 
Figure 5.4, the same map as Figure 5.3, consists of a complete version of the map. It contains the bus routes, and both buildings and bus stops are represented using the symbols in the portuguese traffic signaling regulation [95]. The map was created by capturing an image, in orthographic projection, of the modeled city.

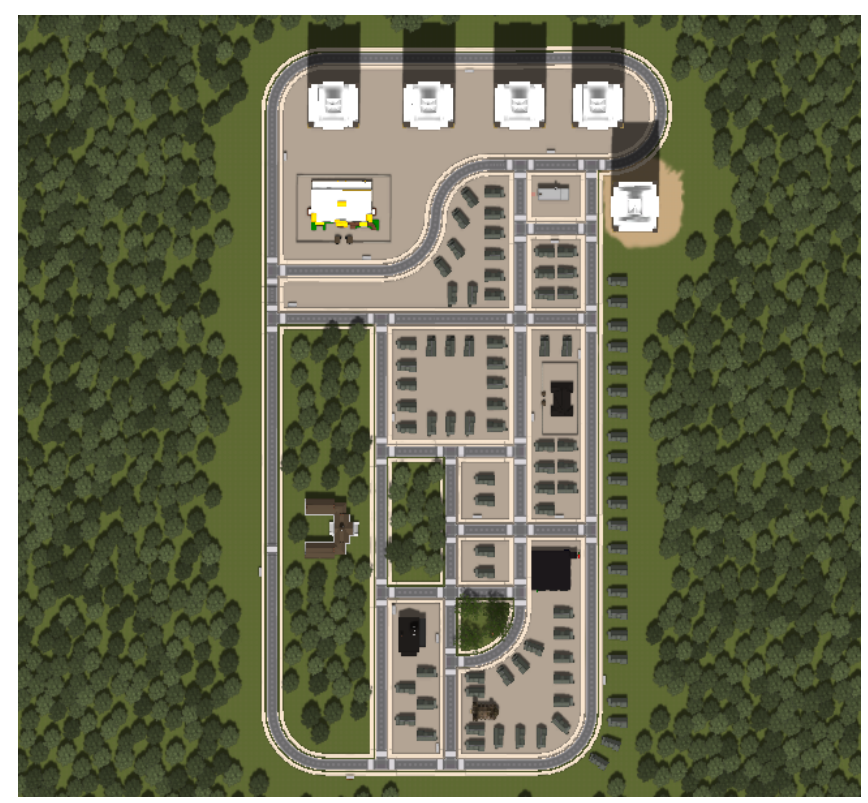

Figure 5.3: Second version of city map.

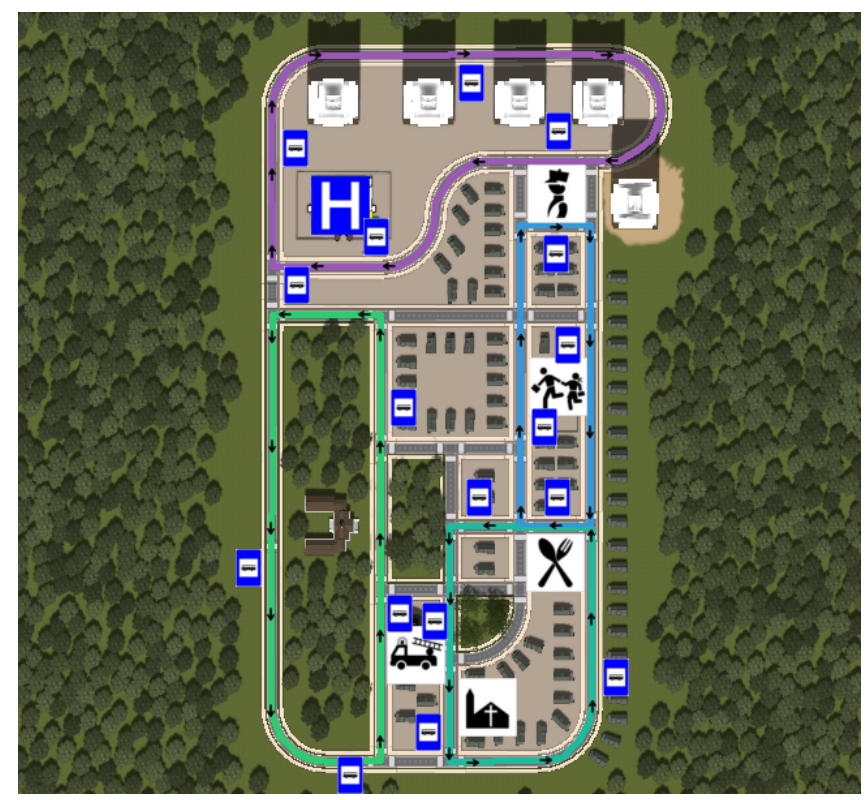

Figure 5.4: Complete version of city map. 
During this project, Petri nets were used to design the game system, with its primary elements, interactions and options. A Petri net is a graphical and mathematical tool used for modelling, analysing and designing different types systems [96] [97]. The creation of a Petri net leads to a more clear view of the game system before implementation, easing the comprehension of the mechanics, the development process, and the detection of potential inconsistencies. Besides game systems, petri nets can also be used to represent a game flow, or game plots [98] [99] [97]. Figure 5.5 contains the petri net which represents the game system designed for this first stage.

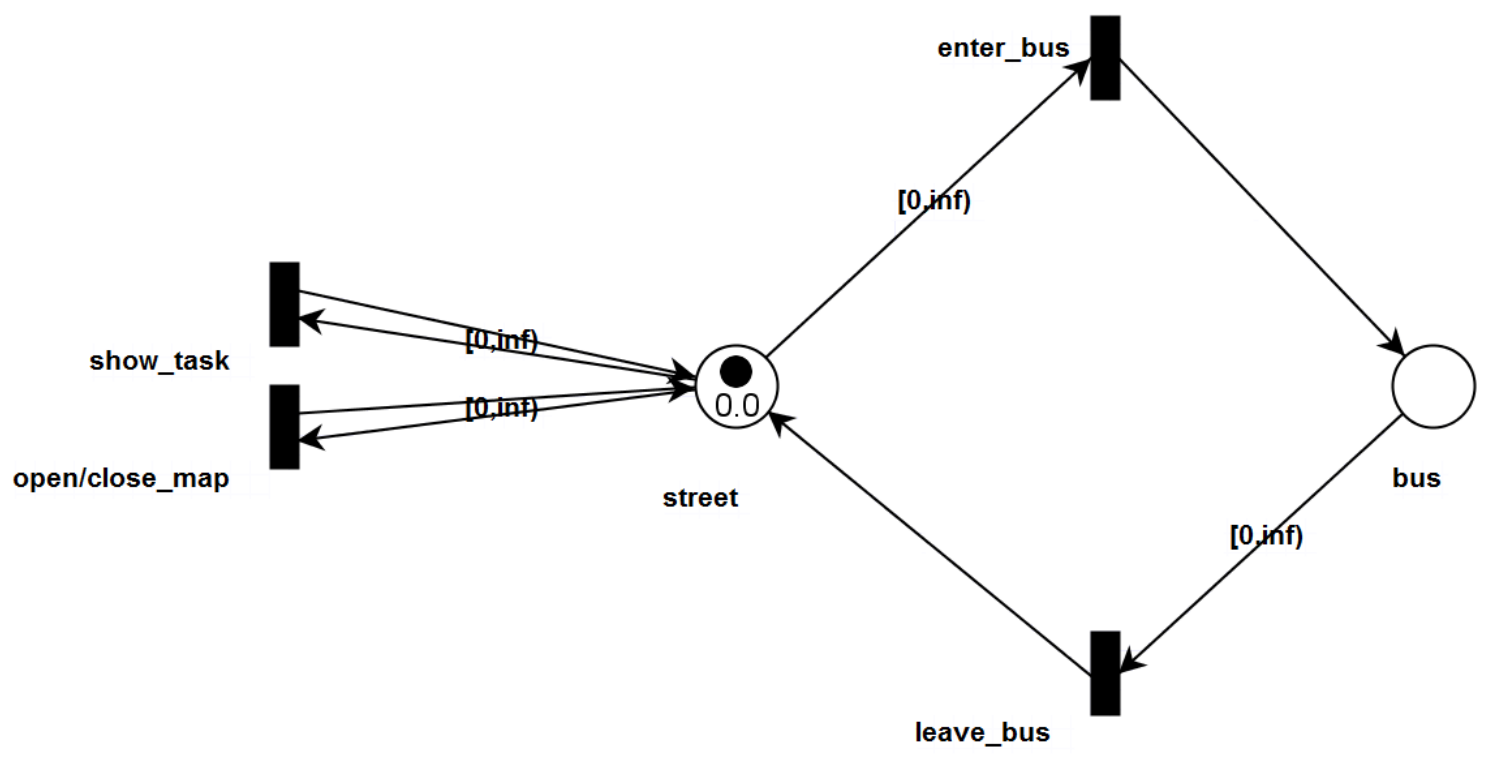

Figure 5.5: Stage 1 petri net representation.

\subsubsection{Implementation}

The objective of the first stage was to create a fully functional prototype of the game to be developed. Accordingly, all ten requirements, presented in the previous chapter, were successfully implemented, resulting in the environment represented in Figure 5.6. 


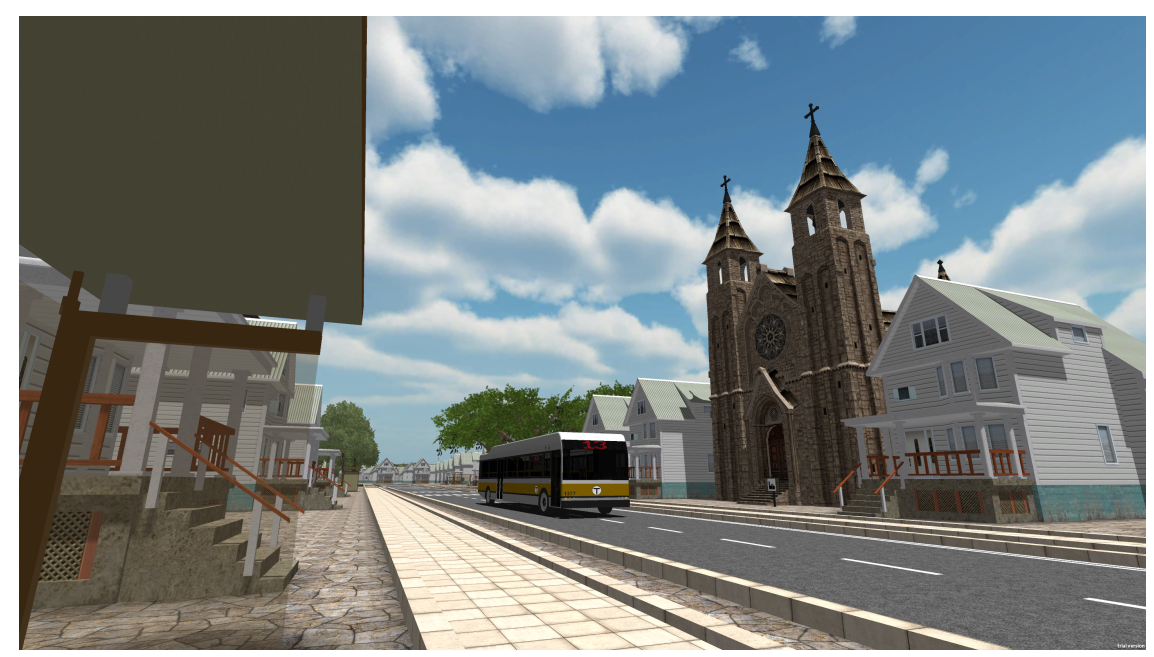

Figure 5.6: Player waiting for the bus.

In order to allow the player to keep track of the current task objective, an extra feature was implemented in which, by pressing a button, a message appears on a green panel with the current objective, as can be seen in Figure 5.7.

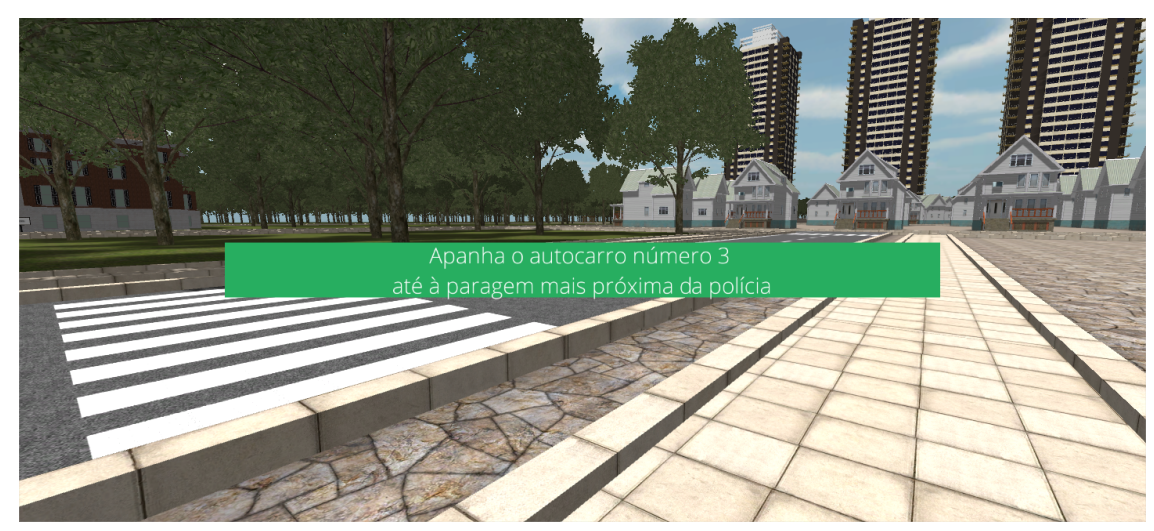

Figure 5.7: A task's current objective can be viewed at any time by pressing a key.

Figure 5.8 shows the map as seen in the game. On it, the red pointer, above the fire station symbol, indicates the location of the player and, the blue pointer, above the bus stop symbol to the left, indicates the current objective's destination. 


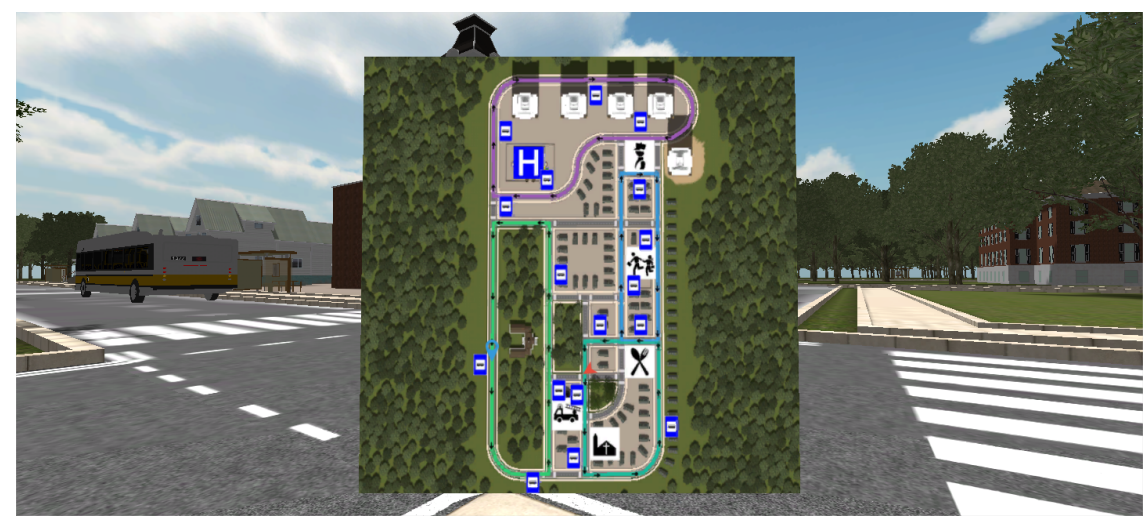

Figure 5.8: Player viewing the map.

The red cross painted on the floor present in the destination is represented in Figure 5.9. When a player steps on the cross, if there are more objectives to be achieved, it changes place to the new destination and the green panel illustrated in Figure 5.7 appears with the new objective written on it.

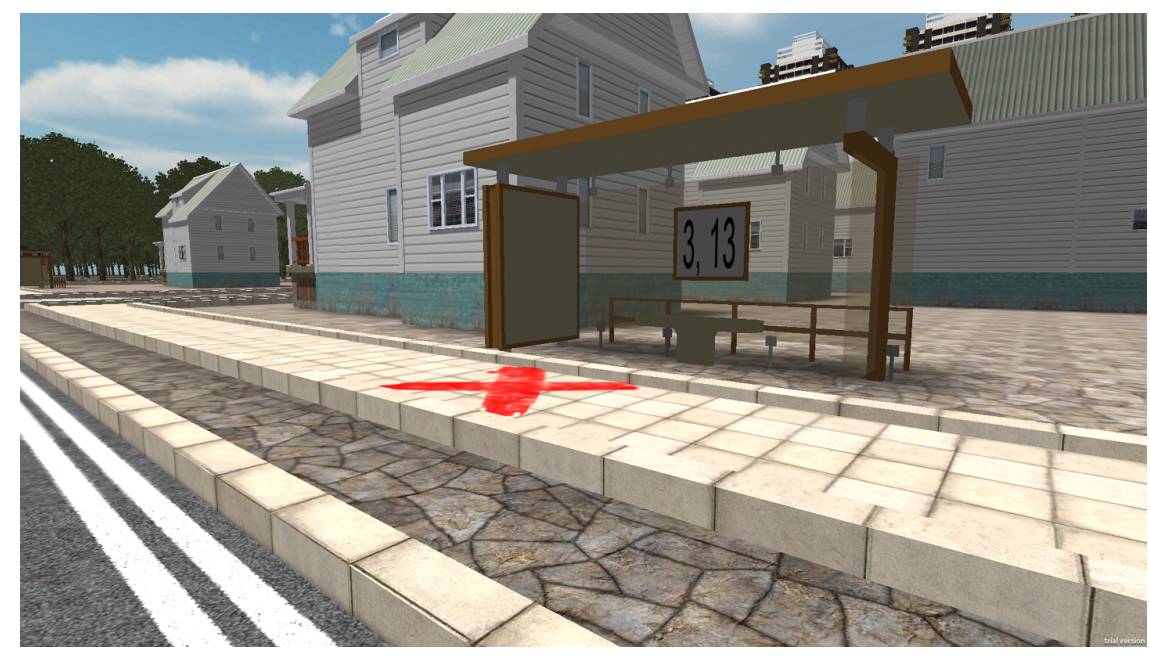

Figure 5.9: In order to complete a task the player should move over the red $\mathrm{X}$ painted on the floor.

Additionally, whenever a player chooses to enter a bus he/she appears sat, inside the bus, next to the window, as seen in Figure 5.10. 


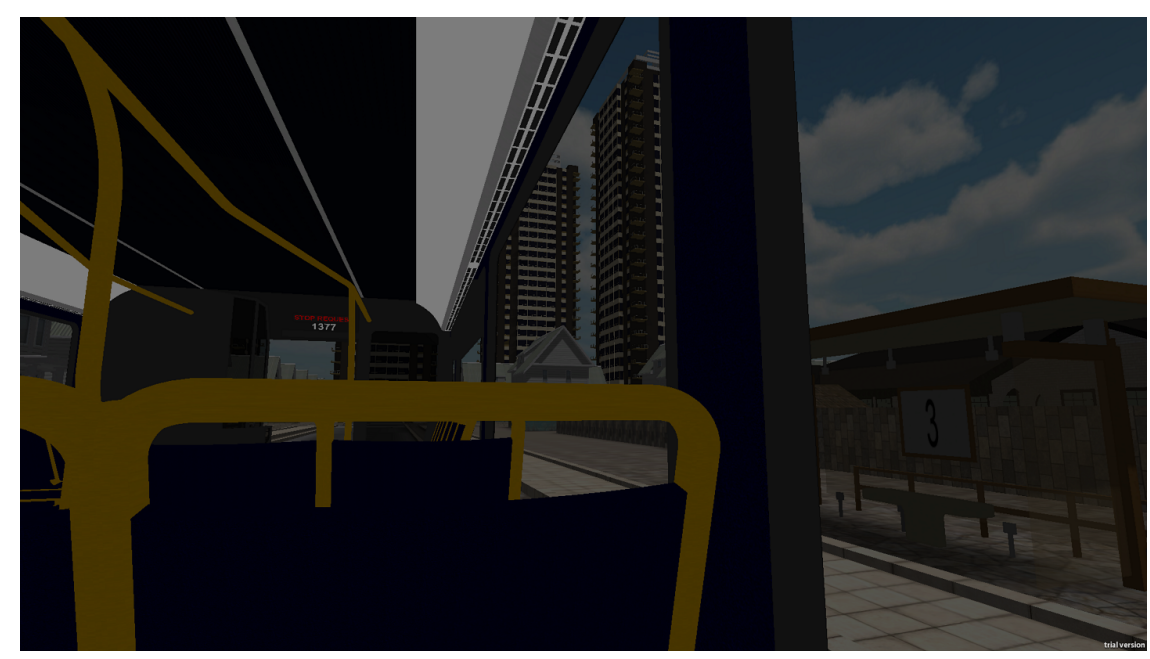

Figure 5.10: Player inside the bus.

\section{Input and display devices}

As planned for this stage, two display options were available: the Oculus Rift and the laptop's screen, for the participants that, for some reason, can not use the Oculus Rift. Additionally, two input styles were also implemented: gamepad and keyboard. When wearing the Oculus Rift the player can not see the input devices and, since the gamepad is held in both hands and has fewer keys, these are more easily identifiable. During this phase, a new type of interaction was also tested in which the rotation of the player's body in the real world would translate as rotation in the virtual world as well, instead of using the head rotation for that purpose. To achieve this, Razer Hydra controllers, which are able to detect their own orientation, were taped to the stool where the users were seated. However, the measurements of the rotation of the stool obtained were not accurate, which lead to a second approach in which the controllers were strapped to the user's waist. Even though the latter did provide the intended results, the movement of the user's body often resulted in the rotation of the controllers strapped, thus disrupting the calibration. Finally, this approach was abandoned due to its physical setup complexity.

\subsubsection{Testing}

A testing phase has been planned for each development stage of the project. The purpose of testing the application in this first stage was to examine the following factors:

- Technology acceptance - using an Head-mounted display (HMD) instead of a 
screen monitor can be overwhelming and using it can cause motion sickness

- Interface comprehension - interface design standards designed for desktop applications are often inadequate for HMD as the borders of the screen are blurred and only the centre of the screen is clear

- Task performance - difference in task performance between individuals with autism and controls.

The individuals who participated in the testing of the game come from different backgrounds, different age ranges, and some of them might be used to playing computer games and, consequently, it might take less time getting used to the controls and mechanics of the game. In order to prevent this fact from affecting the task performance measurements, a tutorial was created to teach how to play the game. Furthermore, the performance in the tutorial can be used to test if the interface is user friendly and intuitive, while the task performance can be used to measure capabilities and progression.

\section{Participants}

Five individuals with ASD, three males and two females, recruited from Associação Portuguesa para as Perturbações do Desenvolvimento e Autismo (APPDA) Coimbra, and six controls, three males and three females, participated in this testing phase. Despite being already diagnosed when admitted in APPDA Coimbra, the diagnoses were confirmed by two psychologists. A written consent was requested and obtained prior to the testing sessions. Further information about the participants with ASD can be found in Table 5.4, and about the controls in Table 5.5.

\begin{tabular}{|c|c|c|}
\hline Participant & Sex & Age (years) \\
\hline A & F & 32 \\
\hline B & F & 25 \\
\hline C & M & 36 \\
\hline D & M & 32 \\
\hline E & M & 36 \\
\hline Mean & - & 4.0 \\
\hline Standard deviation & - & 2.2 \\
\hline
\end{tabular}

Table 5.4: Characteristics of participants with ASD. 


\begin{tabular}{|c|c|c|}
\hline Control participant & Sex & Age (years) \\
\hline F & M & 24 \\
\hline G & M & 26 \\
\hline H & M & 40 \\
\hline I & F & 30 \\
\hline J & F & 38 \\
\hline K & F & 26 \\
\hline Mean & - & 30.7 \\
\hline Standard deviation & - & 6.2 \\
\hline
\end{tabular}

Table 5.5: Characteristics of control participants.

\section{Design}

All participants received the tutorial and the easy task. Control participant $\mathrm{K}$ was unable to complete the easy task due to motion sickness. Participant B was unable to use the Oculus Rift due to vision impairments and Participant $\mathrm{C}$ due to anxiety. Both received the task in a laptop computer instead.

\section{Materials}

The tasks were run on a laptop computer (Windows 8.1, 16.0 GB RAM and an Intel(R) Core(TM) i7 $2.50 \mathrm{GHz}$ processor) . The HMD used was Oculus Rift Development Kit (DK)2, firmware version 2.12. A gamepad was used for input.

\section{Procedure}

The testing process took place in APPDA Coimbra. Present in the sessions were two researchers, who acted as facilitators, and a therapist from APPDA Coimbra. The participants sat in a rotating stool, in front of a laptop where a gamepad and HMD were connected (Figure 5.11.). By using a rotating stool, rather than just rotating the neck to change the view inside the game, the player can keep looking forward and simply rotate the stool instead. As HMDs cover people's eyes, it is often hard to find the right keys to press on the keyboard, hence the use of a gamepad. 


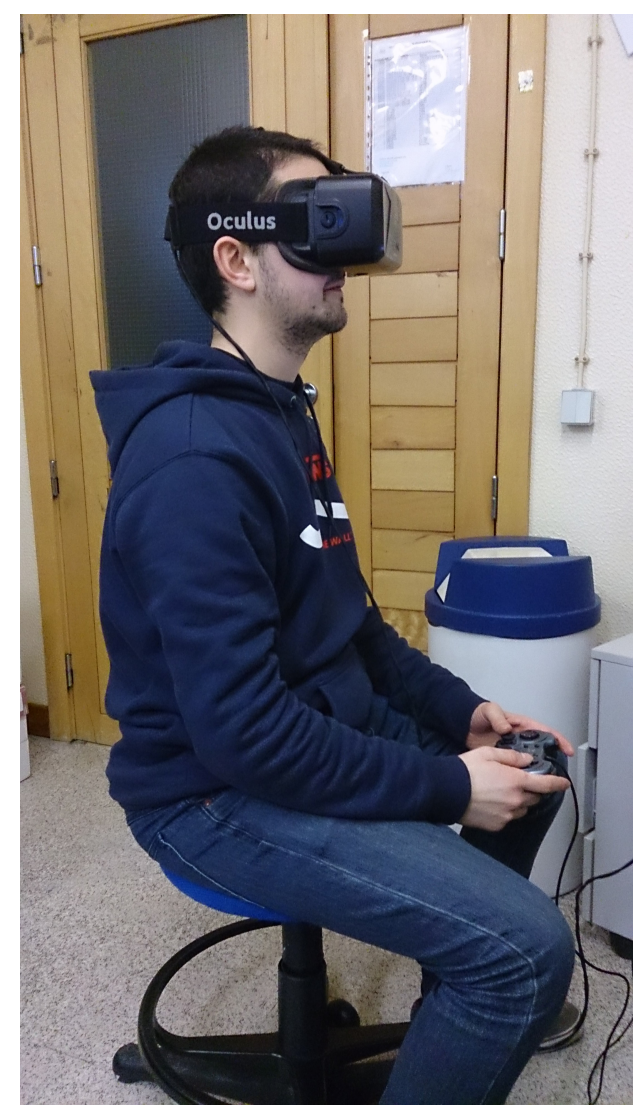

Figure 5.11: Testing setup.

The tutorial task, as the other tasks, has the city as environment and consists of two steps: the first one is to go to an X marked on the floor, and the second to take the bus number 4 and leaving in the first stop. Participants were guided step by step by the facilitators through the tutorial. The game mechanics were explained in the following order:

1. Look around by turning your head

2. Move using the left analog key

3. Rotate in the world by rotating in the stool

4. Walk until you reach the $\mathrm{X}$ painted on the floor

5. Press key "4" to view the current objective

6. Press key "3" to open the map

7. Press key "3" to close the map 
8. Press key "2" to enter the bus

9. Press key "2" to leave the bus.

After step 5 the individuals were asked to read the current objective out loud and, after step 6 , to identify the positions of the player and objective on the map.

The easy task consisted of three steps: going to the bus stop signaled in the map, taking the bus number 3 until the stop closest to the police station, and then going to the police station.

The hard task is the hard version of this task, with one step only: "go to the police station", and was not tested in this phase.

Even though the score system is only planned to the third stage of development, information about the player's performance is already being registered by the game for posterior analysis. The latter includes the total game time and the following actions:

- Opening the map

- Closing the map

- Viewing the current objective

- Entering a bus

- Leaving a bus.

\section{Results}

As previously indicated, during the tutorial participants were asked to read the current objective out loud and identify the location of both player and objective on the map.

Participants A, B and E could locate neither the player nor the target's location on the map. Participant B has, however, serious vision impairments and was not able to read the current objective either. Participants E and F could read the current objective but reported difficulties in doing so. All the controls could identify the player's location on the map, but participants $\mathrm{F}$, J and $\mathrm{K}$ were not able to locate the current objective's position on the map. These results are presented below in Table 5.10 and Table 5.11 for participants with ASD and controls, respectively. 


\begin{tabular}{|c|l|l|l|l|l|l|}
\hline & \multicolumn{5}{|c|}{ Participant } & \\
\hline Observation & A & B & C & D & E & Percentage \\
\hline Can read the current objective & Yes & No & Yes & Yes & Yes & $80 \%$ \\
\hline $\begin{array}{c}\text { Can locate the player's position on } \\
\text { the map }\end{array}$ & No & No & Yes & Yes & No & $40 \%$ \\
\hline $\begin{array}{c}\text { Can locate the current objective's } \\
\text { position on the map }\end{array}$ & No & No & Yes & Yes & No & $40 \%$ \\
\hline
\end{tabular}

Table 5.6: Interface test results from participants with ASD.

\begin{tabular}{|c|l|l|l|l|l|l|l|l|}
\hline & \multicolumn{6}{|c|}{ Control participant } & \\
\hline Observation & F & G & H & I & J & K & Percentage \\
\hline Can read the current objective & Yes & Yes & Yes & Yes & Yes & Yes & $100 \%$ \\
\hline $\begin{array}{c}\text { Can locate the player's } \\
\text { position on the map }\end{array}$ & Yes & Yes & Yes & Yes & Yes & Yes & $100 \%$ \\
\hline $\begin{array}{c}\text { Can locate the current } \\
\text { objective's position on the } \\
\text { map }\end{array}$ & No & Yes & Yes & Yes & No & No & $50 \%$ \\
\hline
\end{tabular}

Table 5.7: Interface test results for control participants.

The game registered both the duration of the task and actions performed by the player for posterior evaluation. Table 5.16 and Table 5.17 indicate the task duration of each participant for each task. The easy task duration values are also represented in Figure 5.12, in which the colour of the circles matches the colour of the participants in Tables 5.16 and 5.17. After entering the bus, Participants A, B, E, G and I tried to open the map and, since the map feature is disabled inside the bus, they reported that they did not know in which stop to leave. Participant B, D, F, G and H entered and left in the correct bus stop. 
CHAPTER 5. GAME DEVELOPMENT

\begin{tabular}{|c|c|c|}
\hline & \multicolumn{2}{|c|}{ Task duration } \\
\hline Participant & Tutorial & Easy Task \\
\hline A & 6.58 & 4.47 \\
\hline B & 4.57 & 15.95 \\
\hline C & 4.44 & 3.53 \\
\hline D & 9.70 & 2.42 \\
\hline E & 9.20 & 17.46 \\
\hline Mean & 6.90 & 8.77 \\
\hline Standard deviation & 2.22 & 6.53 \\
\hline
\end{tabular}

Table 5.8: Tutorial and task results for participants with ASD.

\begin{tabular}{|c|c|c|}
\hline & \multicolumn{2}{|c|}{ Task duration } \\
\hline Control participant & Tutorial & Easy Task \\
\hline F & 4.54 & 4.05 \\
\hline G & 2.68 & 2.34 \\
\hline H & 4.39 & 3.29 \\
\hline I & 4.47 & 9.33 \\
\hline J & 4.58 & 4.10 \\
\hline Mean & 4.40 & - \\
\hline Standard deviation & 4.18 & 4.62 \\
\hline
\end{tabular}

Table 5.9: Tutorial and task results from control participants. 


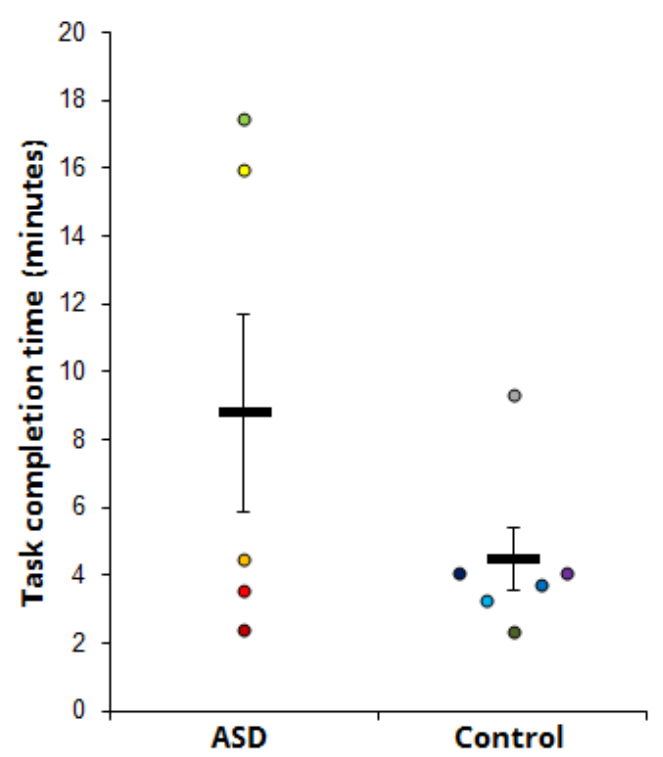

Figure 5.12: Stage 1 task performance comparison between ASD group and control group.

The results obtained indicate that, in terms of interface, there are some components which need to be more visible (i.e. current objective description, player's position on the map, current objective's position on the map). Concerning the fact that the map feature is disabled inside the bus, this was implemented to force the individuals to plan the trip before entering the bus. However, if the map is available outside the bus it is not intuitive that it will be unavailable once inside. In terms of performance, the results show a higher disparity in the ASD group, when compared to the control group. Finally, other than Participant K, no participant reported motion sickness during or after performing the tasks.

\section{Conclusion}

Considering the results obtained from the interface evaluation in this first testing phase, it was decided to change the map system and make it configurable, allowing to choose from two different options. The first option is directed at more inexperienced players and allows full-time access to the map, outside and inside the bus. Consequently, the player will not need to plan in which stop he/she will have to leave in order to reach the destination. The second option, on the other hand, intends to force the players to plan the trip to reach the destination by completely removing the access to the map and, instead, having a map of the city in every bus stop. This second option provides guidance mechanics similar to the stage 1 's, while minimizing the probability of players expecting the map system to be 
available inside the bus.

The appearance of both current objective's panel and pointers used to represent the player and current objective's location on the map were also changed to improve visibility.

In terms of performance, participants with ASD generally performed worse. Moreover, when comparing to the controls, the median time the participants with ASD needed to complete the tutorial was 2.72 minutes higher and the median time to complete the easy task was 4.15 minutes higher.

\subsection{Development of Stage 2}

Just as the first stage of development, the second stage is also divided into three phases: specification, implementation and testing. The requirements identified for the second stage aim at improving the player-bus interaction, from something boolean (enter/leave the bus) towards a more realistic and complex approach (e.g. enter the bus, validate the ticket, sit). The addition of a menu at the beginning of the game, not only incorporates features implemented in the previous stage into the game ("There must be a task available in different difficulty levels for the player to choose"), but also prepares the system for features of the third stage ("There must be multiple tasks available"). Finally, at the end of this stage, the game was uploaded to the NeuroHab platform.

\subsubsection{Specification}

According to the results obtained from stage 1, some elements of the UI (objective panel, and map icons) lacked visibility and were improved in this stage. The map system previously designed also had a negative impact on the performance of players by not being available during bus rides. Consequently, this system was redesigned and a new option was added that allows the player to choose whether to allow or block map access during the game. The map access blockage, however, will only prevent the player from accessing the map from anywhere in the city. Regardless of the option chosen, city maps will always be available on bus stops.

After the creation of the city in stage 1, the requirements defined for stage 2 focused on adding a new in-game environment: the inside of the bus. In order to familiarize players with the process of taking a bus, it is necessary that the game explores the norms and standard procedures involved, such as entering through the front door, validating the ticket, not sitting on reserved seats, etc.

The Petri net modelled for stage 1 was changed to adapt to the new interactions 
planned for stage 2. However, as the map availability became optional in the game, two Petri nets were modelled instead: one, represented on Figure 5.13, with full map access, and another, represented on Figure 5.14, with blocked map access.

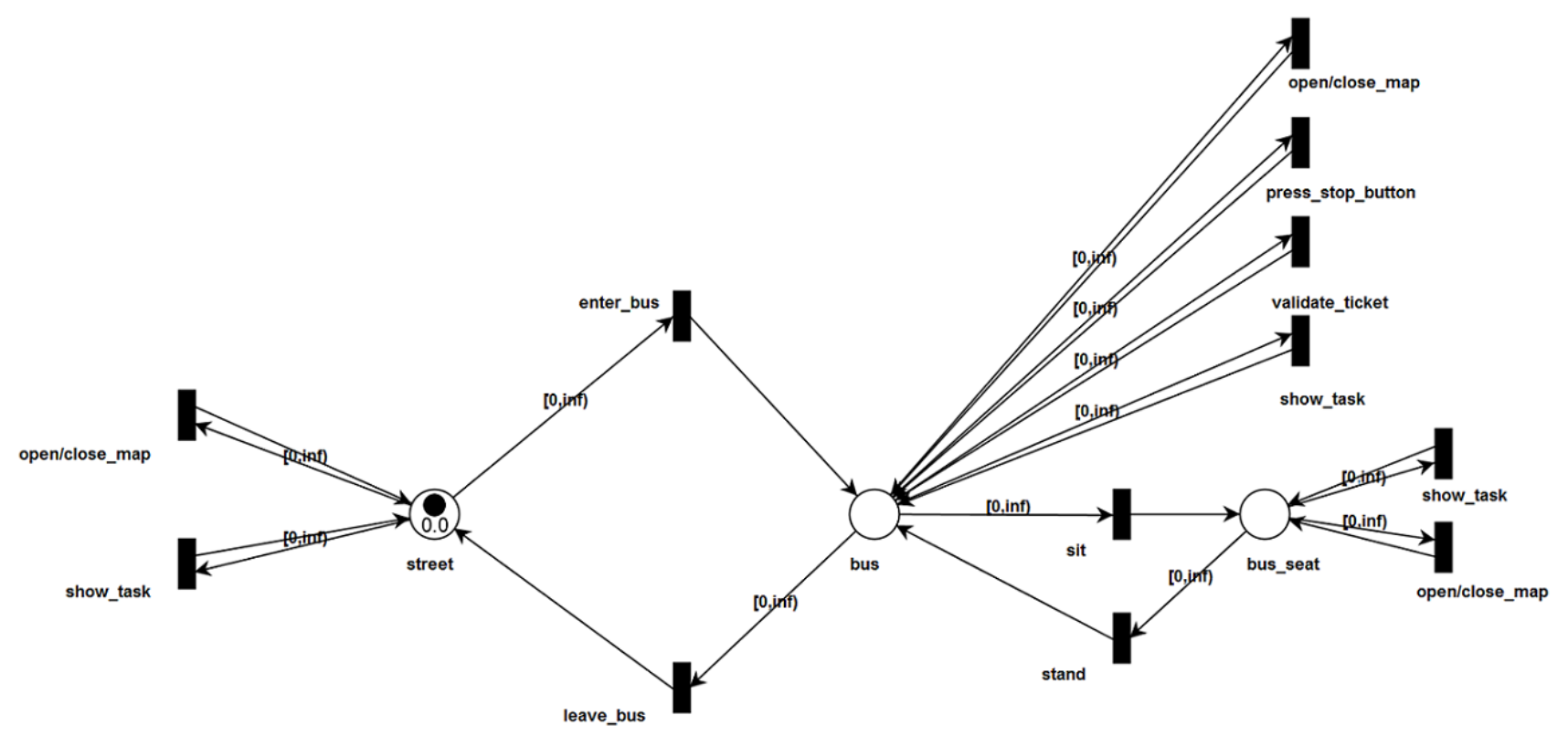

Figure 5.13: Stage 2 petri net representation with full map access. 


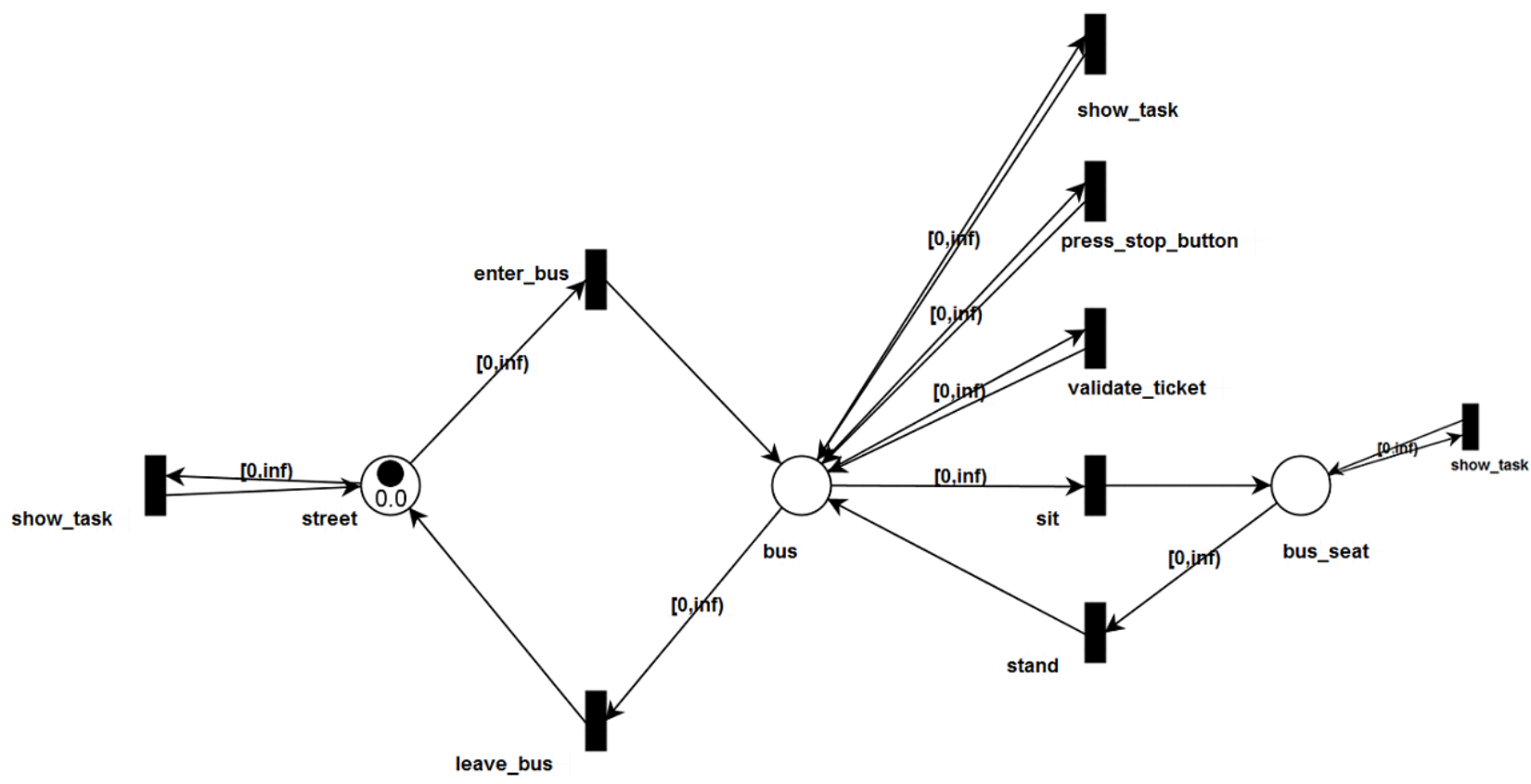

Figure 5.14: Stage 2 petri net representation with blocked map access.

\subsubsection{Implementation}

The objective of the second stage was to create an explorable bus environment to replace the static one, developed in stage 1, where the players simply appeared sat when they entered the bus. Additionally, some GUI elements developed in stage 1 were improved. All 5 requirements identified for this stage were successfully implemented. Some extra features were implemented before the end of the implementation: sound and a new information retrieval method.

\section{Transition from stage 1 to stage 2}

Before the beginning of the implementation of the features from stage 2, the two GUI issues identified in stage 1 were solved. The first issue was that the objective panel was hard to read, due to being too close to the eyes of the player. The panel was, thus, changed to be rendered farther from the player. Figure 5.15 includes a screen capture, with Oculus Rift, of the objective panel in stage 1 (left), and stage 2 (right). 

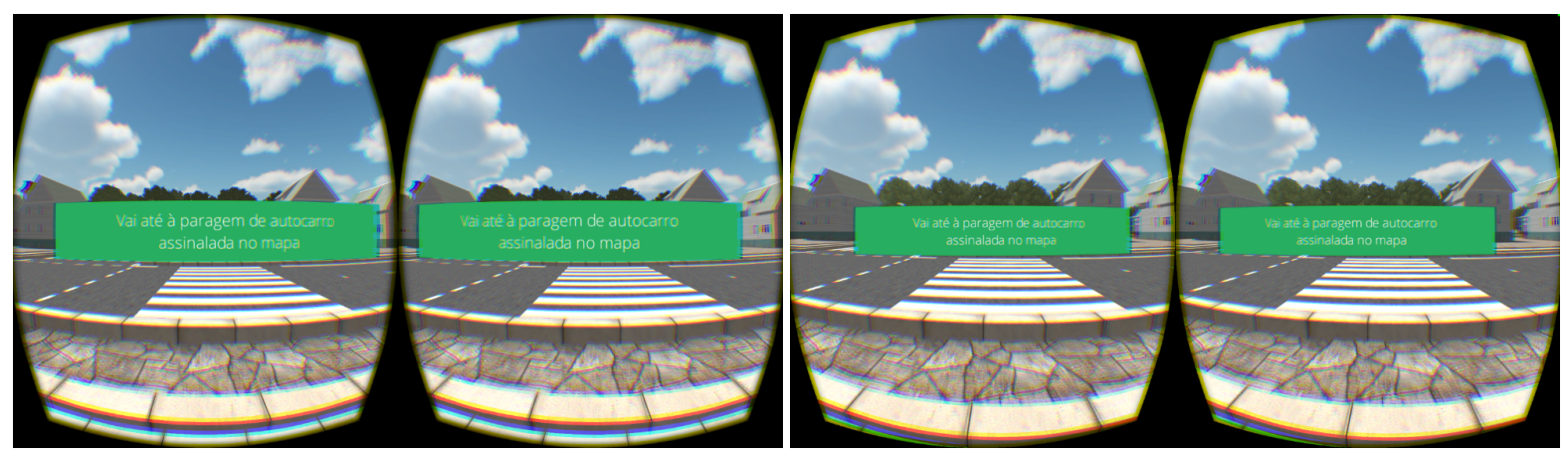

Figure 5.15: Comparison between the objective panel used in stage 1 (left) and stage 2 (right)

The map was also subject to change in response to the difficulties presented in identifying the position of both player and objective on the map. Despite the contrast between the colour of the player's pointer and the map, it was too small, while the objective's pointer was small and had little colour contrast. After generating a new map, with higher resolution, both pointers were enlarged, and the design of the objective' pointer was changed. The result of these changes can be observed on Figure 5.16

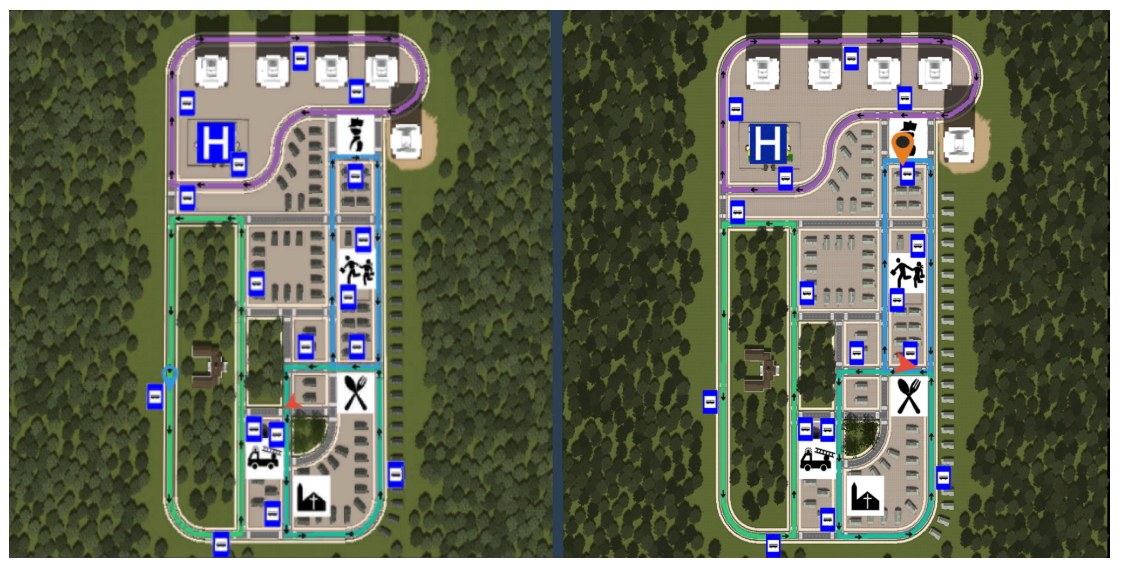

Figure 5.16: Comparison between the map used in stage 1 (left) and stage 2 (right).

The new map, with higher resolution, was also added to bus stops. These maps (present on bus stops) are, however, different from the one carried by the player, since they do not indicate the position of the objective.

\section{Bus environment}


With the GUI issues solved, began the creation of the bus environment. The first step was the replacement of the previously used bus model for a new one. This new model was first created for another project, by Hélio Gonçalves, a 3D modeler working at Institute for Biomedical Imaging and Life Sciences (IBILI). The new bus, in addition to animations for opening and closing the doors, also includes a validating machine, stop buttons, and a sign between some of the seats, identifying them as reserved. The model, already integrated into the game, can be seen on Figures 5.17, 5.18 and 5.19.

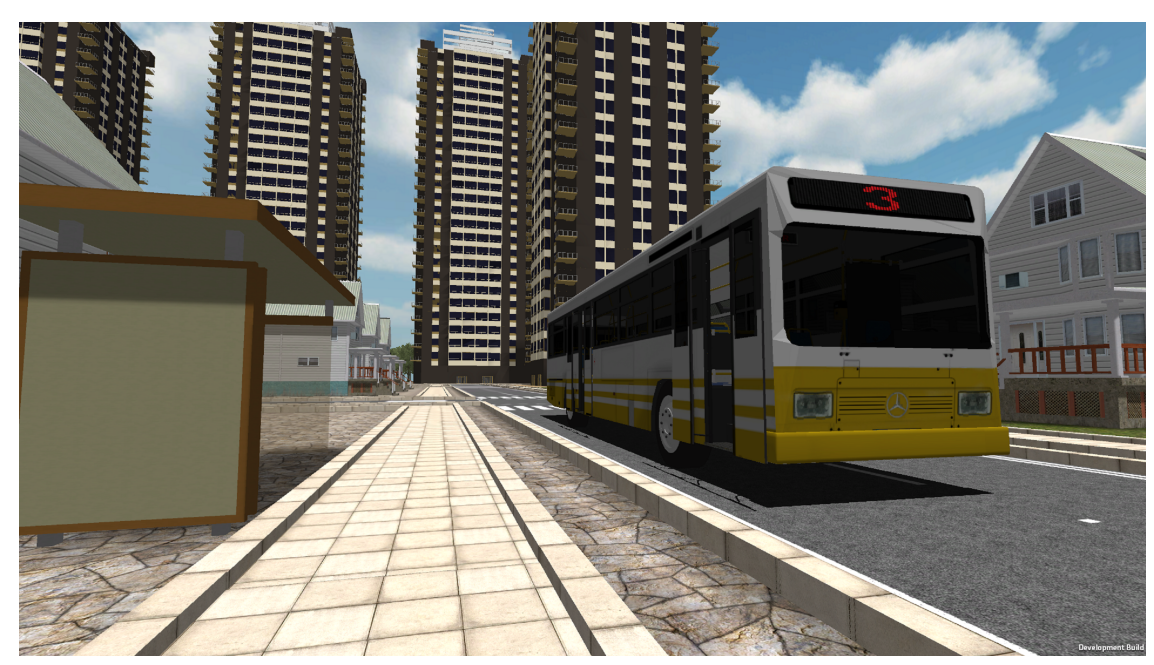

Figure 5.17: New bus model - outside view.

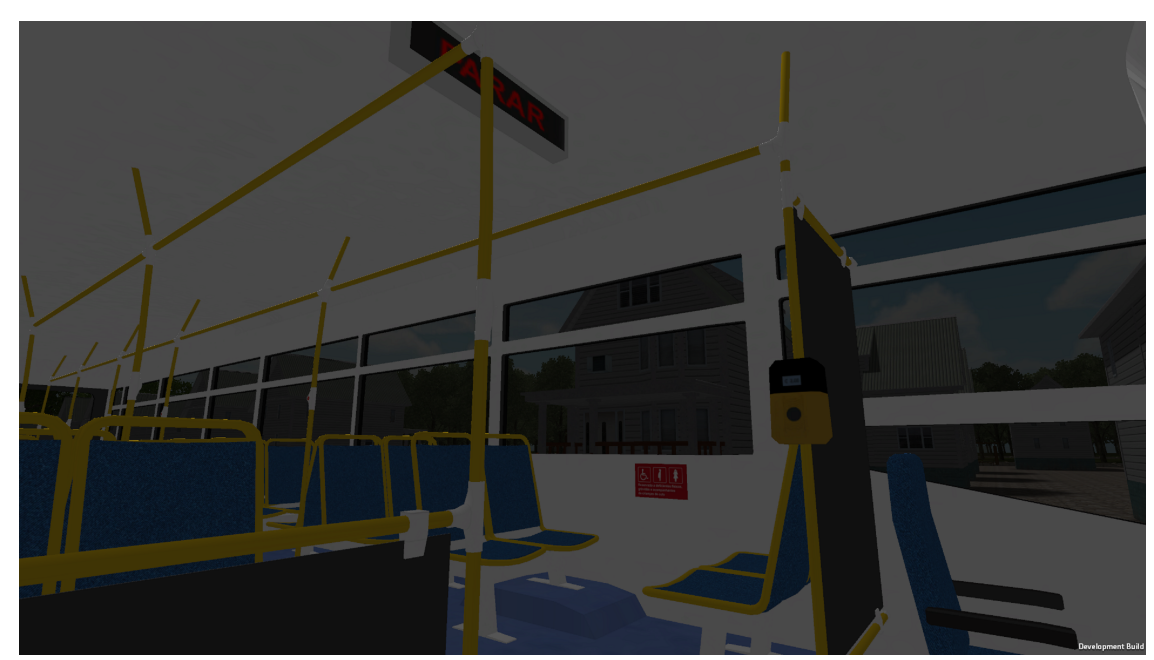

Figure 5.18: New bus model - inside view (with reserved seat sign and validating machine). 


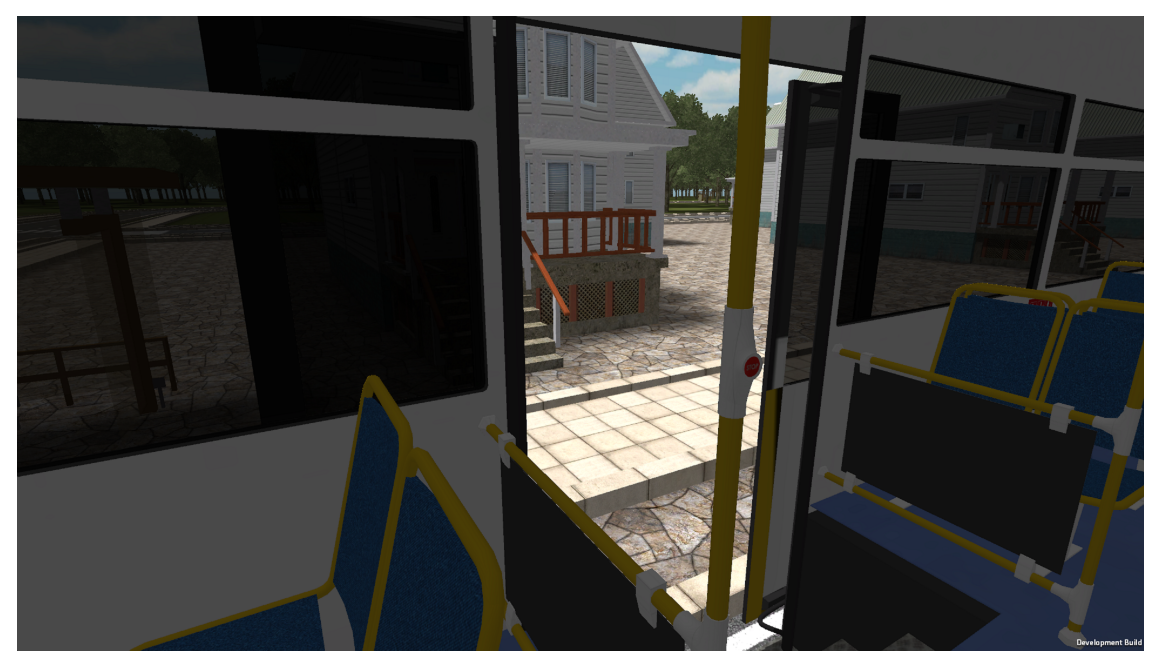

Figure 5.19: New bus model - inside view (with stop button and doors open).

The integration of the new bus model led to the implementation of the interaction with the components it contained (validating machine, stop button, and seats). In stage 1 , an interaction system had been developed which was used for the player to enter the bus. It consisted of looking at an object (e.g. the bus doors) and, if that object could be interacted with, a message would appear with the action associated (e.g. "Enter bus"). Afterwards, the player can press a button to interact and the action is completed. This system was adapted and applied to the features implemented in this stage. Figure 5.20 shows the results obtained. Furthermore, this mechanic is particularly adequate when wearing a HMDs as head movements are simple to perform and it is intuitive to look at something when wanting to interact with it.

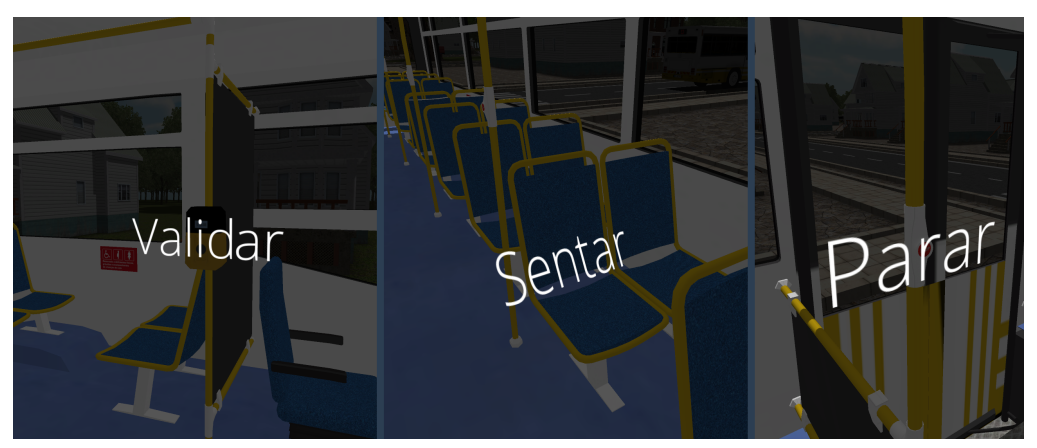

Figure 5.20: Examples of the interaction system - "Validar", "Sentar" and "Parar" ("Validate", "Sit" and "Stop", respectively).

Additionally, the metric system was updated to also register the interactions inside 
the bus, and allow a posterior analysis of whether the player understood the bus norms.

\section{Menu}

For this stage, the creation of a menu system was planned. This system allows the configuration of the game settings, prior to the beginning of the play session. The latter are:

- Which task to attempt

- The difficulty level (easy or hard)

- The map access restrictions (allow or block the map system).

Regarding the menu design, the options are located in an environment with a road and trees. This design decision was made taking into consideration the fact that HMDs grant immersion in the environment surrounding the player. Accordingly, it could be more interesting for the player to be surrounded by an environment with real, game-related components, instead of, for example, a single colour. Figures 5.21 and 5.22 show the resulting menu. The first one, lets the player choose either to play or leave the game. The second contains all the configurations previously described.

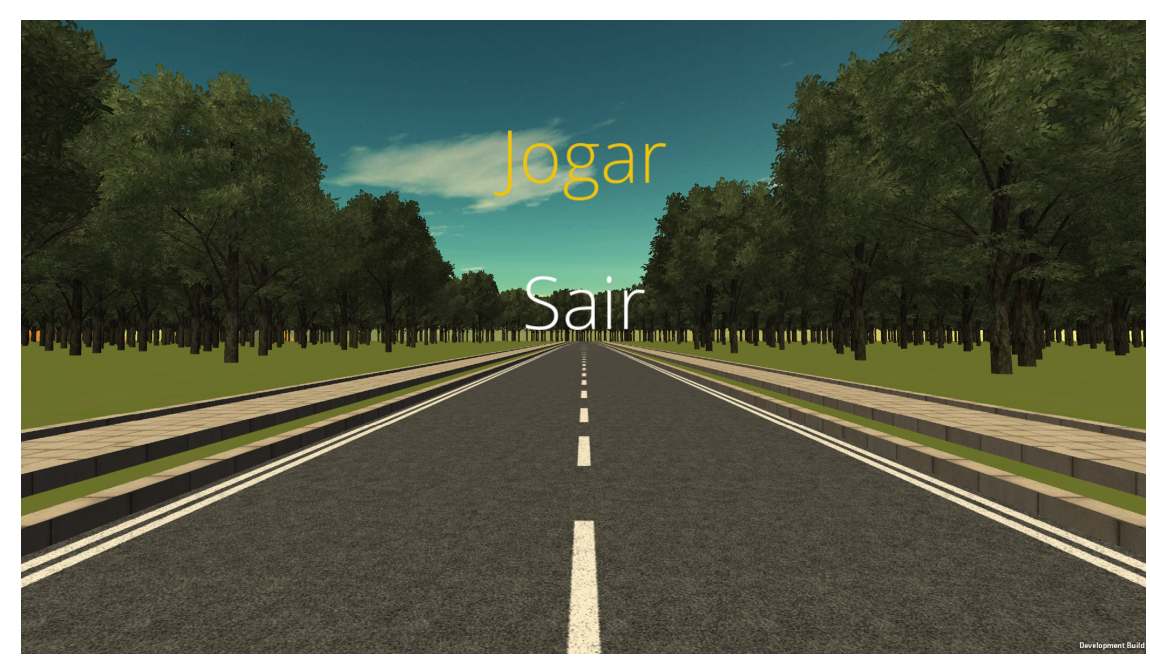

Figure 5.21: Menu system, screen 1 - "Jogar" and "Sair" ("Play" and "Leave", respectively). 


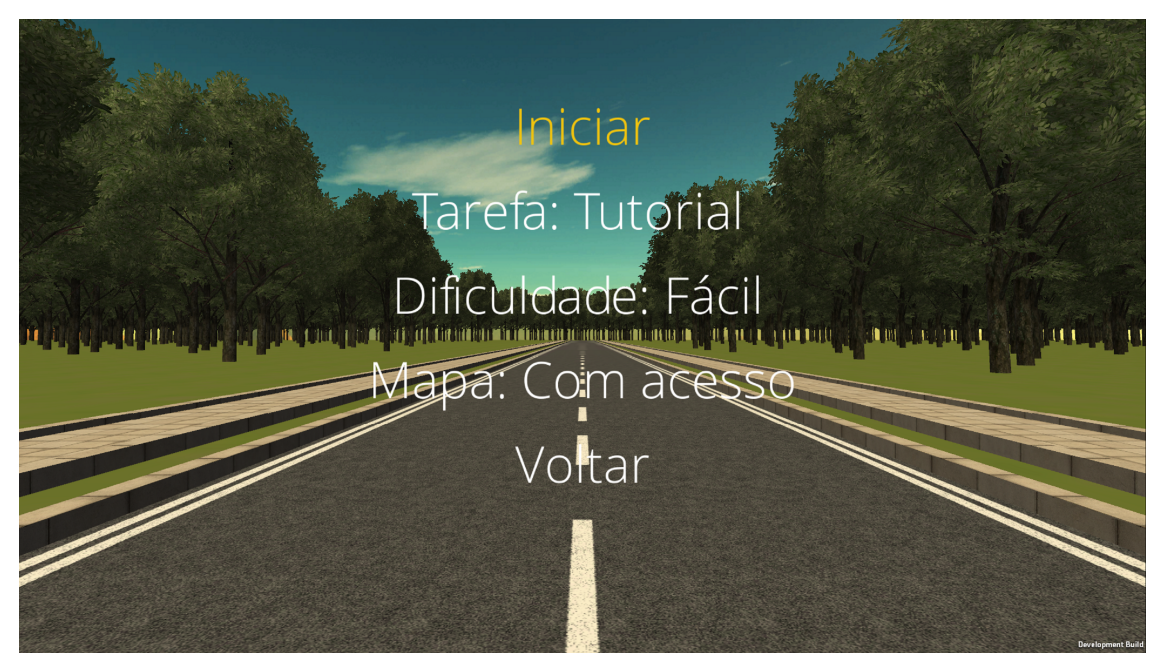

Figure 5.22: Menu system, screen 2 - "Iniciar", "Tarefa", "Dificuldade", "Mapa" and "Voltar" ("Begin", "Task", "Difficulty", "Map" and "Return", respectively).

\section{Sound}

In addition to the features implemented at this point, sounds were also added to enhance the quality and immersion of the game. For this stage, three different sounds were added:

- An ambience sound that loops throughout the game, with birds chipping

- The sound of buses when turned on

- The sound bus doors make when opening and closing.

\section{New information retrieval method}

In stage 1, while the metrics being registered were enough to understand if the player had taken the correct route, they were not enough to properly visualize the play session, and understand, for instance, if the player was able to easily find the destination or the bus stops, or if he/she wandered, looking for it. In order to allow this additional analysis and also to anticipate potential situations where this kind of information might be useful, the position of the player was registered, every two seconds, as well as his/her location (street or bus). Afterwards, a script was written in Python (and using the Python Imaging Library [100]), which used this information, along with a map of the city, to draw the course of the player from the beginning until the end of the task. Figure 5.23 contains two different maps, generated from the data collected in the testing of stage 2 . 


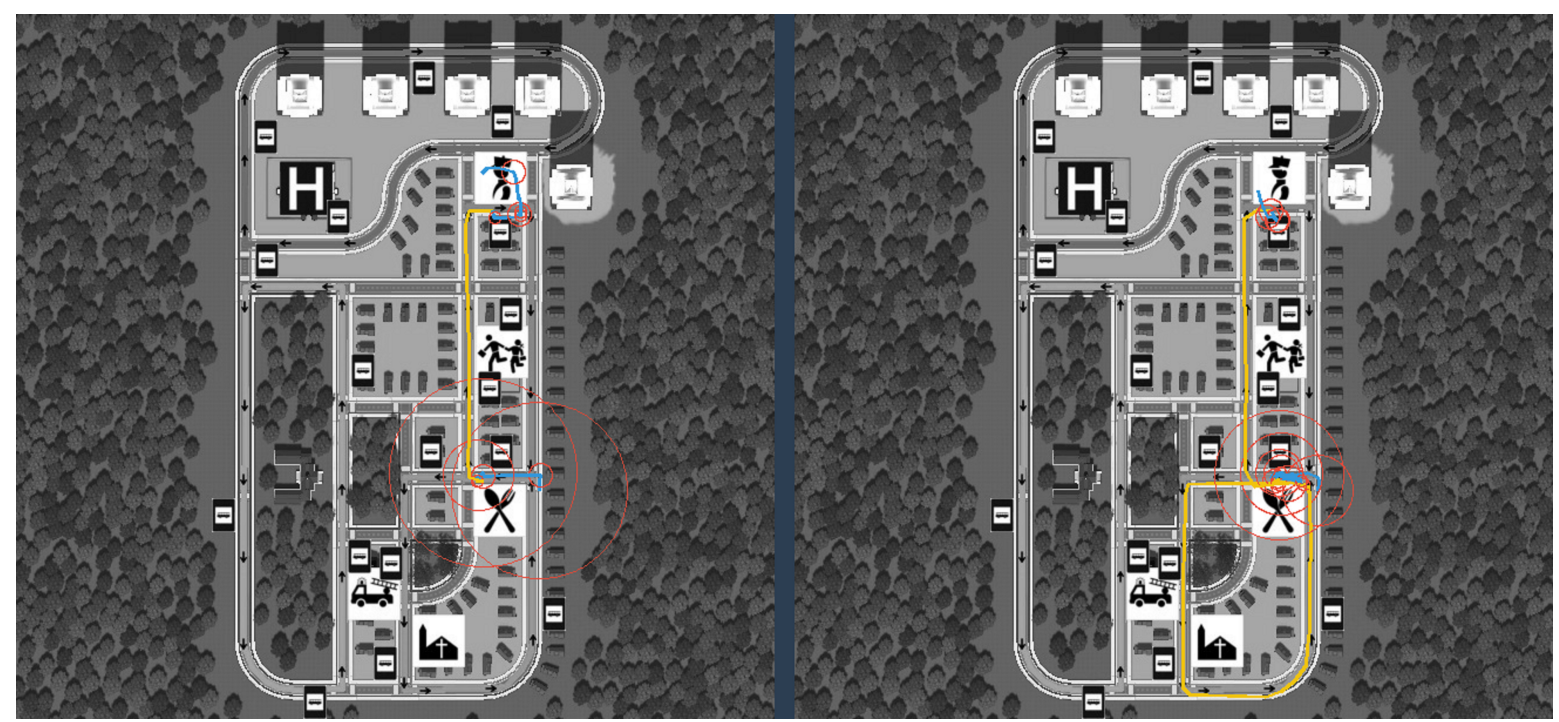

Figure 5.23: Two maps of two different play sessions. The blue lines represent walking courses and yellow lines bus courses. The red circles represent idle time (the longer the player stood, the bigger the radius).

As can be seen, these maps provide a much faster perception and overview of the task than a list of coordinates. For instance, in Figure 5.23, the map on the left represents a task done correctly: the player walked to the bus stop, took the bus until the bus stop closest to the police, and went to the police station. On the other hand, on the map on the right, the player took the wrong bus first, but left on the same bus stop he/she had entered in, and took the right bus to the police station afterwards.

\section{Neurohab}

At the end of the implementation of stage 2, an account was created in the Neurohab platform and the game was uploaded. This step was repeated, in stage 3 , after the development of the game was complete.

\subsubsection{Testing}

After the development of the requirements identified for stage 2, another testing session was conducted to see how the participants responded to the changes made in the game. The two main factors examined were:

- Task performance - difference in task performance between individuals with autism and controls 
- Interface comprehension - how the changes made in the interface, during this stage, will affect the ease of understanding the GUI.

\section{Participants}

The same individuals from stage 1 also participated in stage 2 . Please refer to subsection 5.2 .3 for more details.

\section{Design}

Once again, all participants received the tutorial and the easy task, both with map access. Participant $\mathrm{C}$ completed the tutorial but, due to severe anxiety caused by events not related to this study, was too stressed and did not want to receive the task. Participant B and control participant $\mathrm{K}$ received the task in a laptop computer due to vision impairments, and control participant I due increased sensitivity towards motion sickness.

\section{Materials}

The material used in stage 2 was the same used in stage 1, described in subsection 5.2 .3 .

\section{Procedure}

The testing process took place in APPDA Coimbra and in a residence where some of the participants live. One researcher (facilitator) and a therapist from APPDA Coimbra were present during the acquisitions. A software called Open Broadcaster Software [101] was used to see in the desktop of the computer what was being seen on the Oculus Rift, during the therapy sessions.

In order to equalize, for every session, the process of guiding the player through the tutorial, a script was created. It contains a list of instructions that was read to the players during the tutorial. This list includes the bus norms that are explained to the player as he/she enters the bus, guiding him/her through the standard procedure of taking a bus. The norms considered were:

1. Entering the bus through the front door

2. Validating the ticket

3. Sitting on non-reserved seats

4. Pressing the "STOP" button beforehand

5. Leaving the bus through the back door.

Apart from these changes, the procedure followed was similar to the one of stage 1, as detailed in subsection 5.2.3. 


\section{Results}

Once again, during the tutorial, participants were asked to read the current objective out loud and identify the location of the player and objective on the map. Unlike the results obtained in stage 1, in stage 2, except for one, all the participants succeeded in this task. The results obtained can be seen below in Table 5.10 and Table 5.11 for participants with ASD and controls, respectively.

\begin{tabular}{|c|l|l|l|l|l|l|}
\hline & \multicolumn{5}{|c|}{ Participant } & \\
\hline Observation & A & B & C & D & E & Percentage \\
\hline Can read the current objective & Yes & Yes & Yes & Yes & Yes & $100 \%$ \\
\hline $\begin{array}{c}\text { Can locate the player's position on } \\
\text { the map }\end{array}$ & Yes & Yes & Yes & Yes & Yes & $100 \%$ \\
\hline $\begin{array}{c}\text { Can locate the current objective's } \\
\text { position on the map }\end{array}$ & Yes & Yes & No & Yes & Yes & $80 \%$ \\
\hline
\end{tabular}

Table 5.10: Interface test results from participants with ASD.

\begin{tabular}{|c|l|l|l|l|l|l|l|}
\hline & \multicolumn{6}{|c|}{ Control participant } & \\
\hline Observation & F & G & H & I & J & K & Percentage \\
\hline Can read the current objective & Yes & Yes & Yes & Yes & Yes & Yes & $100 \%$ \\
\hline $\begin{array}{c}\text { Can locate the player's } \\
\text { position on the map }\end{array}$ & Yes & Yes & Yes & Yes & Yes & Yes & $100 \%$ \\
\hline $\begin{array}{c}\text { Can locate the current } \\
\text { objective's position on the } \\
\begin{array}{c}\text { map } \\
\text { map }\end{array}\end{array}$ & Yes & Yes & Yes & Yes & Yes & Yes & $100 \%$ \\
\hline
\end{tabular}

Table 5.11: Interface test results from control participants.

Furthermore, the duration of the tutorials and tasks, registered in every session, can be observed in Table 5.16 (ASD), Table 5.17 (Controls). The duration of the task is also represented in Figure 5.24, following the same configuration as in subsection 5.2.3. 
CHAPTER 5. GAME DEVELOPMENT

\begin{tabular}{|c|c|c|}
\hline & \multicolumn{2}{|c|}{ Task duration } \\
\hline Participant & Tutorial & Easy Task \\
\hline A & 8.25 & 3.29 \\
\hline B & 9.50 & - \\
\hline C & 8.33 & 5.42 \\
\hline D & 8.25 & 5.43 \\
\hline E & 8.35 & 13.90 \\
\hline Mean & 8.54 & 14.18 \\
\hline
\end{tabular}

Table 5.12: Tutorial and task results from participants with ASD.

\begin{tabular}{|c|c|c|}
\hline & \multicolumn{2}{|c|}{ Task duration } \\
\hline Control participant & Tutorial & Easy Task \\
\hline F & 3.42 & 3.90 \\
\hline G & 5.17 & 3.39 \\
\hline H & 5.80 & 8.30 \\
\hline I & 6.58 & 3.40 \\
\hline K & 8.33 & 4.59 \\
\hline Mean & 5.31 & 8.90 \\
\hline Standard deviation & 5.77 & 5.41 \\
\hline
\end{tabular}

Table 5.13: Tutorial and task results from control participants. 


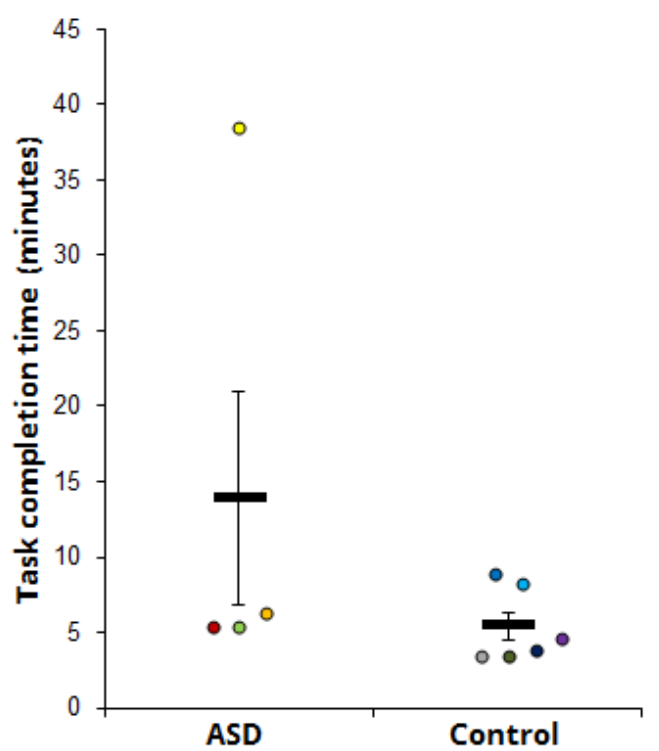

Figure 5.24: Stage 2 task performance comparison between ASD group and control group.

When the easy task begins, the first objective is "Go to the nearest bus stop". However, the nearest bus stop is not visible from where the player starts the game, as it is covered by the restaurant. Additionally, participants A, E, H and K did not look on the map for the nearest stop, and went instead to the closest, visible one. Figure 5.25 represents the course followed by participant A and illustrates the problem observed. 


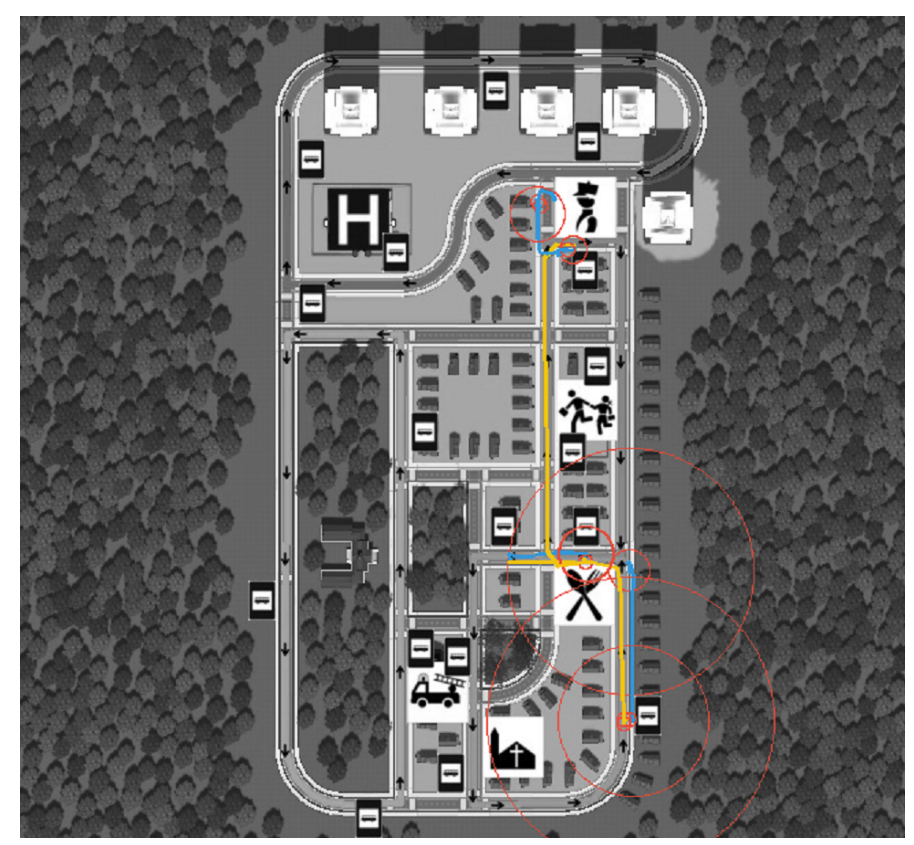

Figure 5.25: Course followed by participant A for the easy task.

Another issue detected was the lack of a bus number on the side of the buses, which forced the players to move in front of the bus to see the number, some times resulting in them missing the bus due to the time lost.

The results obtained from the tutorial assessment show that the changes made to the GUI were successful. Therefore, every participant was able to read the objective, locate the player on the map, and only one participant was unable to identify the objective pointer. Once again, the performance values show that the ASD group demonstrates a higher performance disparity than the control group. Finally, the lack of a bus number on the side of the bus, and the current start position for the easy task caused issues to some of the players.

\section{Conclusion}

According to the results obtained in this stage, the changes made to the interface were profitable and the difficulties in understanding the interface were no longer observed. Additionally, with the new map system in which the players were able to open the map inside the bus, players no longer struggled to know when to leave the bus.

The performance data gathered indicates, once again, higher tutorial and task completion times for the ASD group in comparison to the control group. More specifically, when comparing to the controls, the mean time needed by the partic- 
ipants with ASD to complete the tutorial was 2.77 minutes higher, and the mean time needed to complete the task was 8.49 minutes higher. Comparing to the values obtained in stage 1, there was a task duration increase for both ASD and control group. However, considering all the differences between the two development stages (in which, the addition of the new bus system), the values obtained in each can not be compared and should be analysed independently.

Finally, on the next stage, in addition to the requirements identified, a number was added to the side of the buses and the player starting position for the task was changed.

\subsection{Development of Stage 3}

The third stage was the last stage of development, also divided into the three phases: specification, implementation and testing. This stage aimed at completing the game by:

- Creating more tasks of different complexities

- Populating the game with elements that would increase its resemblance to reality and increase the potential of the game to cause anxiety

- Adding feedback systems that focus of the player's actions and physiology (i.e. score system and biofeedback system).

Finally, after the end of this stage, the game was, once again, uploaded to the NeuroHab platform.

\subsubsection{Specification}

After the testing phase of stage 2, it was decided that some changes would be made in stage 3, prior to the requirement implementation. These changes were: the addition of a panel with the bus number to the side of the bus (so that the player does not need to go in front of the bus to see its number), and changing the starting position of the player for the task (the one used in stage 1 and 2 occasionally led the players to follow a wrong path).

The requirements defined for stage 3 were diverse and did not focus on any particular objective other than adding the necessary features and quality for the game to be complete. Accordingly, the creation of more tasks allows players to attempt different objectives, at different difficulties, thus creating the opportunity to progress by being exposed to varied lifelike challenges. Furthermore, the addition of potential anxiety-provoking elements to the game (i.e. people, dogs and cars), not only 
makes the environments more believable, but also prepares the players for situations they might come across in their life of independent, bus-taking, individuals.

The final version of the game features two feedback systems: a score system and a biofeedback system. The score system attributes a score to the player based on the actions taken and route followed during the game. As a result, the player is praised for what was done correctly, and is informed of what was not and should be improved on following sessions. The biofeedback system is more subtle, and aims at controlling the anxiety felt by the player.

Since, for this stage, no player interactions were planed, the Petri nets modelled for stage 2 and represented on Figure 5.13 and Figure 5.14 are also suitable for this stage.

\subsubsection{Implementation}

The aim of this phase was to complete the development of the application. After the implementation of some changes originated in stage 2, all five requirement destined for this stage were successfully implemented. Some extra features were also added, before the end of this phase.

\section{Transition from stage 2 to stage 3}

Prior to the implementation of the requirements for stage 3, two changes were made in the game. The first change was the modification of the player starting position on the task. When the player started the task in stage 2 and had to go to the nearest bus stop, the latter was covered by the restaurant, and only a farther one was visible. Accordingly, the position was slightly changed, to one from where the players could see the nearest bus stop. Figure 5.26 shows the starting position in stage 2 and stage 3.

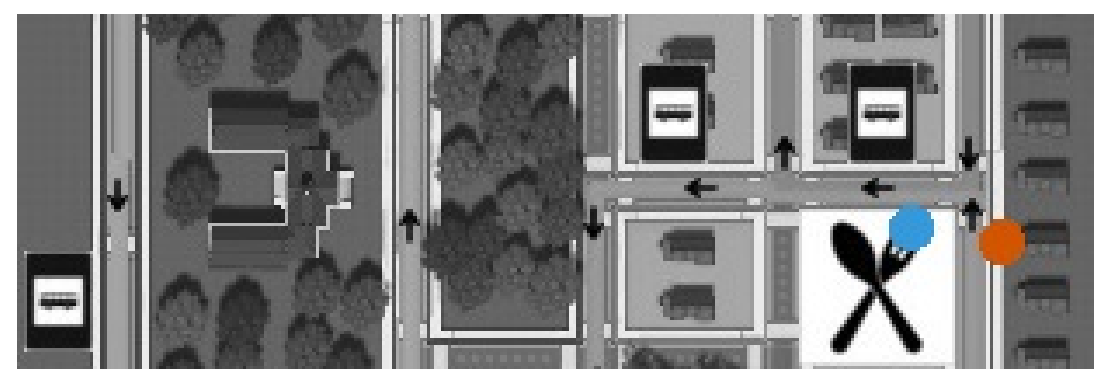

Figure 5.26: Player starting position in stage 2 and 3 represented in orange and blue, respectively.

The other change made in this phase was the addition of a panel with the bus 
number to the side of the buses. Since a panel was being added to the side, another one was also added to the back, so that the players reaching a bus stop where a bus was already idle, could instantly know, if close enough, the number of that bus. Figure 5.27 contains the bus with the new panels.

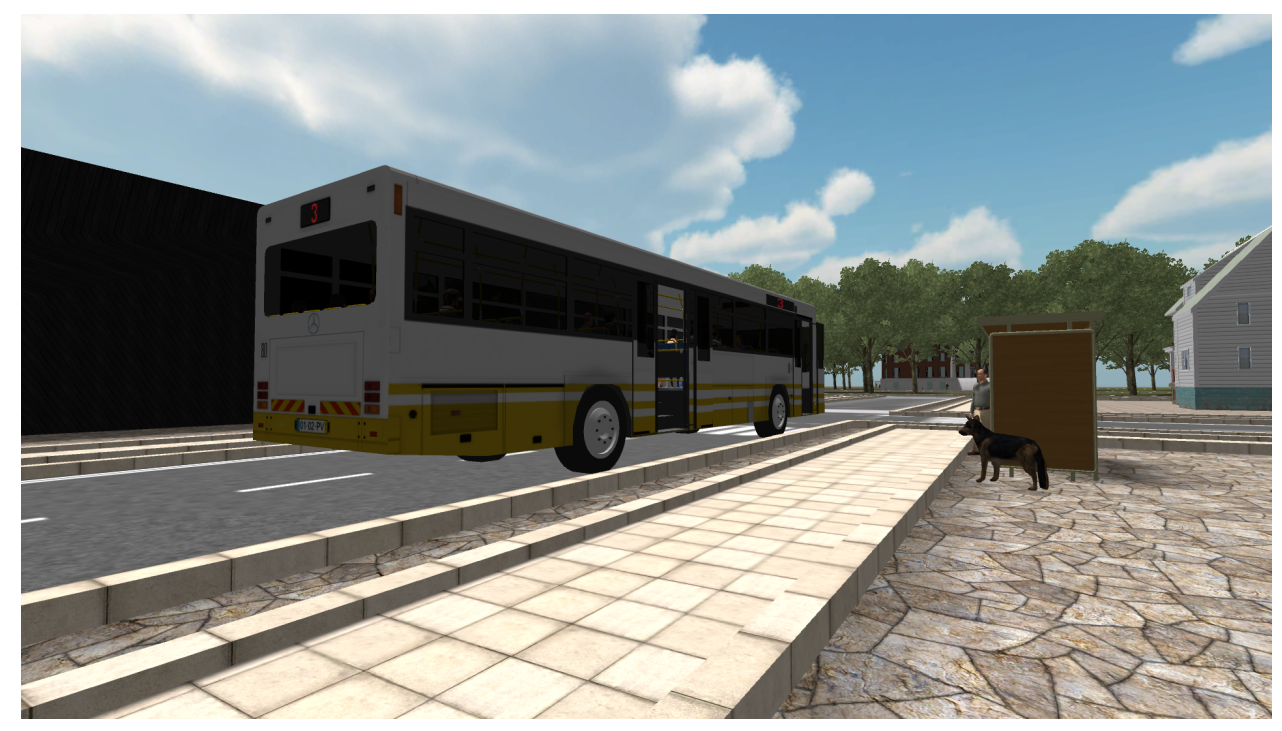

Figure 5.27: Bus with new number panels, added to the side and back.

\section{Multiple tasks}

So far the game only had, besides the tutorial, one task available. In order to have more variability in terms of objectives and challenges, six more tasks were created. Three of the latter required the player to take one bus to reach the destination (similar to the task used so far), while the other three were more complex and required two buses. Figures 5.28, 5.29 and 5.30 represent the routes the players have to follow in order to complete the tasks created. 


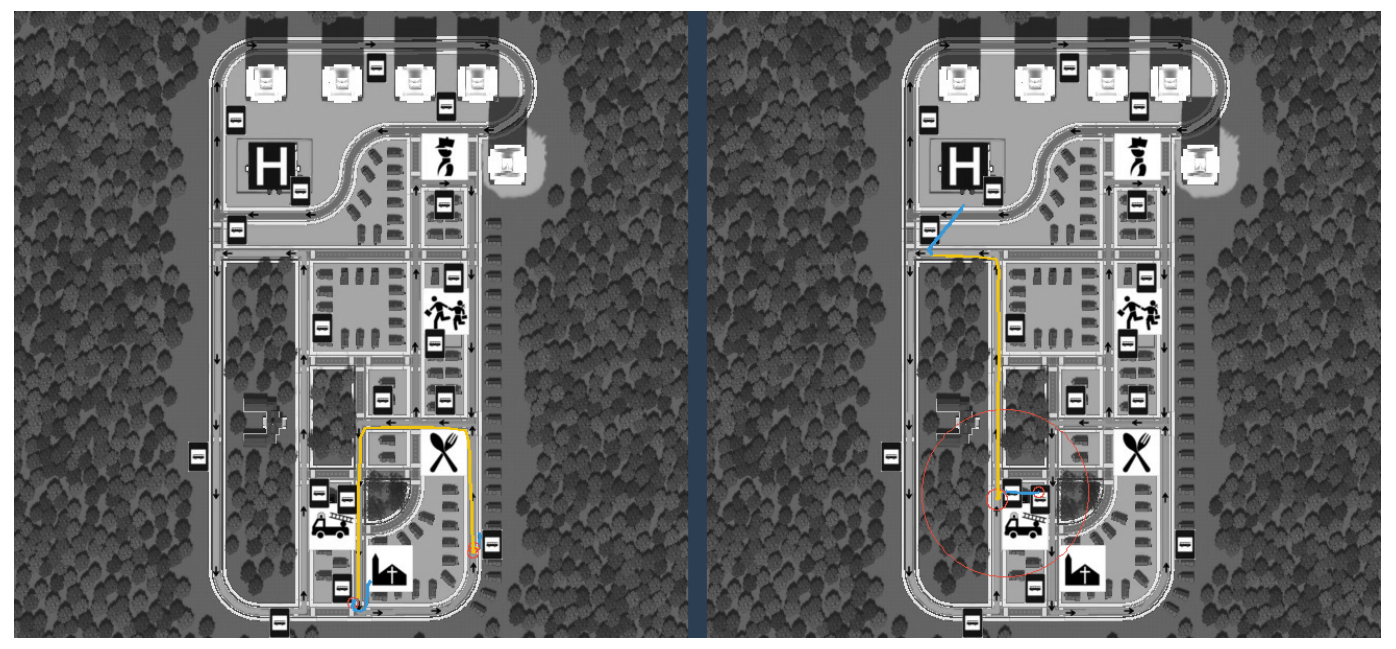

Figure 5.28: Ideal routes for tasks 2 and 3.

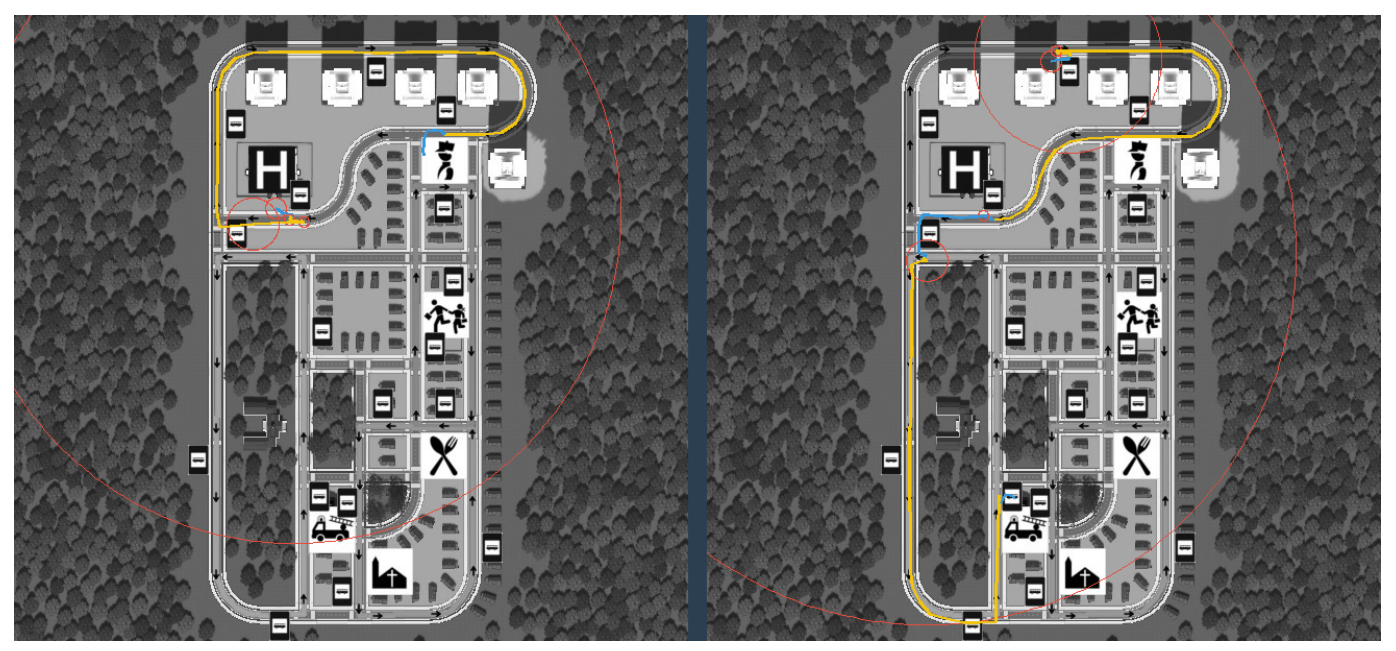

Figure 5.29: Ideal routes for tasks 4 and 5. 


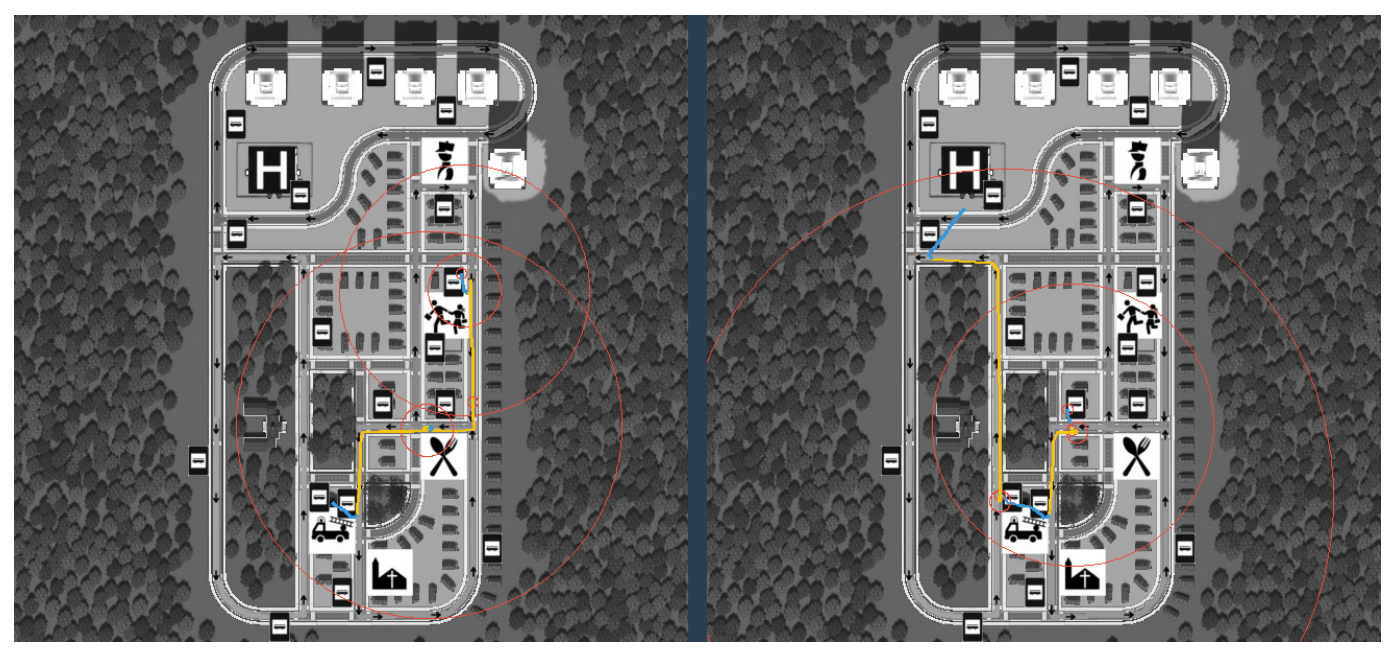

Figure 5.30: Ideal routes for tasks 6 and 7 .

\section{Inhabiting the city}

Requirements 19 and 20 specified that the city needed to have traffic and people, respectively. The addition of traffic was achieved by defining a large route that would include several streets of the city. The system used by the buses to follow their pre-defined routes was then adapted and applied to several cars, scattered throughout the large route. Since the bus routes were designed to cover the majority of the city, it was not possible to define a large route for the cars, without the possibility of them meeting the buses in intersections. In order to exclude potential crashes, a street light system was implemented. Hence, both cars and buses, whenever they come across a traffic light, stop if the red or yellow light is lit, and move if the green light is lit. Figure 5.31 shows a car stopped at a red traffic light, Figure 5.32 contains cars driving in the city, and Figure 5.33 the route followed by the cars. 


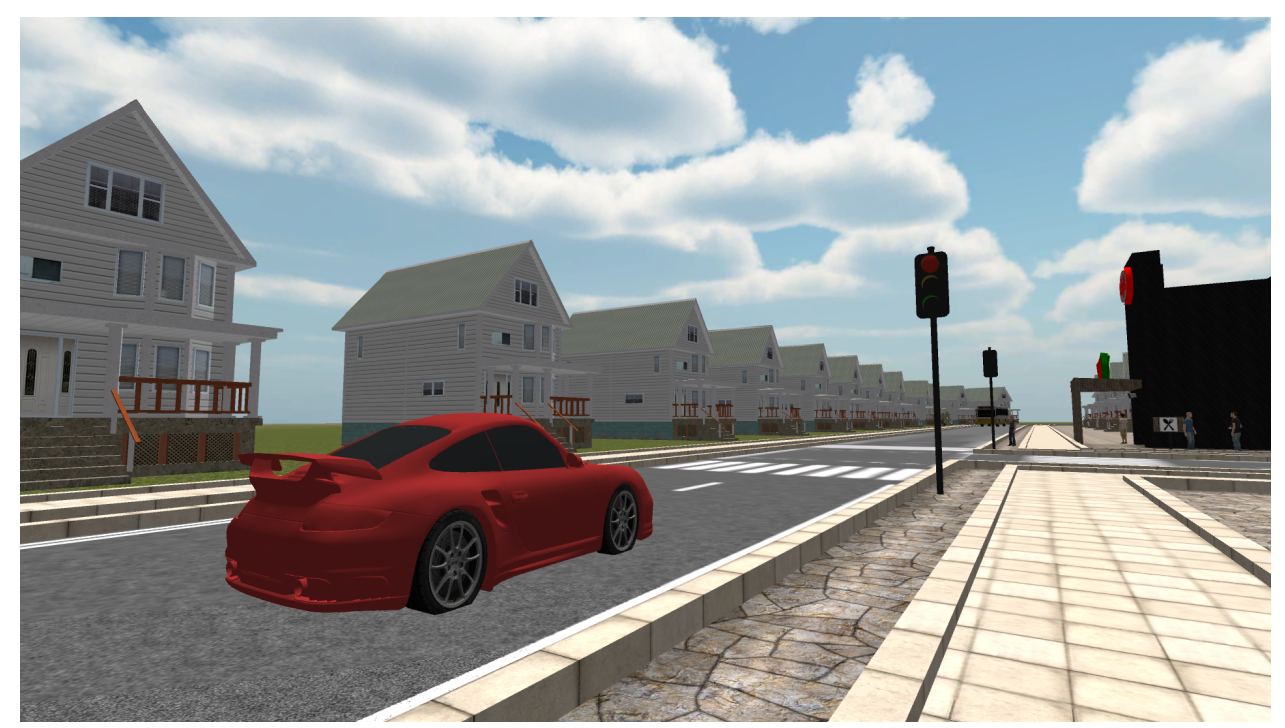

Figure 5.31: A car stopped in front of a traffic light with the red light lit.

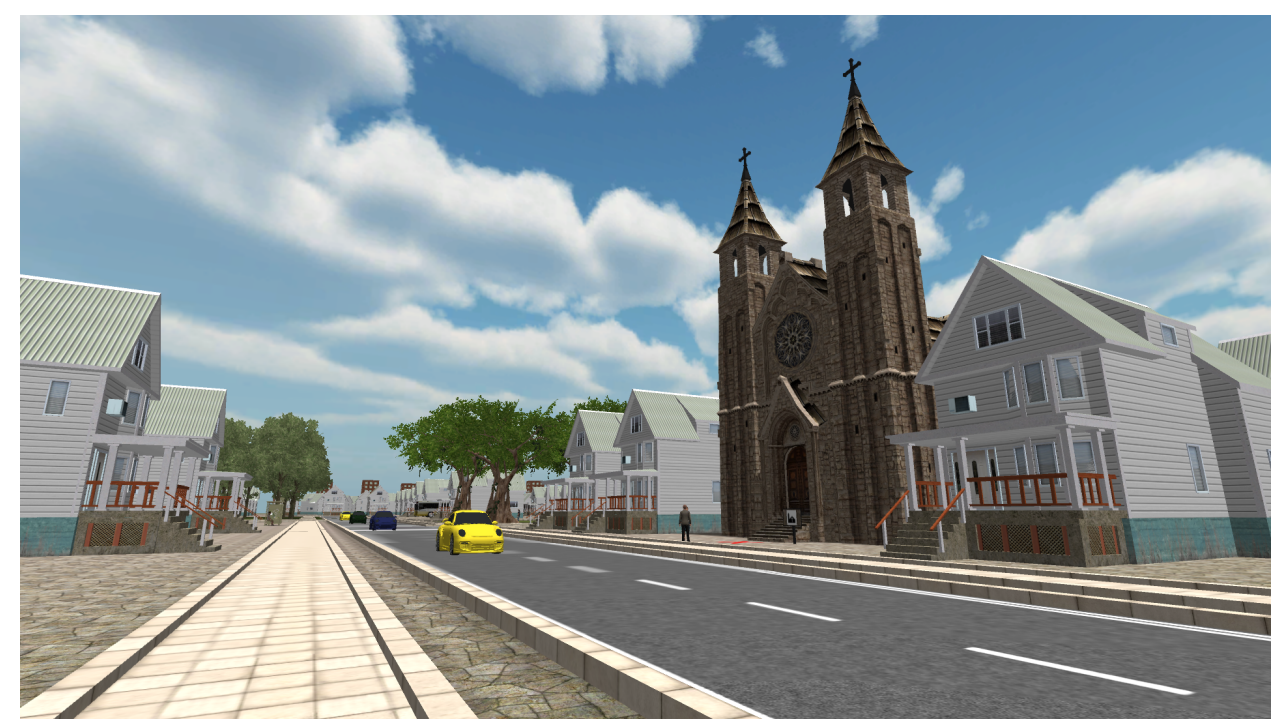

Figure 5.32: Cars driving in the city. 


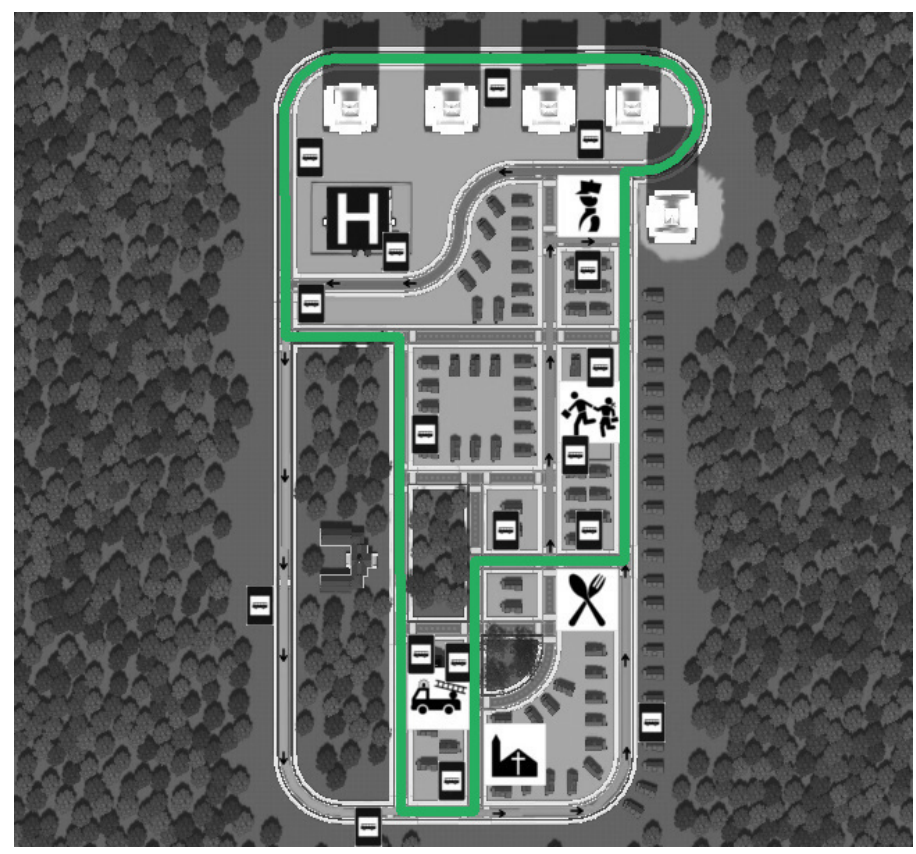

Figure 5.33: Car driving route.

With the addition of cars complete, forty different 3D models (20 males and 20 females) were used to fill the city with people. Due to the large dimension of the city and the existence of four buses and seventeen bus stops, each model was used more than once. However, given the high quantity of models, their repetition is subtle. The models were primarily distributed over the bus stops, some more crowded than others, so that the player gets used to the presence of other people when waiting for the bus (Figure 5.34).

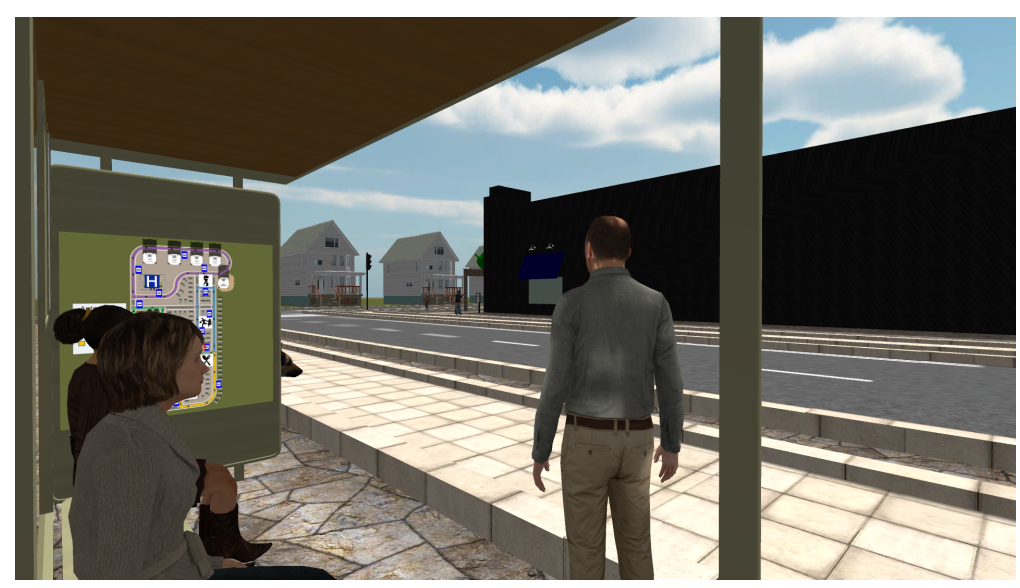

Figure 5.34: People idle, in the bus stop. 
Afterwards, models were placed throughout the map, more concentrated near the main buildings (e.g. restaurant, hospital), some alone and others in groups. To the latter, speaking and listening animations were added to appear as if they were interacting with each other (Figure 5.35). The use of a system, similar to the one applied to the cars, in which people would walk in pre-defined routes was also implemented. However, it was later removed to increase performance.

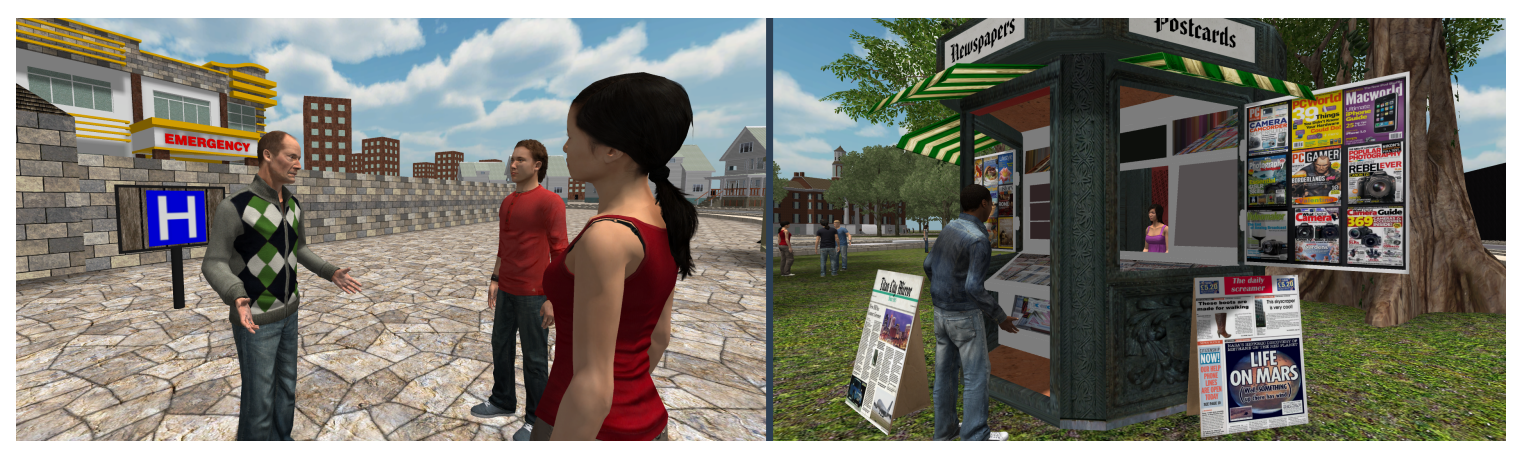

Figure 5.35: People interacting in the street.

Finally, models were also added to the buses. At the beginning of each play session, their presence in the buses is randomized, so that each model has a $50 \%$ chance of disappearing. This way, some buses will be more crowded than others (Figure 5.36).

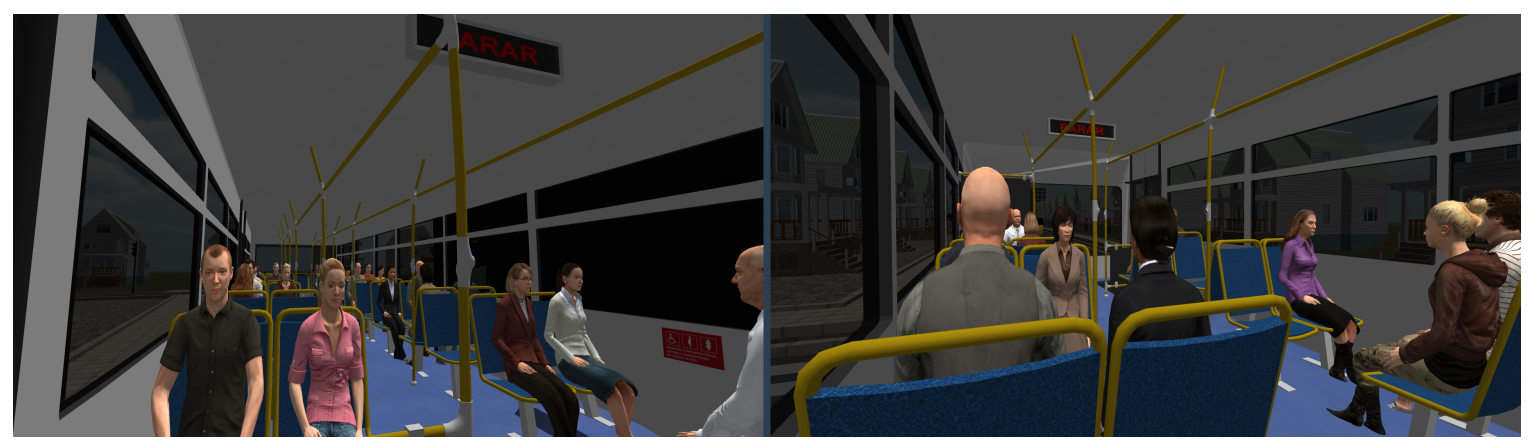

Figure 5.36: People in the bus.

As an extra, two dog models were also added to some of the bus stations, and to the park to potentially increase the anxiety felt by the participants (Figure 5.37). 


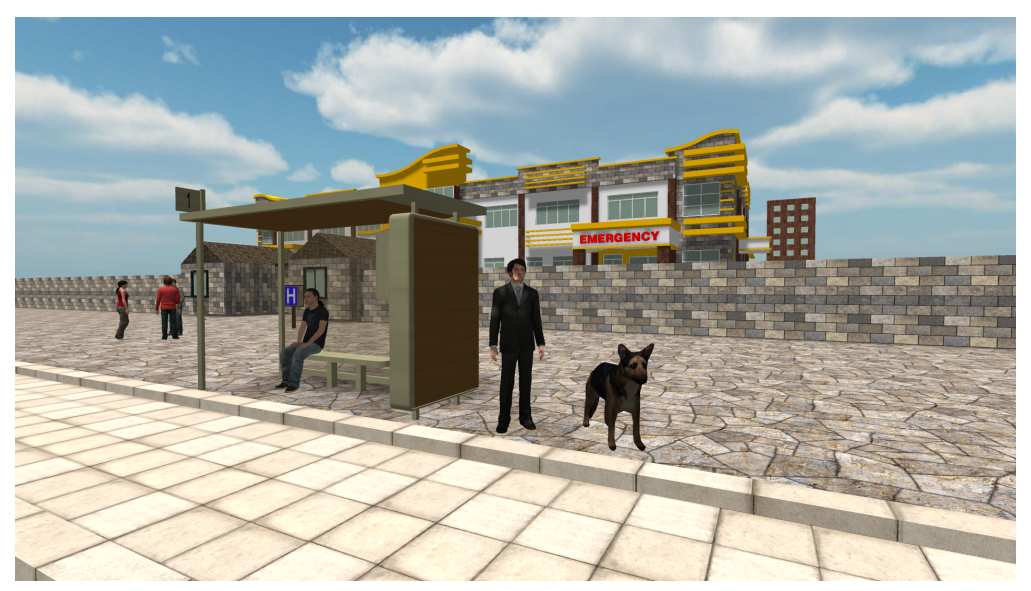

Figure 5.37: Dog near the bus stop.

\section{Score system}

The score system intends to give feedback, at the end of each task, so that the player knows what he/she did correctly, as well as what should be improved on following tasks. The system developed focuses on two components: "Actions" and "Route". The "Actions" component evaluates the capacity of the player to memorize and execute the bus norms. The norms considered were:

- Entering through the front door

- Validating the ticket

- Sitting on an unreserved seat

- Leaving through the back door.

In accordance, the score attributed in this component will consider both the norms respected (five points each) and the ones disrespected (minus points each). Thus, the same way validating the ticket will award the player five points, forgetting to validate will make him/her lose five points. Figure 5.38 contains the "Actions" component of the score menu. 


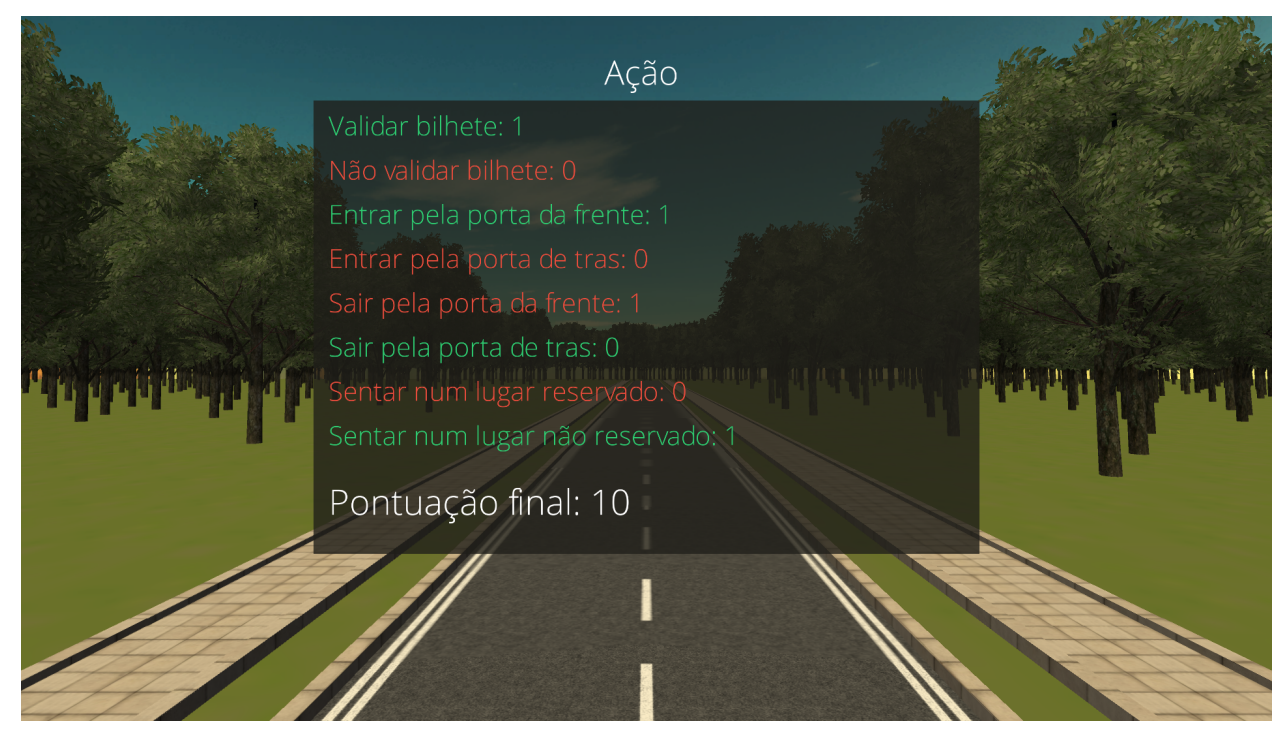

Figure 5.38: Score menu with the "Action" component. In order: "Validate ticket", "Not validate ticket", "Enter through the front door", "Enter through the back door", "Leave through the front door", "Leave through the back door", "Sit in a reserved seat", "Sit in an unreserved seat", "Final score".

The "Route" component, on the other hand, focuses on the course followed by the player. More specifically, it considers how many buses were taken, which ones, in which stop they were taken, and in which stop the player left. This information is then compared to the route the player should have followed. Identical to the "Actions" component, correct procedures will award the player five points and incorrect procedures will make him/her lose five points (except for taking right and wrong buses, which give 15 points to the player, and make him/her lose 20 points, respectively). Figure 5.39 contains the "Route" component of the score menu. 


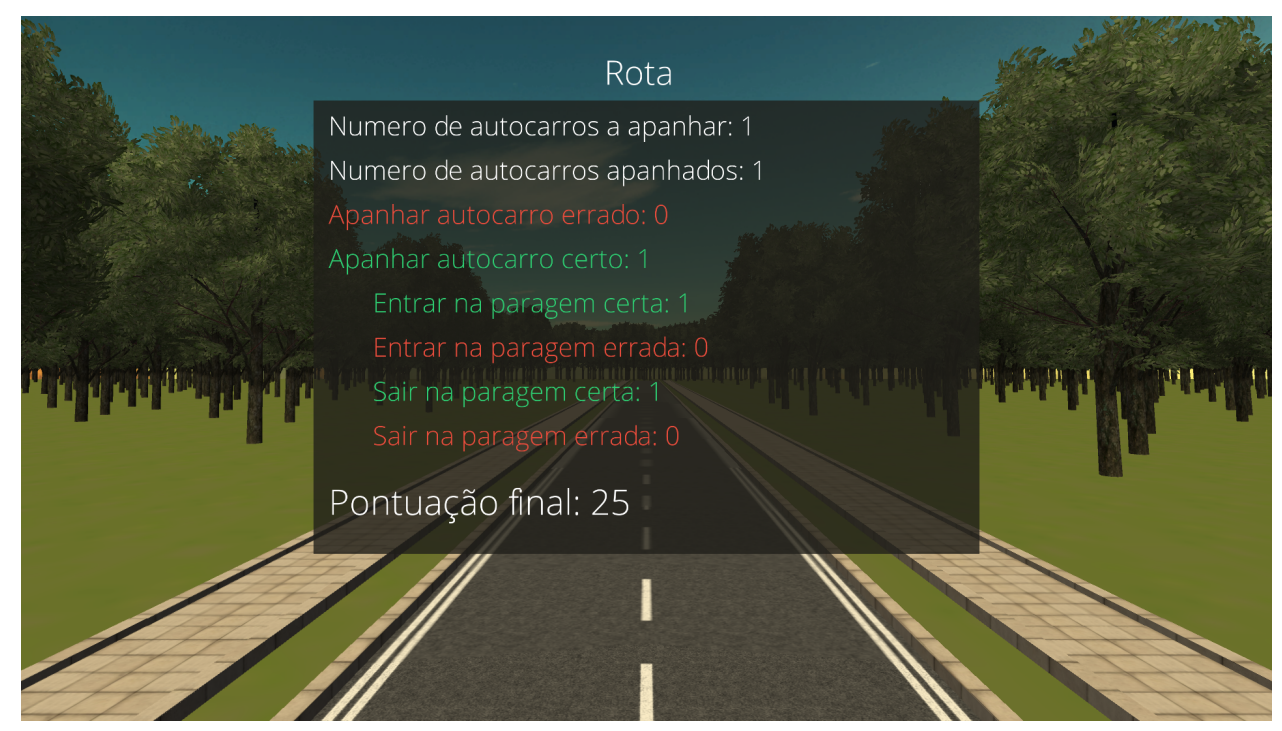

Figure 5.39: Score menu with the "Route" component. In order: "Number of buses to take", "Number of buses taken", "Take a wrong bus", "Take a right bus", "Enter in the right stop", "Enter in the wrong stop", "Leave in the right stop", "Leave in the wrong stop", "Final score".

\section{Biofeedback system}

In this stage, several elements were included, which might trigger player anxiety, such as people, animals and sounds. The biofeedback system ensures that, while the player becomes familiarized with the environment, the latter never becomes hostile to him/her. This is achieved by assessing the anxiety felt by the player, through the analysis of the Electrodermal Activity (EDA), and reducing the stimuli the player is exposed to, in case high anxiety levels are reached. More specifically, this is done in two steps: data collection and processing. The data collection process (illustrated in Figure 5.40) begins by attaching the electrodes to the index and middle finger of the participant and connecting them to the Bionomadix device. The latter measures the EDA and sends it to the Biopac MP150 device. Finally, Unity makes periodical requests to the Biopac device for the last EDA data gathered. 


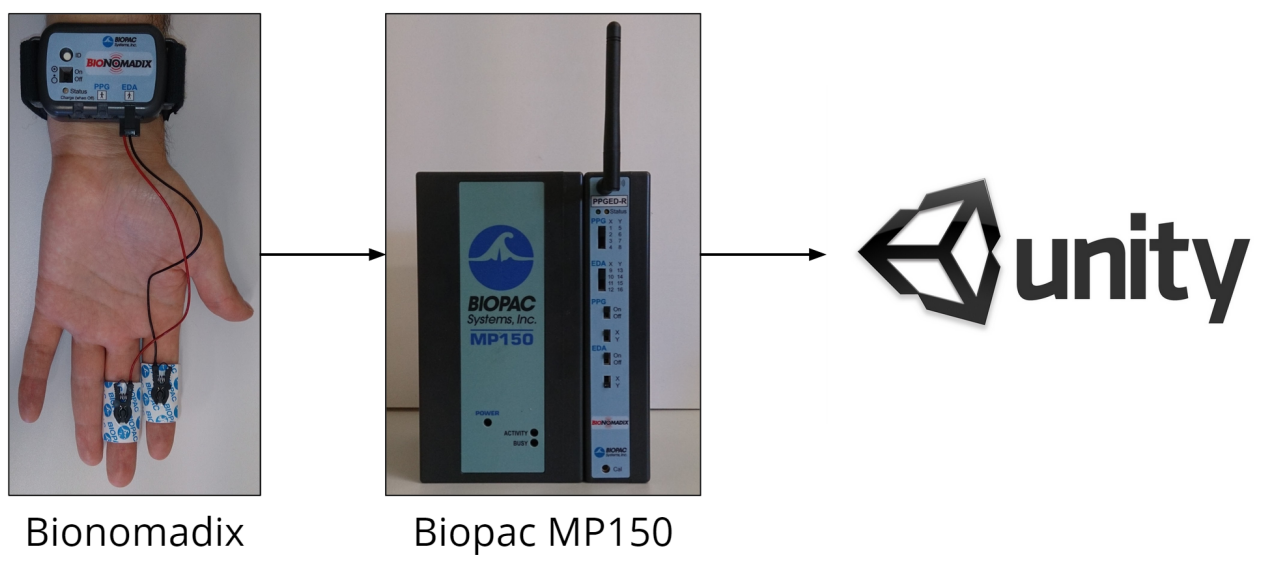

Figure 5.40: Data flow for the biofeedback system.

Once in Unity, the EDA value is normalized. This is done because EDA values are influenced by climatic conditions, physiological factors, demographic characteristics, and can vary greatly between individuals [45]. Consequently, if the values are normalized, they can be interpreted identically, independently of player and conditions. For the normalization of the values, the equation 5.1 is used:

$$
\alpha=\frac{1}{\sigma}\left(y-\frac{1}{N} \sum_{i=1}^{N}\left(x_{i}\right)\right)
$$

in which $y$ is the EDA value to normalize, $N$ the number of previous measures to use, $x_{i}$ the values of those measurements and $\sigma$ their standard deviation as shown in equation 5.2. $\alpha$, the normalized value, is the result of the difference between $y$ and the mean of the last $N$ values, divided by their standard deviation.

$$
\sigma=\sqrt{\frac{1}{N} \sum_{i=1}^{N}\left(x_{i}-\frac{1}{N} \sum_{i=1}^{N}\left(x_{i}\right)\right)^{2}}
$$

The average is always calculated using the last ten values, instead of all previous values, so that it can adapt to potential amplitude changes during the measurements.

After the normalization, if the $\alpha$ obtained is higher than $2 \sigma$, the EDA is considered too high and, thus, the feedback is delivered. Figure 5.41 represents a normal standard deviation distribution. 


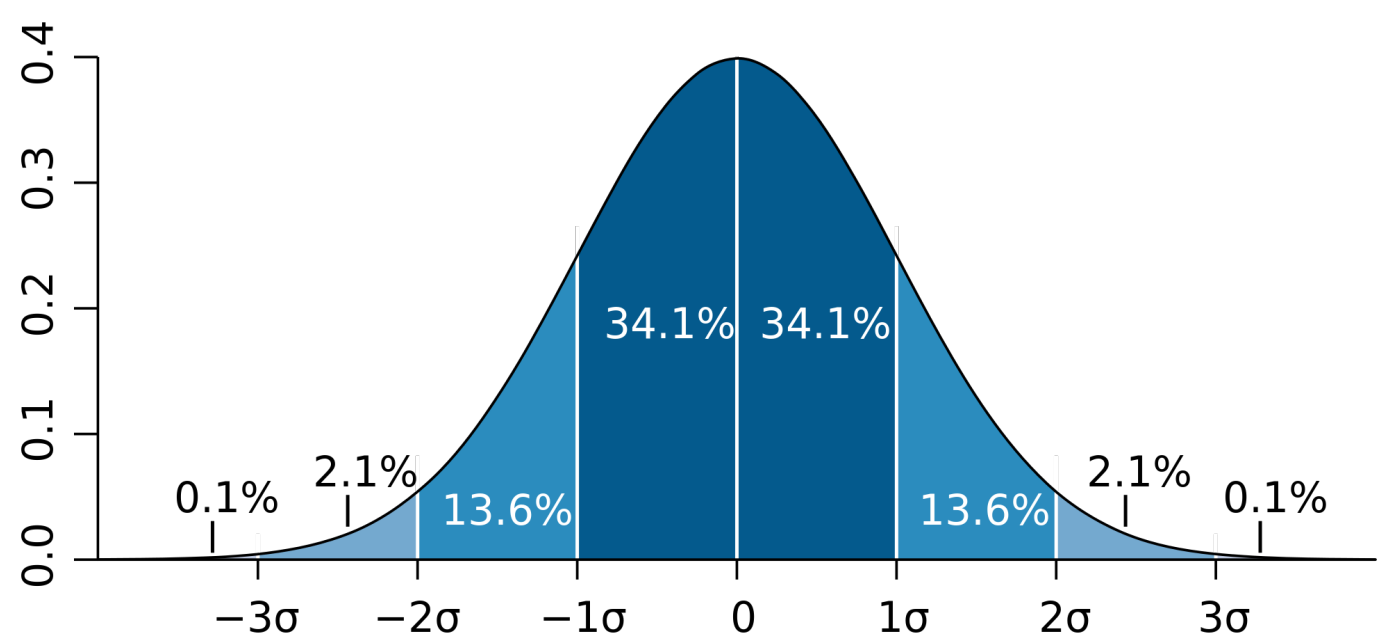

Figure 5.41: Graph of a normal standard deviation distribution.

The biofeedback delivered by the game is subtle and consists of reducing the sound heard by the player by $80 \%$. After ten seconds without high EDA values being registered, the sound returns to normal. The use of subtle biofeedback was chosen to avoid further increase of anxiety or frustration on the player. Furthermore, by reducing the sound heard by the player, he/she will be exposed to less stimuli, which can be helpful in noisy environments such as the inside of a bus.

\section{Performance improvements}

After the majority of the requirements planned for this stage had been implemented, there was a decrease in performance which led to frame rate decrease and, consequently, a high amount of image stuttering. The recent release of Unity 5, still without Oculus Rift support, featured the availability of tools so far exclusive to Unity 4 Pro Licence users (and consequently not available during the development of this project). Within these tools, was the "profiler" which reports the amount of time spent in several aspects of the game (e.g. physics, game logic, rendering) and, thus, helps identifying the heaviest components in the game. In order to understand what was causing the decrease in performance, a copy of the game was upgraded to Unity 5 and the "profiler" was ran during the game. As a result, the rendering of the scene was found to be the heaviest part of the game. The first measures taken to reduce the rendering impact, were:

- Removing the trees surrounding the city

- Removing the people walking in pre-defined routes 
- Decreasing the far clipping plane of the cameras (objects beyond that plane are not rendered).

To compensate for the far clipping and the absence of trees (which led to a more abrupt end of the scene), the use of fog was attempted (Figure 5.42) but, when comparing both, the rendering without fog was considered visually preferable.

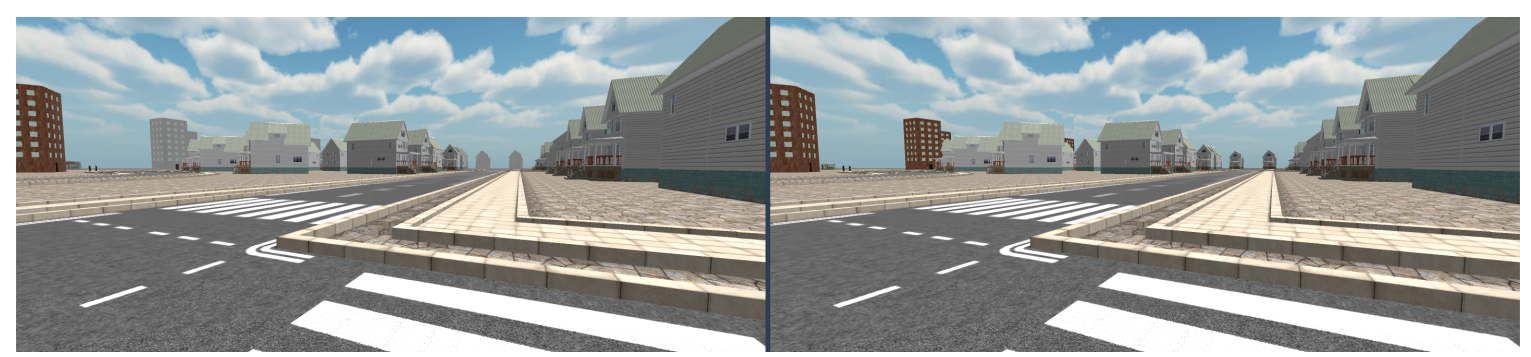

Figure 5.42: City rendered with and without fog (with fog, the farther buildings are grayed out).

Despite the performance gains that resulted from these improvements, there was still a considerable amount of image stuttering in the game. The next approach was to measure the number of draw calls (how many calls the graphics Application Programming Interface needs to render an object) each object had. As a result, it was found that the objects requiring the most draw calls were: cars, offices, bus stops and the fire station. As a response, all these models were replaced for less complex, lighter models (the new car model was available online for free, and new office, fire station and bus stop models were created by Hélio Gonçalves, the 3D modeler working at IBILI). Figures 5.43, 5.44 and 5.45 contain the old and new models used.

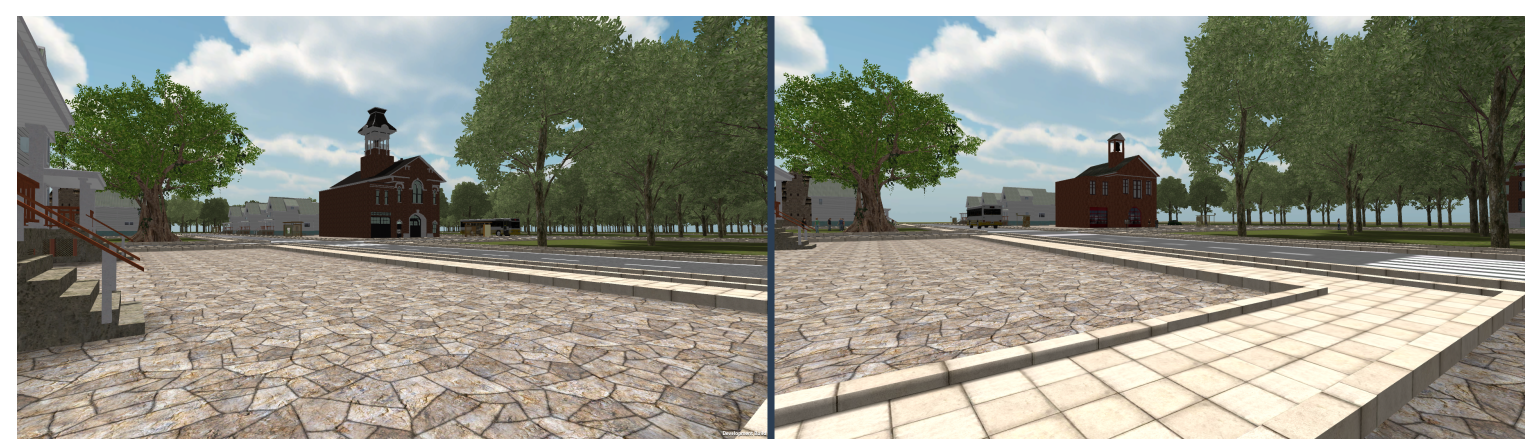

Figure 5.43: Fire Station model replacement (before on the left and after on the right). 


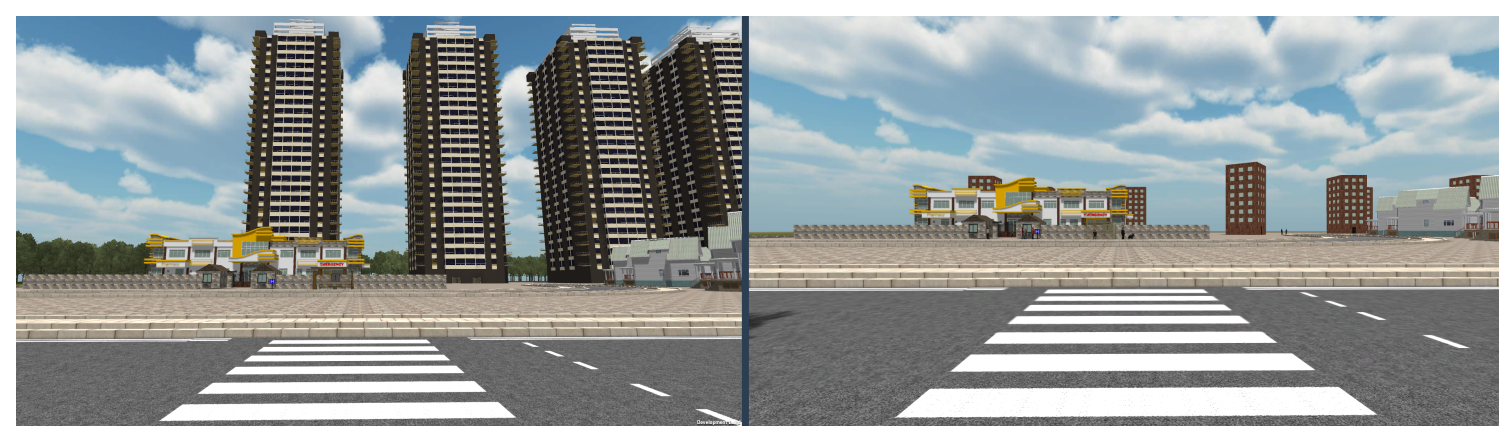

Figure 5.44: Office model replacement (before on the left and after on the right).

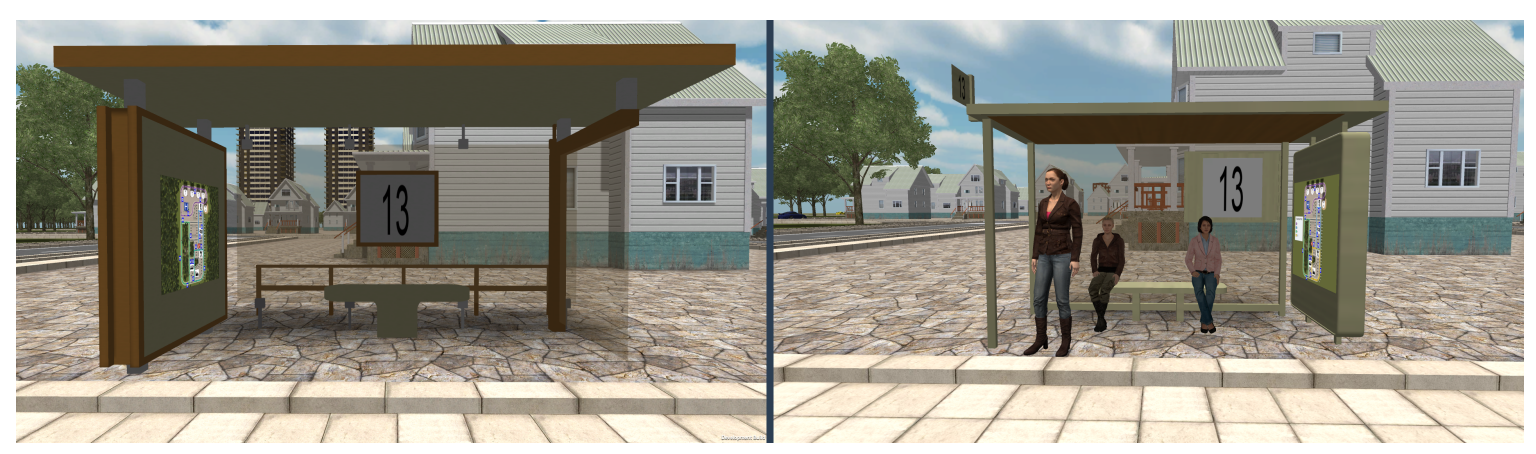

Figure 5.45: Bus stop model replacement (before on the left and after on the right).

After these improvements, the game was able to run at 70 frames per second and the amount of stuttering was no longer significant.

\section{Sound}

An extra feature implemented in this stage was the addition of new sounds to complement the elements added. In order to increase the anxiety-provoking potential of dogs, a barking sound was added that plays in randomized, short intervals. For the same purpose, the sound of a crowd, with people talking, was added to the bus environment.

\section{New map design}

Despite the absence of negative feedback, the map suffered some changes in this stage to make it more comprehensible. Accordingly, the colour of one of the bus routes was changed to become more distinguishable, and a new panel was added with the match between the bus numbers and the colour of the routes. Figure 5.46 contains the new and old map. 


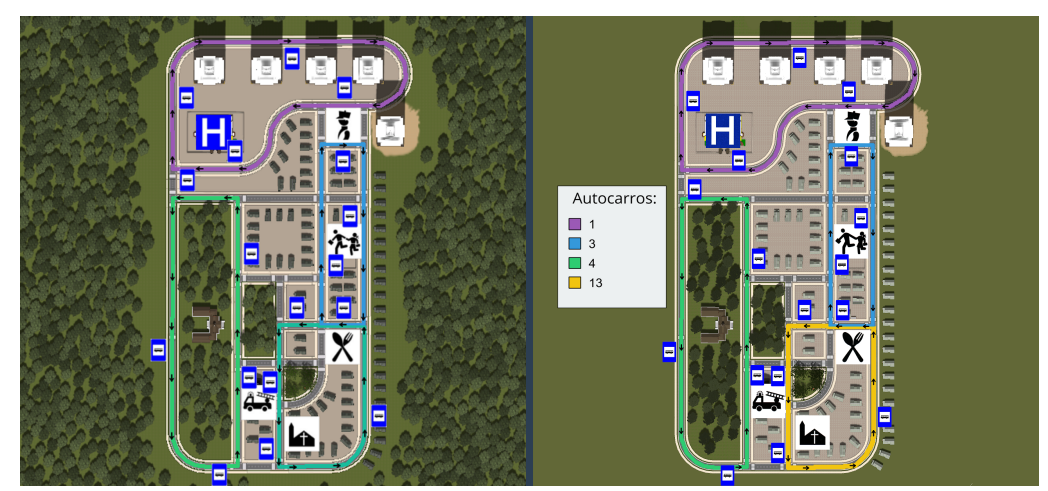

Figure 5.46: Map modifications (before on the left and after on the right).

\section{Neurohab}

Having all requirements been successfully implemented, and the game development completed, the final version of the game was uploaded to Neurohab.

\subsubsection{Testing}

After the development of the requirements identified for stage 3, the final testing session began. The main factor examined in this phase was task performance (difference in task performance between individuals with autism and controls).

\section{Participants}

Unfortunately, participants B, C and $\mathrm{K}$ were unable to participate in this last testing session. To compensate, a new participant with ASD (participant L) and a new control (participant $\mathrm{M}$ ) were recruited. Tables 5.14 and 5.15 contain the updated data from participants with ASD and controls, respectively.

\begin{tabular}{|c|c|c|}
\hline Participant & Sex & Age (years) \\
\hline A & F & 32 \\
\hline D & M & 32 \\
\hline E & M & 36 \\
\hline L & M & 28 \\
\hline Mean & - & 32.0 \\
\hline Standard deviation & - & 2.8 \\
\hline
\end{tabular}

Table 5.14: Characteristics of participants with ASD. 


\begin{tabular}{|c|c|c|}
\hline Control participant & Sex & Age (years) \\
\hline F & M & 24 \\
\hline G & M & 26 \\
\hline H & M & 40 \\
\hline I & F & 30 \\
\hline J & F & 38 \\
\hline M & F & 32 \\
\hline Mean & - & 31.7 \\
\hline Standard deviation & - & 5.8 \\
\hline
\end{tabular}

Table 5.15: Characteristics of control participants.

\section{Design}

The session design followed in this stage was identical to the one of stage 1 and 2: participants received the tutorial and the task 1 in easy mode (the same as in other stages, now referred to as task 1 due to the existence of six other tasks), both with map access. Participants I and M received the task in a laptop computer due to increased sensitivity towards motion sickness.

\section{Materials}

The material used in stage 3 was the same used in stage 1 . Please refer to subsection 5.2.3 for more information.

\section{Procedure}

The testing process took place in IBILI and in a residence where the participants with ASD live. One researcher (facilitator) and a therapist from APPDA Coimbra were present during the acquisitions. The procedure followed in this stage was equal to the one of stage 2 (subsection 5.3.3).

\section{Results}

During the tutorial, only the new participants ( $\mathrm{L}$ and $\mathrm{M}$ ) were asked to read the current objective out loud and identify the location of the player and objective on the map. Both succeeded in this task. Table 5.16 and Table 5.17 contain the duration of the tutorials and tasks for individuals with ASD and controls, respectively. Figure 5.47 also represents the duration of the task for both groups, and follows the configuration detailed in subsection 5.2.3. 
CHAPTER 5. GAME DEVELOPMENT

\begin{tabular}{|c|c|c|}
\hline & \multicolumn{2}{|c|}{ Task duration } \\
\hline Participant & Tutorial & Easy Task \\
\hline A & 4.10 & 3.39 \\
\hline D & 6.19 & 3.32 \\
\hline E & 6.09 & 6.02 \\
\hline L & 8.03 & 6.41 \\
\hline Mean & 6.10 & 4.79 \\
\hline Standard deviation & 1.39 & 1.44 \\
\hline
\end{tabular}

Table 5.16: Tutorial and task results from participants with ASD.

\begin{tabular}{|c|c|c|}
\hline & \multicolumn{2}{|c|}{ Task duration } \\
\hline Control participant & Tutorial & Easy Task \\
\hline F & 6.11 & 3.17 \\
\hline G & 5.55 & 3.34 \\
\hline H & 6.00 & 3.26 \\
\hline I & 6.42 & 3.35 \\
\hline M & 6.20 & 3.29 \\
\hline Mean & 6.12 & 6.03 \\
\hline Standard deviation & 6.07 & 3.74 \\
\hline
\end{tabular}

Table 5.17: Tutorial and task results from control participants. 


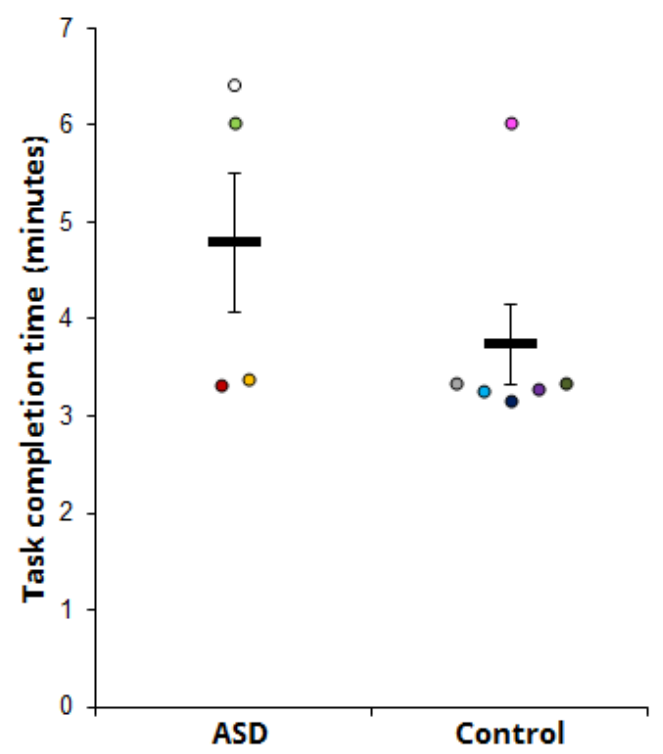

Figure 5.47: Stage 3 task performance comparison between ASD group and control group.

Similar to the results obtained in stage 1 and stage 2, when comparing to the control group, the higher performance disparity in the ASD group can be observed. Additionally, after changing the starting position of the player for task 1, no participant went to the wrong bus stop. Finally, during the task, participants D and E showed interest in interacting with people and dogs by asking if it was possible to do so.

\section{Conclusion}

The results obtained in this stage indicate that, by changing the player starting position in task 1, players no longer went to the wrong bus stop, as previously observed in stage 2 . The performance values obtained led to a conclusion consistent with the one from stage 1 and 2: ASD group shows higher disparity in performance than the control group, and, generally, takes longer to complete the tutorial and tasks. However, for this stage in particular, when comparing to the controls, the mean time needed by the participants with ASD to complete the tutorial was only 0.03 minutes higher, and the mean time needed to complete the task was only 1.05 minutes higher. Until this stage, the performance difference between the ASD group and the control group had never been so low. However, as explained in stage 2, taking into consideration all the differences between stage 2 and 3, the results obtained in each should be analysed independently. Nevertheless, during the validation of the application, the progress obtained from subsequent sessions 
will be assessed.

\subsection{Conclusion}

In the first six months (five of development) of this study, a serious game was created to teach people with ASD how to take buses for transportation. After choosing a game engine adequate to develop a game with the requirements defined, the development period began, divided into three stages. On the fist stage, a fully functional prototype of the game was created. The second stage added more complexity to it, and the third stage concluded the development. By conducting testing sessions after each stage, it was possible to frequently analyse how people interacted with the game, and also detect some usability problems. This led to the implementation of some extra features in the game, but also to a quality increase of the final result. In the end, all requirements had been successfully completed without delays. During the testing sessions, two groups played the game: one with individuals with ASD, and another with individuals with typical development. When comparing the time each group needed to complete the tasks in the game, it was observable that participants with ASD generally performed worse. Once the game development was complete, it was possible to assess its potential as a therapy tool and understand how it could, in fact, help individuals with ASD become more independent. The game was developed using the Unity game engine and programmed in $\mathrm{C} \#$, resulting in approximately 2000 lines of code. 


\section{Chapter 6}

\section{Therapy and Results}

This chapter describes the last two months of this study, in which the potential of the game developed as a therapy tool was analysed. More specifically, it aimed at understanding its efficacy in rehabilitation, and what results can be expected if it is used by individuals with Autism Spectrum Disorder (ASD). This process focused on three main aspects: performance changes, anxiety changes, and knowledge retention.

This sections starts by describing the efforts made to acquire participants, and continues with the description and analysis of the intervention, following the same structure as the testing sessions from the development stages. Accordingly, this section includes: the profile of the participants, the design of the acquisition process, the materials used, and the procedures followed. In the end, it presents the results obtained and the conclusions reached.

\subsection{Preparation}

Since the participants from the three development stages had already been exposed to the game, they were no longer eligible to participate in the validation. In order to recruit new participants, Associação Portuguesa para as Perturbações do Desenvolvimento e Autismo (APPDA) Coimbra was contacted but had no more people with ASD, apart from those who had already been a part of the project. As a response, both APPDA Viseu and APPDA Leiria were contacted in order to establish a protocol between them and Institute for Biomedical Imaging and Life Sciences (IBILI). For a protocol to be established with the institutions, meetings took place, and documents were prepared (one describing the project, and an informed consent). After the protocols were established, the therapy sessions began. Despite the establishment of a protocol with APPDA Leiria, no one was available to participate in this study. Consequently, all the participants involved were recruited from APPDA Viseu. 


\subsection{Design and Procedure}

The therapy process, using the serious game developed, consisted of three sessions, between 20 and 40 minutes each, in which players received the tutorial (to remember how to play the game) and a task. In the first session, participants completed a questionnaire to assess their experience in using buses for transportation. At the beginning of every session, participants were also asked to describe the process of taking a bus, from the moment they arrived at the bus stop, until they reached their destination, but never received feedback on the answer given.

For the three sessions, specific tasks were chosen to encourage progress, starting with a simple task (one bus only), in easy mode (players are guided step by step), followed by another simple task in hard mode (players are only told the place they must go to), and, at the end, a complex task (two buses) in hard mode. These tasks, along with the session dates, are listed below.

- Session 1 (Saturday, 23/05/2015) - Tutorial and task 1, easy

- Session 2 (Saturday, 06/06/2015) - Tutorial and task 3, hard

- Session 3 (Tuesday, 30/06/2015) - Tutorial and task 6, hard.

One of the participants of this study that had intellectual disability, due to the difficulties presented in completing the first session, received the task of session 2 in easy mode instead. Nevertheless, the third session remained equal for all participants. The therapy sessions took place in APPDA Viseu, integrated with other activities organized. The date of each session depended only on the availability of the participants and of APPDA Viseu. In each session, one researcher was present, who acted as facilitator. A script was used to guide the players through the tutorial. Participants P2, P6 and P9 received the tasks in a laptop computer, without the Oculus Rift, due to vision impairments.

\subsection{Participants}

The ideal profile defined for the participants to be eligible for this study was:

- having ASD

- being between 13 and 30 years old

- not having intellectual disability (IQ equal to 70 or higher) or having mild intellectual disability (IQ between 50 and 69 [69])

- not being able to use buses autonomously. 
Despite these characteristics, one participant (P8), who takes buses, autonomously, every day to get to work, was still included in the project. Table 6.1 contains information about each participant that was a part of this study, and their assiduity can be seen on Table 6.2.

\begin{tabular}{|c|c|c|c|}
\hline Participant & Sex & Age (years) & IQ \\
\hline P1 & M & 16 & 95 \\
\hline P2 & M & 13 & 68 \\
\hline P3 & M & 18 & 77 \\
\hline P4 & M & 22 & 87 \\
\hline P5 & M & 17 & $?$ \\
\hline P6 & M & 16 & 89 \\
\hline P7 & M & 18 & $?$ \\
\hline P8 & F & 30 & 75 \\
\hline P9 & M & 17 & 83 \\
\hline P10 & $\mathrm{M}$ & 18.8 & 10.5 \\
\hline Mean & - & 4.45 & \\
\hline $\begin{array}{l}\text { Standard } \\
\text { deviation }\end{array}$ & - & & \\
\hline
\end{tabular}

Table 6.1: Characteristics of participants.

\begin{tabular}{|c|c|c|c|}
\hline Participant & Session 1 & Session 2 & Session 3 \\
\hline $\mathrm{P} 1$ & $\checkmark$ & $x$ & $x$ \\
\hline$\overline{\mathrm{P} 2}$ & $\sqrt{ }$ & $\sqrt{ }$ & $\checkmark$ \\
\hline P3 & $\checkmark$ & $\checkmark$ & $\checkmark$ \\
\hline P4 & $\checkmark$ & $\checkmark$ & $\checkmark$ \\
\hline $\mathrm{P} 5$ & $\checkmark$ & $\checkmark$ & $\checkmark$ \\
\hline P6 & $\checkmark$ & $\checkmark$ & $\checkmark$ \\
\hline P7 & $\checkmark$ & $\checkmark$ & $x$ \\
\hline P8 & $\checkmark$ & $\checkmark$ & $\checkmark$ \\
\hline$\overline{\mathrm{P} 9}$ & $\checkmark$ & $x$ & $x$ \\
\hline $\mathrm{P} 10$ & $\sqrt{ }$ & $\checkmark$ & $x$ \\
\hline
\end{tabular}

Table 6.2: Assiduity of participants in sessions.

Both players P5 and P10 took a specific bus to school every day. However, the latter did not have any reserved seats and stopped in every stop. Besides, since these buses were only taken to go to school and to return home, neither had 
experience in planning a bus trip. Consequently, they were considered eligible and regular participants for this study. Participant P7 did the second session in the date of the third session.

\subsection{Materials}

Identically to the development stage, all tasks were run on a laptop computer (Windows 8.1, 16.0 GB RAM and an Intel(R) Core(TM) i7 2.50 GHz processor). The Head-mounted display (HMD) used was Oculus Rift Development Kit (DK)2, firmware version 2.12, and a gamepad was used for input. In every session, players sat on rotating chairs, available in the location of the sessions.

\subsection{Results}

The results obtained in the three sessions conducted were analysed focusing on three mains aspects:

- Performance changes - duration of each task

- Anxiety changes - how Electrodermal Activity (EDA) values vary in successive sessions

- Knowledge retention - how the awareness of the bus norms improves between sessions.

\subsubsection{Performance changes}

The performance changes were measured using the time taken by players to complete the tasks received in each session. These values can be observed on Table 6.3 and Figure 6.1, in which the colour of the players in Table 6.3 matches the colours of the circles in Figure 6.1. 


\begin{tabular}{|c|c|c|c|}
\hline & \multicolumn{3}{|c|}{ Task duration (minutes) } \\
\hline Participant & Session 1 & Session 2 & Session 3 \\
\hline P1 & 3.95 & - & - \\
\hline P2 & 3.48 & 5.9 & 4.37 \\
\hline P3 & 3.57 & 7.42 & 4.17 \\
\hline P4 & 5.12 & 5.43 & 5.38 \\
\hline P5 & 5.33 & 7.80 & 6.92 \\
\hline P6 & 9.03 & 2.52 & - \\
\hline P7 & 5.53 & 5.532 & 4.85 \\
\hline P8 & 3.40 & 8.00 & - \\
\hline P9 & 3.50 & - & 5.01 \\
\hline P10 & 3.57 & 2.23 & 0.94 \\
\hline Mean & 4.65 & 5.60 & \\
\hline $\begin{array}{l}\text { Standard } \\
\text { deviation }\end{array}$ & 1.67 & 2.09 & \\
\hline
\end{tabular}

Table 6.3: Task performance table.

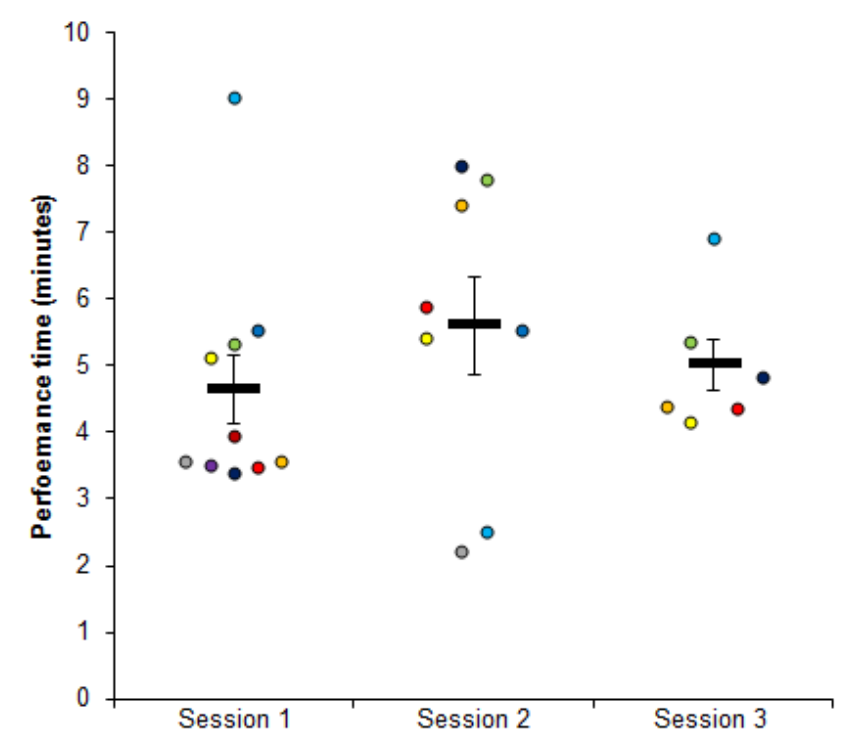

Figure 6.1: Task performance graph.

In session 1 , the task 1 was received in easy mode, in which players are guided step by step, from the starting position until the final location. Tasks in easy mode do not require as heavy planning as the ones in hard mode, but slowly introduce the 
player to this concept and demonstrate how buses can be used to travel between bus stations, in a city, within their routes. The hard tasks, on the other hand, only tell the player where they must go to complete the task (e.g. "go to the hospital"). In these tasks, players have to analyse the map to discover which bus or buses can be used to take them to the destination. Furthermore, the tasks received in session 1 and session 2 required the player to take one bus, while the one from session 3 required the player to take two. Accordingly, when analysing the results, the duration of each task can not be compared directly. However, it is possible to observe the amount of dispersion through the standard deviation. Moreover, when looking at the results from session 1, there was little variety in task duration, between the players. This is natural considering the step by step approach from session 1. On session 2, however, the players, for the first time, were not given any clue, resulting in a higher dispersion in the results. In the last session, players already had some practice in planning a trip, but had to discover that bus routes can be combined to reach farther destinations. Nevertheless the results converged again, reaching a standard deviation even lower than in session 1.

\subsubsection{Anxiety Changes}

As described in subsection 5.4.2, the integration with an EDA measuring device was implemented to assess the anxiety levels felt in each session and analyse how successive sessions had an impact on its intensity. Since individual EDA results have little relevance due to the amount of factors that can interfere with the measurements [45], a heat map was created, on top of the city map. This way, it is possible to see where the majority of players felt anxious, within the city, minimizing the impact caused by external factors in EDA levels. The heatmaps were created using heatmap.js [102], an open source heat map visualization library for JavaScript. Since the game has two major environments (the city streets and the inside of the buses), two different heat map groups were created for each session, one which represents the anxiety felt on the streets of the city (Figure 6.2), and another with the anxiety felt inside the buses (Figure 6.3). Figure 6.4 contains the average of the standard deviations of the EDA values of all the players that completed this study, for the tasks in session 1 and session 3 . 


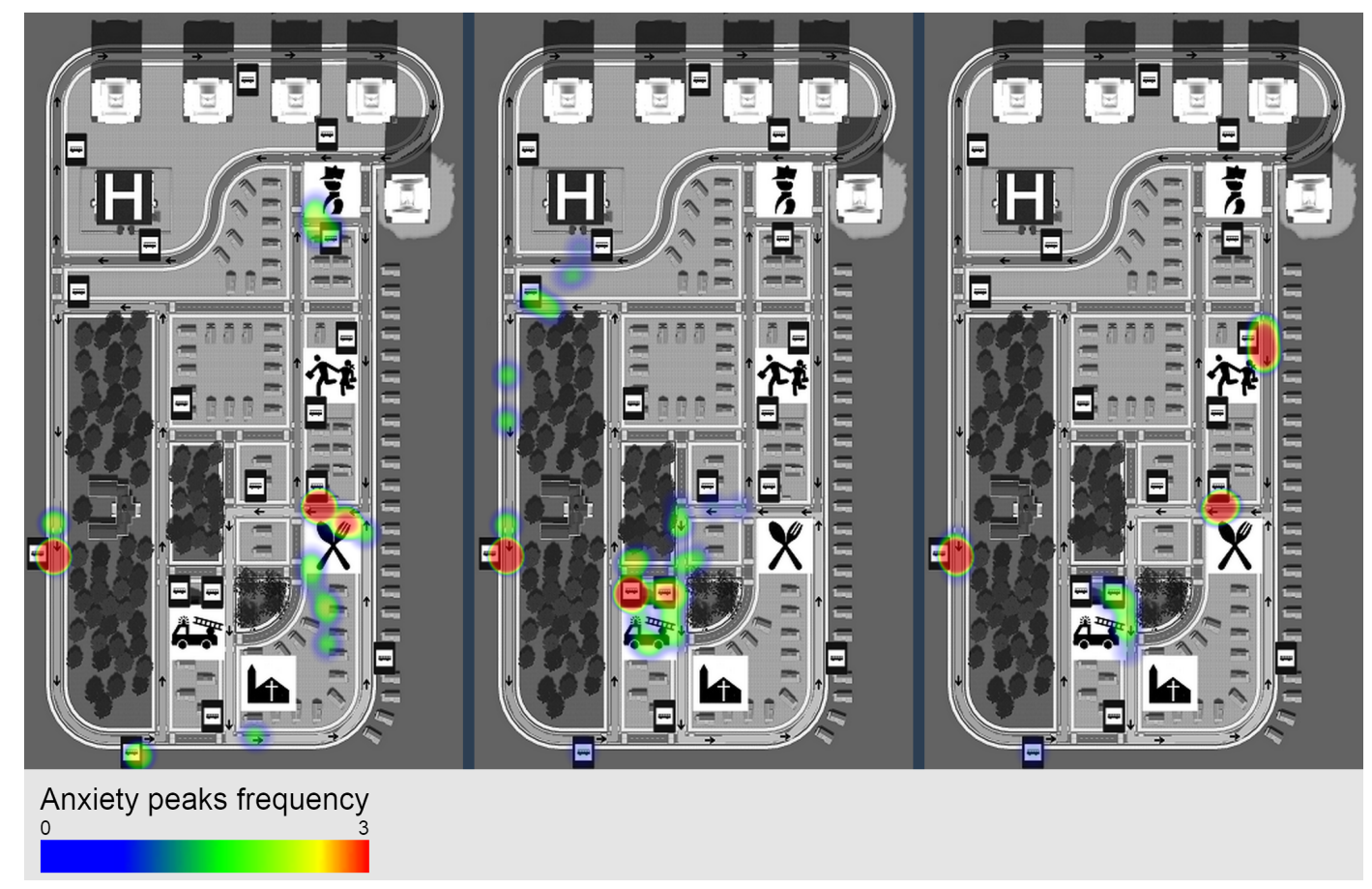

Figure 6.2: Heat maps created with the EDA values, from the street, obtained from all participants that completed the therapy. Data from the tutorial and tasks. Sessions 1, 2 and 3 from left to right. 


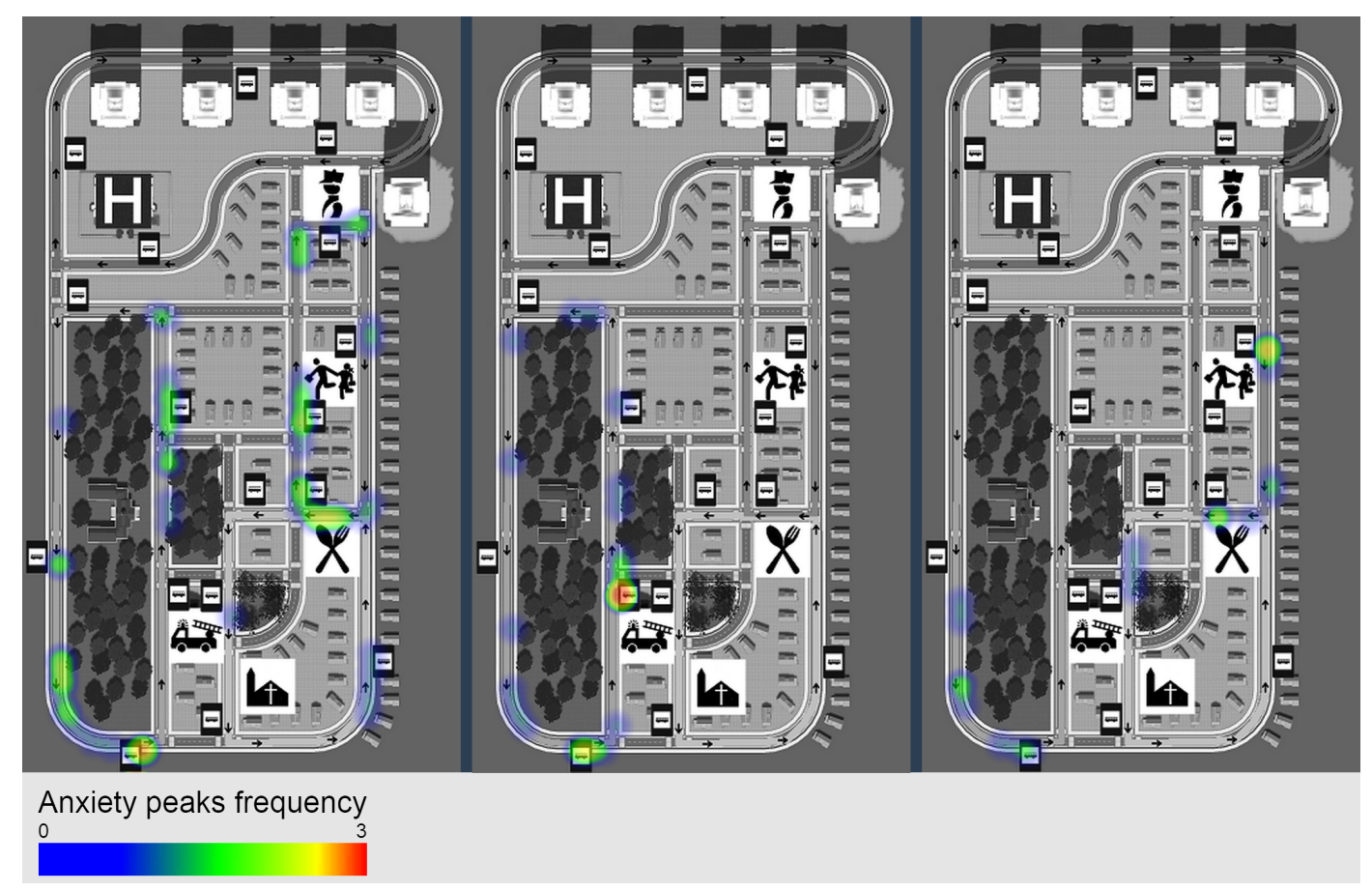

Figure 6.3: Heat maps created with the EDA values, from inside the bus, obtained from all participants that completed the therapy. Data from the tutorial and tasks. Sessions 1, 2 and 3 from left to right.

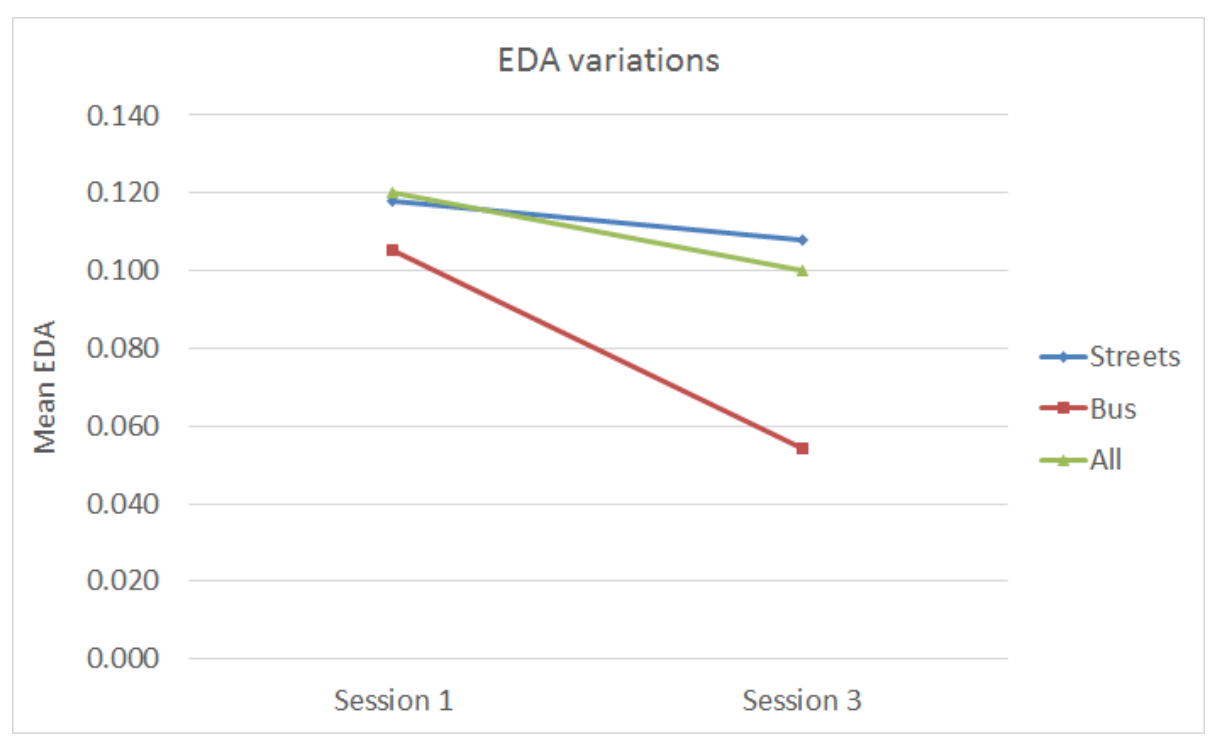

Figure 6.4: Average of the standard deviations of the EDA values from all the participants that completed the study, from the tasks in session 1 and 3. 
In both figures above, the three images represent the EDA measurements obtained in sessions 1, 2 and 3 respectively. According to Figure 6.2, players felt most anxious in three different situations:

- When waiting for the bus at the bus stops (red areas near the bus stop signs)

- When planning the trip or looking for the correct bus stop in the starting areas (i.e. green areas near the restaurant in session 1, the fire station in stage 2 , one of the bus stops in session 3)

- When reaching or looking for the destination in the finishing areas (i.e. green areas near the police station in session 1, the hospital in session 2, and the fire station in session 3).

Even though the players received three therapy sessions, there was no significant decrease observable in the anxiety felt when outside of the bus, which is natural due to the amount of information the player must process before entering the bus and after leaving it (e.g. planning the route, looking for the final destination). When inside of the bus, however, as seen in Figure 6.3, the anxiety felt reduced throughout the three sessions. More specifically, in session 1 (map on the left) there were several green areas, especially on bus stops (when the players were getting inside and outside of the bus), and on the lower left corner (which corresponds, in the tutorial, to the part when the bus norms were taught, as well as the first contact with the bus environment). In session 3 , however, there is barely any green area on the map.

\subsubsection{Knowledge Retention}

The knowledge retention factor evaluated how much information was retained in between the sessions, not only theoretically but also in practice. Furthermore, three main elements were evaluated:

- Memorization of the bus taking process

- Following the norms

- Planning the route.

\section{Memorization of the bus taking process}

At the beginning of each session, players were asked to describe the process of taking a bus, from the moment they got to the bus stop until they left, considering their experience from previous therapy sessions. The optimal answer considered was: wait, enter, validate ticket, avoid reserved seats, sit, wait, press the stop button, leave. No feedback was given after the answer, so the players would only 
learn from what they experienced in the game. Table 6.4, Table 6.5 and Table 6.6 contain the answers given in sessions 1, 2 and 3, respectively.

\begin{tabular}{|c|c|c|c|c|c|c|c|c|c|}
\hline & \multicolumn{8}{|c|}{ Process of taking a bus (Session 1) } & \multirow[b]{2}{*}{$\sqrt{ } \%$} \\
\hline Partic. & Wait & Enter & $\begin{array}{l}\text { Ticket } \\
\text { valdn. }\end{array}$ & $\begin{array}{c}\text { Avoid } \\
\text { r. } \\
\text { seats }\end{array}$ & Sit & Wait & $\begin{array}{c}\text { Press } \\
\text { STOP } \\
\text { btn. }\end{array}$ & Leave & \\
\hline $\mathrm{P} 1$ & $\sqrt{ }$ & $\checkmark$ & $\checkmark$ & $x$ & $x$ & $x$ & $\sqrt{ }$ & $\checkmark$ & $62.5 \%$ \\
\hline $\mathrm{P} 2$ & $\checkmark$ & $\checkmark$ & $x$ & $x$ & $\checkmark$ & $\checkmark$ & $\checkmark$ & $\checkmark$ & $75 \%$ \\
\hline$\overline{\mathrm{P}} 3$ & $\checkmark$ & $\checkmark$ & $\checkmark$ & $x$ & $\checkmark$ & $\checkmark$ & $\sqrt{ }$ & $\sqrt{ }$ & $87.5 \%$ \\
\hline $\mathrm{P} 4$ & $\checkmark$ & $x$ & $\sqrt{ }$ & $x$ & $\sqrt{ }$ & $\checkmark$ & $x$ & $\checkmark$ & $62.5 \%$ \\
\hline $\mathrm{P} 5$ & $\checkmark$ & $\checkmark$ & $\checkmark$ & $x$ & $x$ & $x$ & $x$ & $\checkmark$ & $50 \%$ \\
\hline$\overline{\mathrm{P} 6}$ & $\checkmark$ & $\sqrt{ }$ & $x$ & $x$ & $x$ & $x$ & $x$ & $\sqrt{ }$ & $37.5 \%$ \\
\hline P7 & $x$ & $\checkmark$ & $\checkmark$ & $x$ & $\checkmark$ & $\checkmark$ & $x$ & $\checkmark$ & $62.5 \%$ \\
\hline$\overline{\mathrm{P} 8}$ & $\checkmark$ & $\checkmark$ & $\checkmark$ & $x$ & $\sqrt{ }$ & $\checkmark$ & $\sqrt{ }$ & $\sqrt{ }$ & $87.5 \%$ \\
\hline P9 & $\checkmark$ & $\checkmark$ & $\checkmark$ & $\checkmark$ & $\checkmark$ & $\checkmark$ & $\checkmark$ & $\checkmark$ & $100 \%$ \\
\hline$\overline{\text { P10 }}$ & $\checkmark$ & $\sqrt{ }$ & $x$ & $x$ & $\sqrt{ }$ & $\checkmark$ & $x$ & $\sqrt{ }$ & $62.5 \%$ \\
\hline $\boldsymbol{\Omega} \%$ & $90 \%$ & $90 \%$ & $70 \%$ & $10 \%$ & $70 \%$ & $70 \%$ & $50 \%$ & $100 \%$ & - \\
\hline
\end{tabular}

Table 6.4: Process description accuracy in session 1 (Partic. $=$ participant, valdn. $=$ validation, $\mathrm{r}$. seats $=$ reserved seats, STOP btn. $=$ STOP button $)$.

\begin{tabular}{|c|c|c|c|c|c|c|c|c|c|}
\hline & \multicolumn{8}{|c|}{ Process of taking a bus (Session 2) } & \multirow[b]{2}{*}{$\sqrt{1} \%$} \\
\hline Partic. & Wait & Enter & $\begin{array}{l}\text { Ticket } \\
\text { valdn. }\end{array}$ & $\begin{array}{c}\text { Avoid } \\
\text { r. } \\
\text { seats }\end{array}$ & Sit & Wait & $\begin{array}{c}\text { Press } \\
\text { STOP } \\
\text { btn. }\end{array}$ & Leave & \\
\hline $\mathrm{P} 1$ & - & - & - & - & - & - & - & - & - \\
\hline$\overline{\mathrm{P} 2}$ & $\sqrt{ }$ & $\sqrt{ }$ & $\sqrt{ }$ & $\sqrt{ }$ & $\sqrt{ }$ & $\sqrt{ }$ & $\sqrt{ }$ & $\sqrt{ }$ & $100 \%$ \\
\hline $\mathrm{P} 3$ & $\checkmark$ & $\checkmark$ & $\checkmark$ & $\checkmark$ & $\checkmark$ & $\checkmark$ & $\checkmark$ & $\checkmark$ & $100 \%$ \\
\hline$\overline{\mathrm{P} 4}$ & $\sqrt{ }$ & $\sqrt{ }$ & $\sqrt{ }$ & $\sqrt{ }$ & $\sqrt{ }$ & $\sqrt{ }$ & $\sqrt{ }$ & $\sqrt{ }$ & $100 \%$ \\
\hline $\mathrm{P} 5$ & $\checkmark$ & $\checkmark$ & $\checkmark$ & $x$ & $x$ & $\checkmark$ & $x$ & $\checkmark$ & $62.5 \%$ \\
\hline P6 & $x$ & $x$ & $\checkmark$ & $x$ & $\checkmark$ & $\checkmark$ & $\checkmark$ & $\checkmark$ & $62.5 \%$ \\
\hline P7 & $\checkmark$ & $\checkmark$ & $x$ & $x$ & $x$ & $\checkmark$ & $\checkmark$ & $\checkmark$ & $62.5 \%$ \\
\hline P8 & $\checkmark$ & $\checkmark$ & $\checkmark$ & $\checkmark$ & $\checkmark$ & $\checkmark$ & $\checkmark$ & $\checkmark$ & $100 \%$ \\
\hline P9 & - & - & - & - & - & - & - & - & - \\
\hline $\mathrm{P} 10$ & $\checkmark$ & $\checkmark$ & $\checkmark$ & $\checkmark$ & $\checkmark$ & $\checkmark$ & $\checkmark$ & $\checkmark$ & $100 \%$ \\
\hline$\sqrt{ } \%$ & $87.5 \%$ & $87.5 \%$ & $87.5 \%$ & $62.5 \%$ & $75 \%$ & $100 \%$ & $87.5 \%$ & $100 \%$ & - \\
\hline
\end{tabular}

Table 6.5: Process description accuracy in session 2 (Partic. = participant, valdn. $=$ validation, $\mathrm{r}$. seats $=$ reserved seats, $\mathrm{STOP}$ btn. $=\mathrm{STOP}$ button $)$. 


\begin{tabular}{|c|c|c|c|c|c|c|c|c|c|}
\hline & \multicolumn{8}{|c|}{ Process of taking a bus (Session 3) } & \multirow[b]{2}{*}{$\sqrt{ } \%$} \\
\hline Partic. & Wait & Enter & $\begin{array}{l}\text { Ticket } \\
\text { valdn. }\end{array}$ & $\begin{array}{c}\text { Avoid } \\
\text { r. } \\
\text { seats }\end{array}$ & Sit & Wait & $\begin{array}{c}\text { Press } \\
\text { STOP } \\
\text { btn. }\end{array}$ & Leave & \\
\hline $\mathrm{P} 1$ & - & - & - & - & - & - & - & - & - \\
\hline $\mathrm{P} 2$ & $\checkmark$ & $\checkmark$ & $\checkmark$ & $\checkmark$ & $\checkmark$ & $\checkmark$ & $\checkmark$ & $\checkmark$ & $100 \%$ \\
\hline P3 & $\sqrt{ }$ & $\sqrt{ }$ & $\sqrt{ }$ & $\sqrt{ }$ & $\sqrt{ }$ & $\sqrt{ }$ & $\sqrt{ }$ & $\sqrt{ }$ & $100 \%$ \\
\hline $\mathrm{P} 4$ & $\checkmark$ & $\checkmark$ & $\checkmark$ & $\checkmark$ & $\checkmark$ & $\checkmark$ & $\checkmark$ & $\checkmark$ & $100 \%$ \\
\hline$\overline{\mathrm{P} 5}$ & $\sqrt{ }$ & $\sqrt{ }$ & $\sqrt{ }$ & $\checkmark$ & $\sqrt{ }$ & $\sqrt{ }$ & $x$ & $\sqrt{ }$ & $87.5 \%$ \\
\hline $\mathrm{P} 6$ & $x$ & $\checkmark$ & $\checkmark$ & $x$ & $\checkmark$ & $x$ & $\checkmark$ & $\sqrt{ }$ & $62.5 \%$ \\
\hline $\mathrm{P} 7$ & - & - & - & - & - & - & - & - & - \\
\hline P8 & $\checkmark$ & $\checkmark$ & $\checkmark$ & $\checkmark$ & $\checkmark$ & $\checkmark$ & $\checkmark$ & $\checkmark$ & $100 \%$ \\
\hline P9 & - & - & - & - & - & - & - & - & - \\
\hline P10 & - & - & - & - & - & - & - & - & - \\
\hline$\sqrt{1 \%}$ & $83.3 \%$ & $100 \%$ & $100 \%$ & $83.3 \%$ & $100 \%$ & $83.3 \%$ & $83.3 \%$ & $100 \%$ & - \\
\hline
\end{tabular}

Table 6.6: Process description accuracy in session 3 (Partic. = participant, valdn. $=$ validation, $\mathrm{r}$. seats $=$ reserved seats, STOP btn. $=$ STOP button $)$.

When globally analysing the results from the tables above, in session 1 only one participant referred that reserved seats should be avoided, and only half mentioned pressing the STOP button to leave. Validating the ticket is also a core step in the bus taking process and was referred by $70 \%$ of the participants (buying tickets was considered equivalent to ticket validation). On the second session, two weeks after having played the game for the first time in session 1, the number of players that included, in the process description, the ticket validation, the avoidance of reserved seats, and pressing the STOP button, increased from 70\%, $10 \%$ and $50 \%$ to $87.5 \%, 62.5 \%$ and $87.5 \%$, respectively. In the last session, all players referred the ticket validation, and only one forgot to mention the avoidance of reserved seats and pressing the STOP button.

When focusing on the results obtained by the participants that followed through all three sessions, participants P2, P3, P4 and P8 described 100\% of the process after session 1, even with 24 days between session 2 and 3. P6 went from only describing three elements in session 1 , to describing five in session 2, but maintained in session 3. Additionally, the Shapiro-Wilk test was used to assess the normality of the data, whose result $(\mathrm{p}<0.01)$ indicated a significant deviation from a normal distribution. Accordingly, a Wilcoxon Signed-Ranks Test was then conducted, which showed that, by the third session $(\mathrm{Mdn}=100.0)$, the therapy resulted in a statistically significant higher process description accuracy, when compared to the first session $(\mathrm{Mdn}=68.8)(\mathrm{Z}=-2.220, \mathrm{p}<.026)$. 


\section{Following the norms}

As described in subsection 5.4.2, a score system gives feedback to the player, at the end of each task, about the players' actions (norms followed) and route followed. The actions considered were:

- Validating the ticket

- Entering through the front door

- Leave through the back door

- Sitting in a non-reserved seat.

These actions were used to evaluate the capacity of the player to follow the norms learned on the tutorial. Table 6.7 and Figure 6.5 contain the score percentage obtained by participants in each session.

\begin{tabular}{|c|c|c|c|}
\hline & \multicolumn{3}{|c|}{ Score (Actions) } \\
\hline Participant & Session 1 & Session 2 & Session 3 \\
\hline P1 & $50 \%$ & - & - \\
\hline P2 & $100 \%$ & $100 \%$ & $87.5 \%$ \\
\hline P3 & $75 \%$ & $100 \%$ & $100 \%$ \\
\hline P4 & $75 \%$ & $100 \%$ & $100 \%$ \\
\hline P5 & $50 \%$ & $100 \%$ & $87.5 \%$ \\
\hline P6 & $75 \%$ & $75 \%$ & $87.5 \%$ \\
\hline P7 & $100 \%$ & $100 \%$ & - \\
\hline P8 & $100 \%$ & $75 \%$ & - \\
\hline P9 & $100 \%$ & - & - \\
\hline P10 & $100 \%$ & $100 \%$ & $6.3 \%$ \\
\hline Mean & $82.50 \%$ & $93.8 \%$ & \\
\hline $\begin{array}{l}\text { Standard } \\
\text { deviation }\end{array}$ & $19.5 \%$ & $10.8 \%$ & \\
\hline
\end{tabular}

Table 6.7: Score percentage results for "Actions". 


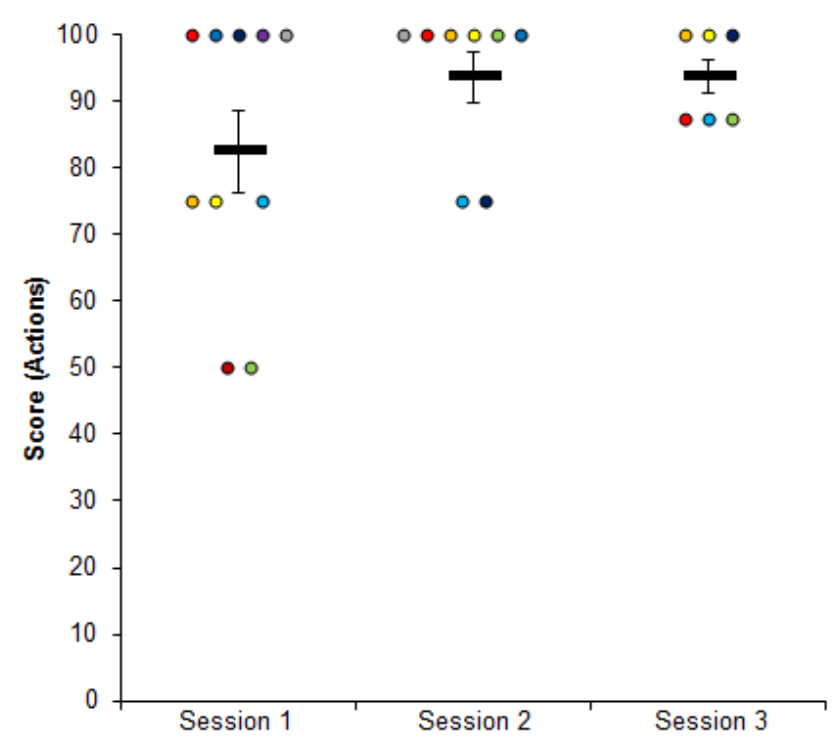

Figure 6.5: Score results for "Actions".

The results obtained show that most players were able to follow the norms, but still showing a generalized improvement from the 1st session to the 2nd, and a higher conversion of the results in successive sessions.

\section{Planning the route}

In sessions 2 and 3 (the ones in hard mode), at the beginning of the tasks, players were asked which route they were planning on taking and were given feedback, but never the answer. In session 2 , the objective was to go to the hospital by taking a bus that would leave the player on a bus stop close to it. There is, however, one bus line that stops in front of the hospital, but whose stops were far from the player starting position for that task. Nevertheless, participants P2, P3 and P7 explained that they wanted to take between two and three buses, so that they could take the bus that would leave them in front of the hospital. Afterwards, they were told that it is not necessary to take buses that stop exactly in front of the places, and that some times there are faster ways. The three players then identified the correct route to the place. In session 3, P6 wanted to walk and take one bus, instead of taking two. He was told that, in these tasks, the objective was to walk as little as possible, and realized that it was possible to take two buses instead. All the other players were able to properly plan the trip to the destination.

Since this feedback was given, the route scores, present in Table 6.8 and Figure 6.6, do not reflect the capacity of the participants to correctly plan a trip. Nevertheless, it can be used to see whether participants pressed the STOP button early enough 
to leave in the correct stop, or if they did not do it beforehand, and left in the next stop instead, as happened with P3 in session 2.

\begin{tabular}{|c|c|c|c|}
\hline & \multicolumn{3}{|c|}{ Score (Route) } \\
\hline Participant & Session 1 & Session 2 & Session 3 \\
\hline P1 & $100 \%$ & - & - \\
\hline P2 & $100 \%$ & $100 \%$ & $100 \%$ \\
\hline P3 & $100 \%$ & $60 \%$ & $100 \%$ \\
\hline P4 & $100 \%$ & $100 \%$ & $100 \%$ \\
\hline P5 & $100 \%$ & $100 \%$ & $100 \%$ \\
\hline P6 & $20 \%$ & $100 \%$ & $100 \%$ \\
\hline P7 & $60 \%$ & $100 \%$ & - \\
\hline P8 & $100 \%$ & $100 \%$ & $100 \%$ \\
\hline P9 & $100 \%$ & - & - \\
\hline P10 & $100 \%$ & $100 \%$ & $100 \%$ \\
\hline Mean & $88 \%$ & $95 \%$ & $0 \%$ \\
\hline $\begin{array}{c}\text { Standard } \\
\text { deviation }\end{array}$ & $25.6 \%$ & $13.2 \%$ & \\
\hline
\end{tabular}

Table 6.8: Score percentage results for "Route".

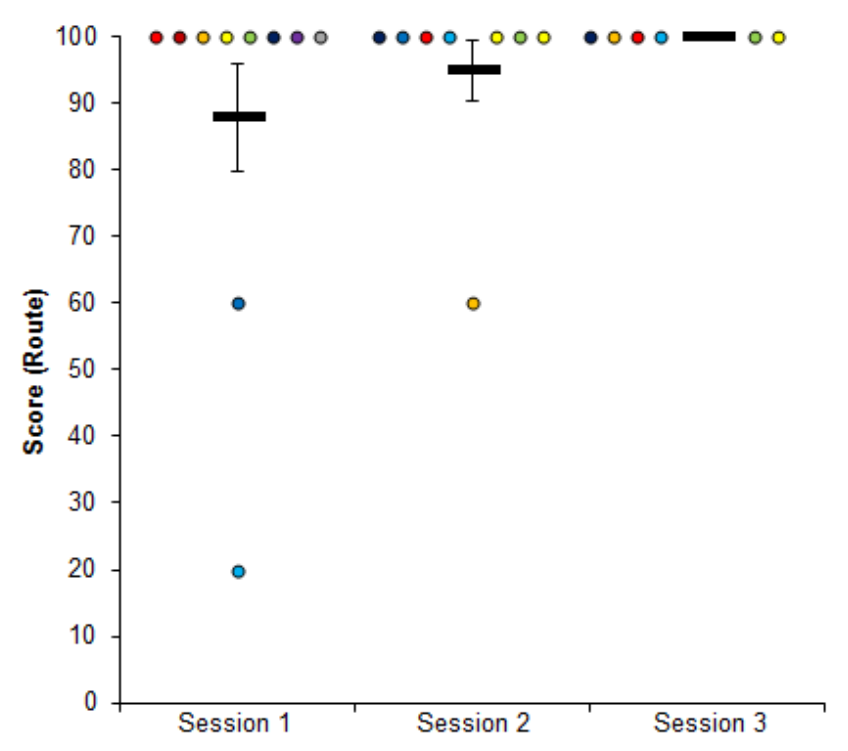

Figure 6.6: Score results for "Route". 


\subsection{Conclusions}

This section aimed at assessing the potential of the serious game developed as a tool for rehabilitation. Accordingly, three therapy sessions were conducted, for which ten participants with ASD were recruited. From these ten, six followed through all the sessions, two dropped out after the first session, and another two after the second. From the six participants that maintained throughout the sessions, two had intellectual disability, and one was already able to take buses autonomously. Nevertheless, it is important to highlight that the latter, despite her practice, reported that the game had helped her in real life navigating through less familiar routes, pressing the STOP button earlier, and avoiding the reserved seats in which she had been sitting so far.

The evaluation of the application focused on three main aspects. The first one was performance changes, in which the time taken by the participants to complete the tasks was analysed to understand how it changed over the three sessions. The results obtained showed that, with the sessions, the task durations tended to converge and the disparity previously observed was no longer evident, even when submitted to new challenges.

The second aspect considered was the change in anxiety levels experienced during the task, both when walking on the streets and inside the buses. By using heat maps to represent the EDA values obtained, it was possible to observe a generalized anxiety in bus stops and near the starting and finishing areas. This led to the conclusion that, when outside the buses, players felt most anxious when planning the trip and looking for the bus stop, when waiting for the bus, and when looking for the final destination. A similar analysis was conducted using the anxiety felt inside the bus, in which higher anxiety levels were observed when entering/leaving the bus and during the tutorial. Although, throughout the three sessions, the anxiety experienced on the streets maintained, by the third session the anxiety felt inside the buses was practically nonexistent.

The final aspect evaluated was the retention of knowledge between sessions. This included: memorizing the process of taking the bus, following the norms previously learned, applying them in the task, and being able to successfully plan a route to the destination. According to the results obtained, participants demonstrated a statistically significant increase in their knowledge of the bus taking process and norms. Furthermore, when receiving the tasks, most players did not show difficulties in applying the norms learned. Most participants were also able to plan the routes to the destination with ease, but the different tasks chosen still proved useful in teaching how different bus routes can be combined, and that the fastest bus is not always the one that stops in front of the place. 
In conclusion, by using the game as a therapy tool, in just three sessions it was possible to improve the general efficiency of participants and expose them to peculiar scenarios in which they could train their planning skills, but, more importantly, it was possible to nearly extinguish the anxiety felt in bus environments, and teach the bus norms necessary to autonomously use buses for transportation, both in theoretical and practical contexts. 


\section{Chapter 7}

\section{Conclusion and Future Work}

The aim of this project was to create a serious game, with virtual reality support, which would serve as a therapy tool to help individuals with Autism Spectrum Disorder (ASD) become more independent. The application focused on teaching how to use buses for transportation, from planning a trip from a certain position to a desired destination, to learning the core bus norms (e.g. validating ticket, avoiding reserved seats) and applying all these concepts in a realistic yet safe, immersive, virtual environment.

During the first seven months of the project, all the work planned was concluded and the objectives proposed were achieved without delays. Accordingly, after gathering enough information, including analysing the context of the project, comparing the game engines available and identifying the requirements for the game, the application development began. The game was developed and tested throughout three stages of development, the first corresponding to a fully functional prototype, and the last to the complete application. Every stage ended with a testing phase, in which participated between four and five individuals with ASD and between five and six individuals with typical development. These phases were used to detect potential issues, observe how people interacted with the game, and compare the performance of participants with ASD with the ones with typical development. In all three phases from the three stages, the former generally performed worse. By testing the application throughout its development, the opportunities to implement some extra features were identified, which increased the overall quality of the game.

Once the development was complete, the last two months of the project were dedicated to the validation of the potential of the application when used as a tool for rehabilitation. To that end, three therapy sessions were conducted, in which participated ten individuals with ASD, from which six completed the therapy. According to the results obtained, the completion of successive sessions reduced the dispersion previously observed in the task duration of the participants. Furthermore, 
the Electrodermal Activity (EDA) values registered showed that, by exposing and familiarizing, in each session, the participants to the bus environment, by the third session the anxiety felt had been nearly extinguished. Additionally, participants were asked, at the beginning of every session, to describe the process of taking a bus. The results revealed a statistically significant increase in the accuracy of the description of the process and norms, obtained by being exposed to them, in a practical, virtual, immersive context. Also, participants obtained high success rates in the application of norms learned within the game. Finally, during the therapy, most participants were able to plan the route to the destination without the need of feedback.

In addition to the work developed and results achieved, an abstract was submitted and accepted for the VI Annual Meeting of the Institute for Biomedical Imaging and Life Sciences (IBILI) and an extended abstract was submitted for the International Conference on Virtual Rehabilitation (ICVR) 2015. Accordingly, posters describing this study were created and presented during the conferences (please see Appendix A and Appendix B). The one presented in ICVR2015 was awarded an honourable mention in the category of "Best Student Poster".

Despite the results obtained, there is still room for further research on this topic. More specifically, it would be interesting to repeat the therapy sessions with a larger population, divided into two groups, one would receive the therapy with immersive virtual reality, and another would receive the therapy on a computer display. This way, it would be possible to analyse and understand the true impact of immersive virtual reality technologies on rehabilitation. Furthermore, by taking participants in a true bus trip after the therapy sessions, it would be possible to understand the extent to which the knowledge obtained transfers to real life situations. Finally, after the development of NeuroHab (a serious game platform to which the game was uploaded), the platform will be ready to apply gamification concepts to the use of the game, including techniques such as goals and rewards, increasing their motivation to engage in rehabilitation.

Finally, the game developed stands out for its use of emerging, immersive virtual reality technologies, whose use in therapies and serious games is still in its infancy. The results obtained reveal that serious games, using these technologies, can be used effectively in helping people with ASD become more independent, specifically regarding the use of buses for transportation, whose know how also applies to most public transportation systems. 


\section{Bibliography}

[1] H. M. Zakari, M. Ma, and D. Simmons, "A Review of Serious Games for Children with Autism Spectrum Disorders (ASD)," in Serious Games Development and Applications. Springer, 2014, pp. 93-106.

[2] American Psychiatric Association, Diagnostic and Statistical Manual of Mental Disorders, 5th ed. Arlington: American Psychiatric Publishing, 2013. [Online]. Available: http://encore.llu. edu/iii/encore/record/C_Rb1280248_SDSM-V_P0,2_Orightresult_ _X3;jsessionid=ABB7428ECBC4BA66625EDD0E0C5AAFA5?lang=eng\& suite=cobalt $\$ \backslash$ delimiter"026E30F $\$$ nhttp://books.google.com/books?id= EIbMlwEACAAJ\&pgis $=1$

[3] O. Bimber, "Thinking Virtual," Computer, vol. 47, no. 7, pp. 22-23, Jul. 2014. [Online]. Available: http://www.computer.org/csdl/mags/co/2014/ 07/mco2014070022.html

[4] A. Rizzo, A. Hartholt, M. Grimani, A. Leeds, and M. Liewer, "Virtual Reality Exposure Therapy for Combat-Related Posttraumatic Stress Disorder," Computer, vol. 47, no. 7, pp. 31-37, 2014.

[5] P. M. G. Emmelkamp, M. Krijn, a. M. Hulsbosch, S. De Vries, M. J. Schuemie, and C. a. P. G. Van der Mast, "Virtual reality treatment versus exposure in vivo: A comparative evaluation in acrophobia," Behaviour Research and Therapy, vol. 40, pp. 509-516, 2002.

[6] D. Strickland, L. M. Marcus, G. B. Mesibov, and K. Hogan, "Brief report: two case studies using virtual reality as a learning tool for autistic children." Journal of autism and developmental disorders, vol. 26, no. 6, pp. 651-659, 1996.

[7] S. Parsons and S. Cobb, "State-of-the-art of virtual reality technologies for children on the autism spectrum," European Journal of Special Needs Education, vol. 26, no. December 2014, pp. 355-366, 2011.

[8] S. H. A. Chen and V. Bernard-Opitz, "Comparison of personal and computerassisted instruction for children with autism." Mental retardation, 1993. 
[9] S. Mouga, J. Almeida, F. Duque, and G. Oliveira, "Adaptive Profiles in Autism and Other Neurodevelopmental Disorders," 2014.

[10] S. W. White, D. Oswald, T. Ollendick, and L. Scahill, "Anxiety in children and adolescents with autism spectrum disorders," Clinical Psychology Review, vol. 29, no. 3, pp. 216-229, 2009. [Online]. Available: http://dx.doi.org/10.1016/j.cpr.2009.01.003

[11] M. Simões, S. Mouga, F. Pedrosa, P. Carvalho, and M. Castelo-Branco, "Neurohab : a platform for virtual training of daily living skills in autism spectrum disorder," Procedia Technology, vol. 16, pp. 1417-1423, 2014. [Online]. Available: http://dx.doi.org/10.1016/j.protcy.2014.10.161

[12] A. Nazeer and M. Ghaziuddin, "Autism spectrum disorders: Clinical features and diagnosis," Pediatric Clinics of North America, vol. 59, no. 1, pp. 19-25, 2012. [Online]. Available: http://dx.doi.org/10.1016/j.pcl.2011.10.007

[13] National Institute of Neurological Disorders and Stroke, "Autism Fact Sheet: National Institute of Neurological Disorders and Stroke (NINDS)," 2014, accessed: 2015-01-22. [Online]. Available: http: //www.ninds.nih.gov/disorders/autism/detail_autism.htm\#259223082

[14] C. Lord, M. Rutter, and a. L. Couteur, "Autism diagnostic interview-revised: A revised version of a diagnostic interview for caregivers of individuals with possible pervasive developmental disorders," Journal of Autism and Developmental Disorders, vol. 24, no. 5, pp. 659-685, 1994.

[15] C. Lord, S. Risi, L. Lambrecht, E. H. J. Cook, B. L. Leventhal, P. C. DiLavore, A. Pickles, and M. Rutter, "The Autism Diagnostic Observation Schedule-Generic: A Standard Measure of Social and Communication Deficits Associated with the Spectrum of Autism," Journal of Autism and Developmental Disorders, vol. 30, no. 3, pp. 205-223, 2000.

[16] Centers for Disease Control and Prevention, "CDC | Healthcare Providers | Autism Spectrum Disorder (ASD) | NCBDDD," accessed: 2015-01-22. [Online]. Available: http://www.cdc.gov/ncbddd/autism/hcp-screening. html

[17] H. V. Ratajczak, "Theoretical aspects of autism: Causes-A review," Journal of immunotoxicology, vol. 8, no. 1, pp. 68-79, 2011.

[18] E. Fombonne, "The epidemiology of autism: a review." Psychological medicine, vol. 29, pp. 769-786, 1999. 
[19] A. Klin, J. McPartland, F. R. Volkmar, and Others, "Asperger syndrome," Handbook of autism and pervasive developmental disorders, vol. 1, pp. 88$125,2005$.

[20] C. P. Johnson and S. M. Myers, "Identification and evaluation of children with autism spectrum disorders." Pediatrics, vol. 120, no. 5, pp. 1183-1215, 2007.

[21] O. I. Lovaas, "Behavioral treatment and normal educational and intellectual functioning in young autistic children." Journal of consulting and clinical psychology, vol. 55, no. 1, pp. 3-9, 1987.

[22] S. J. Sheinkopf and B. Siegel, "Home-based behavioral treatment of young children with autism." Journal of autism and developmental disorders, vol. 28, no. 1, pp. 15-23, 1998.

[23] Committee on Educational Interventions for Children with Autism, Educating Children with Autism -chapter 2, 2001.

[24] M. Gutierrez, F. Vexo, and D. Thalmann, Stepping into virtual reality. Springer, 2008.

[25] G. Kim, Designing Virtual Reality Systems, 2005. [Online]. Available: http://link.springer.com/content/pdf/10.1007/978-1-84628-230-0.pdf

[26] M. Slater, "A Note on Presence Terminology," Emotion, vol. 3, pp. 1-5, 2003.

[27] M. Slater and S. Wilbur, "A Framework for Immersive Virtual Environments (FIVE): Speculations on the Role of Presence in Virtual Environments," pp. 1-20, 1997.

[28] M. V. Sanchez-Vives and M. Slater, "From presence to consciousness through virtual reality." Nature reviews. Neuroscience, vol. 6, no. April, pp. 332-339, 2005 .

[29] G. Merchant, Virtual literacies: Interactive spaces for children and young people. Routledge, 2013, vol. 84.

[30] Oculus VR, "Oculus Rift Development Kit 1 Order Page | Oculus Rift Virtual Reality Headset for 3D Gaming," accessed: 2015-01-22. [Online]. Available: https://www.oculus.com/order/dk1/

[31] The All New Oculus Rift Development Kit 2 (DK2) Virtual Reality Headset | Oculus Rift - Virtual Reality Headset for 3D Gaming," accessed: 2015-01-22. [Online]. Available: https://www.oculus.com/dk2/ 
[32] Durovis Dive, "Durovis Dive - 3D Virtual Reality Gaming on a Smartphone," accessed: 2015-01-22. [Online]. Available: http://www.durovis.com/index. html

[33] KZero Worldswide, "VR Headset Sales Forecasts and Market Penetration $2014-2018$ - KZero Worldswide," accessed: 2015-01-22. [Online]. Available: http://www.kzero.co.uk/blog/ vr-headset-sales-forecasts-and-market-penetration-2014-2018/

[34] EON Reality, "Augmented and Virtual Reality Market to Reach \$1.06 Billion USD by 2018; EON Reality Highlighted as a Market Leader in Report," accessed: 2015-01-22. [Online]. Available: http://www.eonreality.com/ augmented-virtual-reality-market-reach-1-06-billion-usd-2018-eon-reality-highlighted-market

[35] Sony Playstation, "SONY COMPUTER ENTERTAINMENT ANNOUNCES "PROJECT MORPHEUS" - A VIRTUAL REALITY SYSTEM THAT EXPANDS THE WORLD OF PLAYSTATION@4 (PS4 ${ }^{\mathrm{TM}}$ ) | PRESS RELEASE - PLAYSTATION@," 2014, accessed: 2015-01-22. [Online]. Available: http://us.playstation.com/corporate/about/press-release/ sce-announces-project-morpheus-a-virtual-reality-system-that-expands-the-world-of-ps4. html

[36] Oculus VR, "Gear VR Innovator Edition | Oculus Rift - Virtual Reality Headset for 3D Gaming," accessed: 2015-01-22. [Online]. Available: https://www.oculus.com/gear-vr/

[37] Google Cardboard, "Google Cardboard - Google," accessed: 2015-01-22. [Online]. Available: https://www.google.com/get/cardboard/

[38] Kickstarter, "Kickstarter," accessed: 2015-01-26. [Online]. Available: https://www.kickstarter.com/

[39] Facebook, "Facebook," accessed: 2015-01-26. [Online]. Available: https: //www.facebook.com/

[40] S. Dredge, "Facebook closes its \$2bn Oculus Rift acquisition. What next? | Technology | The Guardian," accessed: 2015-01-26. [Online]. Available: http://www.theguardian.com/technology/2014/jul/22/ facebook-oculus-rift-acquisition-virtual-reality

[41] "First Look at the Rift, Shipping Q1 2016," accessed: 2015-06-21. [Online]. Available: https://www.oculus.com/en-us/blog/ first-look-at-the-rift-shipping-q1-2016/ 
[42] R. Pflanzer and W. Mcmullen, "Lesson 9 BIOPAC Systems , Inc . I . INTRODUCTION," vol. 93117, no. 805, 2000.

[43] J. Braithwaite, D. Watson, J. Robert, and R. Mickey, "A Guide for Analysing Electrodermal Activity (EDA) \& Skin Conductance Responses (SCRs) for Psychological Experiments," ..., pp. 1-42, 2013. [Online]. Available: http://www.bhamlive.bham.ac.uk/Documents/ college-les/psych/saal/guide-electrodermal-activity.pdf

[44] Experiment 33 : The Galvanic Skin Response ( GSR ) and Emotion, pp. 179-186.

[45] W. Boucsein, Electrodermal Activity, 2nd ed. Springer, 2012.

[46] a. Garcia-Palacios, H. Hoffman, a. Carlin, T. a. Furness, and C. Botella, "Virtual reality in the treatment of spider phobia: A controlled study," Behaviour Research and Therapy, vol. 40, pp. 983-993, 2002.

[47] H. G. Hoffman, A. Garcia-Palacios, A. Carlin, T. a. Furness III, and C. Botella-Arbona, "Interfaces That Heal: Coupling Real and Virtual Objects to Treat Spider Phobia," International Journal of Human-Computer Interaction, vol. 16, no. 2, pp. 283-300, 2003.

[48] "Virtual Reality Exposure Therapy," accessed: 2015-05-30. [Online]. Available: http://ict.usc.edu/prototypes/pts/

[49] A. Rizzo, J. Difede, B. O. Rothbaum, G. Reger, J. Spitalnick, J. Cukor, and R. Mclay, "Development and early evaluation of the Virtual Iraq/Afghanistan exposure therapy system for combat-related PTSD," Annals of the New York Academy of Sciences, vol. 1208, no. 1, pp. 114-125, 2010.

[50] G. Reger, K. Holloway, C. Candy, B. O. Rothbaum, J. Difede, A. Rizzo, and G. Gahm, "Effectiveness of Virtual Reality Exposure Therapy for Active Duty Soldiers in a Military Mental Health Clinic," Journal of traumatic stress, vol. 24, no. 1, pp. 93-96, 2011.

[51] H. G. Hoffman, D. R. Patterson, and G. J. Carrougher, "Use of virtual reality for adjunctive treatment of adult burn pain during physical therapy: a controlled study," The Clinical Journal of Pain, vol. 16, no. 3, pp. 244-250, 2000 .

[52] M. Bellani, L. Fornasari, L. Chittaro, and P. Brambilla, "Virtual reality in autism: state of the art," Epidemiology and Psychiatric Sciences, vol. 20, no. 03, pp. 235-238, 2011. 
[53] D. Strickland, "Virtual reality for the treatment of autism," Studies in Health Technology and Informatics, vol. 44, pp. 81-86, 1997.

[54] D. R. Michael and S. L. Chen, Serious games: Games that educate, train, and inform. Muska \& Lipman/Premier-Trade, 2005.

[55] E. M. Whyte, J. M. Smyth, and K. S. Scherf, "Designing Serious Game Interventions for Individuals with Autism," 2014.

[56] S. Parsons, A. Leonard, and P. Mitchell, "Virtual environments for social skills training: comments from two adolescents with autistic spectrum disorder," vol. 47, pp. 186-206, 2006. [Online]. Available: http://eprints.soton.ac.uk/170819/

[57] P. Mitchell, S. Parsons, and A. Leonard, "Using virtual environments for teaching social understanding to 6 adolescents with autistic spectrum disorders," Journal of Autism and Developmental Disorders, vol. 37, pp. 589-600, 2007.

[58] M. Maskey, J. Lowry, J. Rodgers, H. McConachie, and J. R. Parr, "Reducing specific phobia/fear in young people with autism spectrum disorders (ASDs) through a virtual reality environment intervention," PLoS ONE, vol. 9, no. 7, 2014 .

[59] E. F. Lopresti, "Cognitive Skills Enhancement Program."

[60] The Sims 3, "Home - Community - The Sims 3," accessed: 2015-01-22. [Online]. Available: http://www.thesims3.com/

[61] J. Du, C. Fan, H. Jiang, H. Sun, X. Li, and M. Zhao, "Biofeedback combined with cue-exposure as a treatment for heroin addicts," Physiology and Behavior, vol. 130, pp. 34-39, 2014.

[62] S. Raaijmakers, F. Steel, M. de Goede, N. van Wouwe, J. van Erp, and a. M. Brouwer, "Heart Rate Variability and Skin Conductance Biofeedback: A Triple-Blind Randomized Controlled Study," 2013 Humaine Association Conference on Affective Computing and Intelligent Interaction, pp. 289-293, 2013. [Online]. Available: http://ieeexplore.ieee.org/lpdocs/ epic03/wrapper.htm?arnumber $=6681445$

[63] G. Henriques, S. Keffer, C. Abrahamson, and S. J. Horst, "Exploring the effectiveness of a computer-based heart rate variability biofeedback program in reducing anxiety in college students," Applied Psychophysiology Biofeedback, vol. 36, pp. 101-112, 2011. 
[64] a. U. Alahakone and S. M. N. a. Senanayake, "A real time vibrotactile biofeedback system for improving lower extremity kinematic motion during sports training," SoCPaR 2009 - Soft Computing and Pattern Recognition, pp. 610-615, 2009.

[65] M. E. McKinney and R. J. Gatchel, "The comparative effectiveness of heart rate biofeedback, speech skills training, and a combination of both in treating public-speaking anxiety." Biofeedback and self-regulation, vol. 7, no. 1, pp. 71-87, 1982.

[66] Q. a. Morarend, M. L. Spector, D. V. Dawson, S. H. Clark, and D. C. Holmes, "The use of a respiratory RATE biofeedback device to reduce dental anxiety: An exploratory investigation," Applied Psychophysiology Biofeedback, vol. 36, pp. 63-70, 2011.

[67] M. L. Weinman, K. M. Semchuk, G. Gaebe, and R. J. Mathew, "The effect of stressful life events on EMG biofeedback and relaxation training in the treatment of anxiety." Biofeedback and self-regulation, vol. 8, no. 2, pp. 191205, 1983.

[68] M. Ghaziuddin and K. Mountain-Kimichi, "Defining the intellectual profiles of Asperger syndrome: comparison with high functioning autism." vol. 34, no. 3, pp. 279-284, 2004.

[69] "ICD-10 Version:2015," accessed: 2015-07-02. [Online]. Available: http: //apps.who.int/classifications/icd10/browse/2015/en\#/F70.0

[70] T. Westeyn, P. Presti, and T. Starner, "ActionGSR: A combination galvanic skin response-accelerometer for physiological measurements in active environments," Proceedings - International Symposium on Wearable Computers, ISWC, no. Figure 2, pp. 129-130, 2007.

[71] H. Kurniawan, A. V. Maslov, and M. Pechenizkiy, "Stress detection from speech and galvanic skin response signals," Proceedings of CBMS 2013 26th IEEE International Symposium on Computer-Based Medical Systems, pp. 209-214, 2013.

[72] L. Williams and A. Cockburn, "Agile software development: It's about feedback and change," Computer, vol. 36, pp. 39-43, 2003.

[73] Agilemanifesto.org, "Manifesto for Agile Software Development," 2001, accessed: 2015-01-25. [Online]. Available: http://www.agilemanifesto.org/

[74] J. Highsmith, Agile Software Development Ecosystems, 2002. 
[75] J. Highsmith, "MESSY, EXCITING, AND ANXIETY-RIDDEN: ADAPTIVE SOFTWARE DEVELOPMENT," vol. X, no. 1, pp. 1-8, 1997.

[76] Unity, "Unity - Game Engine," accessed: 2015-01-26. [Online]. Available: http://unity3d.com/

[77] Crytek, "CryENGINE® 3 | Crytek," accessed: 2015-01-26. [Online]. Available: http://www.crytek.com/cryengine/cryengine3/overview

[78] Valve, "Valve Developer Community," accessed: 2015-01-26. [Online]. Available: https://developer.valvesoftware.com/wiki/Main_Page

[79] Unreal Engine Technology, "Unreal Engine Technology | Home," accessed: 2015-01-26. [Online]. Available: https://www.unrealengine.com/

[80] YoYo Games, "GameMaker: Studio | YoYo Games," accessed: 2015-01-26. [Online]. Available: https://www.yoyogames.com/studio

[81] Indie DB, "Game Engines - Indie DB," accessed: 2015-01-22. [Online]. Available: http://www.indiedb.com/engines?sort=ranktoday-asc

[82] Wikipedia, "List of game engines," accessed: 2015-01-26. [Online]. Available: http://en.wikipedia.org/wiki/List_of_game_engines

[83] C. Chapple, "The top 16 game engines for 2014 | Game Development Tools \& Tech | Develop," 2014, accessed: 2015-0122. [Online]. Available: http://www.develop-online.net/tools-and-tech/ the-top-16-game-engines-for-2014/0192302

[84] A. Pattrasitidecha, "Comparison and evaluation of 3D mobile game engines," 2014. [Online]. Available: http://publications.lib.chalmers.se/ records/fulltext/193979/193979.pdf

[85] W3Schools, "OS Statistics," accessed: 2015-01-22. [Online]. Available: http://www.w3schools.com/browsers/browsers_os.asp

[86] IDC, "IDC: Smartphone OS Market Share 2014, 2013, 2012, and 2011," accessed: 2015-01-22. [Online]. Available: http://www.idc.com/prodserv/ smartphone-os-market-share.jsp

[87] WorldViz, "Vizard Virtual Reality Software Toolkit | WorldViz, LLC. | Virtual Reality Software," accessed: 2015-01-26. [Online]. Available: http://www.worldviz.com/products/vizard

[88] Marmalade, "The fastest cross-platform $\mathrm{C}++$ game development SDK | Marmalade," accessed: 2015-01-26. [Online]. Available: https://www. madewithmarmalade.com/ 
[89] ShiVa, "ShiVa 1.9.2 - Cross Platform Game Development," accessed: 2015-01-26. [Online]. Available: http://www.shivaengine.com/

[90] Stack Exchange, "Game Development Stack Exchange," accessed: 2015-0122. [Online]. Available: http://gamedev.stackexchange.com/

[91] S. Overflow, "Stack Overflow," accessed: 2015-01-22. [Online]. Available: http://stackoverflow.com/

[92] Amazon.com, "Amazon.com: Online Shopping for Electronics, Apparel, Computers, Books, DVDs \& more," accessed: 2015-01-22. [Online]. Available: http://www.amazon.com/

[93] J. Wohl, "Amazon most satisfying website to shop: survey | Reuters," 2012, accessed: 2015-01-22. [Online]. Available: http://www.reuters.com/article/ 2012/12/27/us-usa-retail-online-idUSBRE8BQ01820121227

[94] Unity, "Unity - Fast Facts," accessed: 2015-01-22. [Online]. Available: https://unity3d.com/pt/public-relations

[95] Ministério da Administração Interna, "Regulamento de Sinalização do Trânsito," accessed: 2015-01-27. [Online]. Available: http://www.afesp.pt/ admin/ficheiros/DR22A-RegulamentodeSinalizacaodeTransito.pdf

[96] M. Zhou, "Petri Nets in Flexible and Agile Automation," pp. 1-42, 1995.

[97] M. A. Syufagi, M. Hariadi, and M. H. Purnomo, "Petri net model for serious games based on motivation behavior classification," International Journal of Computer Games Technology, vol. 2013, 2013.

[98] C. Brom and A. Abonyi, "Petri-Nets for Game Plot," Proceedings of AISB artificial intelligence and simulation behaviour convention, Bristol, vol. 3, pp. 6-13, 2006.

[99] M. Araújo and L. Roque, "Modeling games with petri nets," Breaking New Ground: Innovation in Games, Play, Practice and Theory. DIGRA2009. Londres, Royaume Uni, 2009.

[100] "Python Imaging Library (PIL)," accessed: 2015-06-09. [Online]. Available: http://www.pythonware.com/products/pil/

[101] "Open Broadcaster Software," accessed: 2015-06-18. [Online]. Available: https://obsproject.com/

[102] P. Wied, "heatmap.js Heat Map Visualization Library," accessed: 2015-0701. [Online]. Available: http://www.patrick-wied.at/static/heatmapjs/ 
[103] M. Bernardes, F. Barros, M. Simões, and M. Castelo-Branco, "A serious game with virtual reality for travel training with Autism Spectrum Disorder," International Conference on Virtual Rehabilitation, ICVR 2015, vol. in press, 2015 .

[104] "Unity - Manual: Unity Manual," accessed: 2015-07-04. [Online]. Available: http://docs.unity3d.com/Manual/index.html 


\section{Appendix A}

\section{Poster presented at IBILI Meeting 2014}

The VI Annual Meeting of IBILI was a conference that took place on December 11th and 12th at the Faculty of Medicine of the University of Coimbra, Portugal. The conference included lectures and poster sessions on the following topics: Translational Research in Vision Sciences and Imaging; New challenges in Cardio and Vascular Translation Research; Translational Research in Neuroscience and Chronic Disease; and Vision. For this conference, an abstract of this project was submitted and accepted for the "Translational Research in Neuroscience and Chronic Disease" topic. Consequently a poster was presented in a poster session that took place. The latter is represented below, on Figure A.1. 


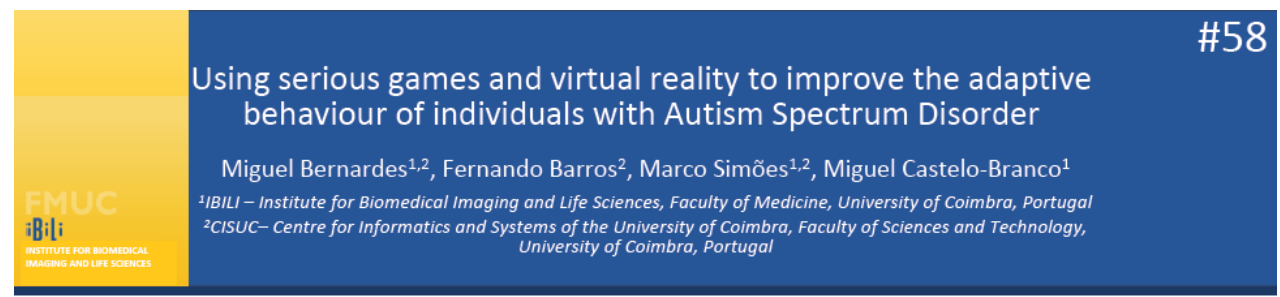

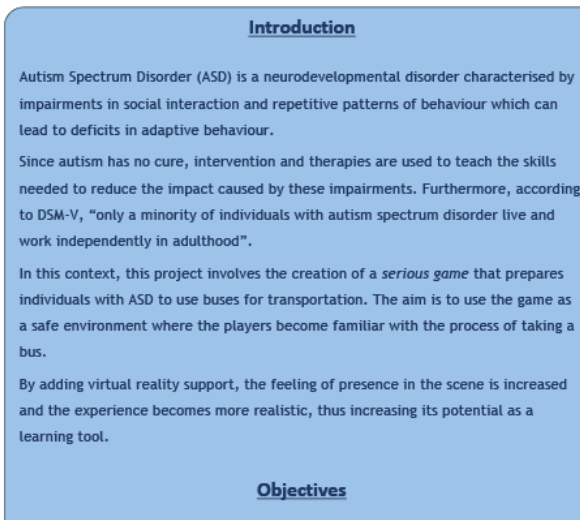

The game consists of placing the player in a three-dimensional city and setting a task that involves taking a bus to reach a specific destination. This includes activities such as planning a route, waiting for the right bus, choosing a place to sit and deciding when to press the stop button and leave.

Since this game is designed to be used by individuals within a broad age range and from different backgrounds, who might have experience with using public transportation systems, the tasks will be available in two different difficulties: easy and hard. The easy mode will guide the player through all the steps required to go from the starting point to the destination. The hard mode, aimed at more experienced individuals, will only inform the players of their final destination, being players responsible for creating a plan to reach the destination.

In order to measure the player's performance, two different methods are used: a score system and a biofeedback system.

The score system takes into consideration several details regarding the task execution and uses them to evaluate the overall performance. Examples include:

- Which buses are taken and in which bus stops;

- In which bus stops does the player leave the bus;

- How long it takes to complete the task.

The biofeedback system, on the other hand, is based on electrodermal activity, which measures the anxiety level of the player throughout the task.

With these metrics, it is possible to analyse the impact of practice on both task performance and anxiety reduction.

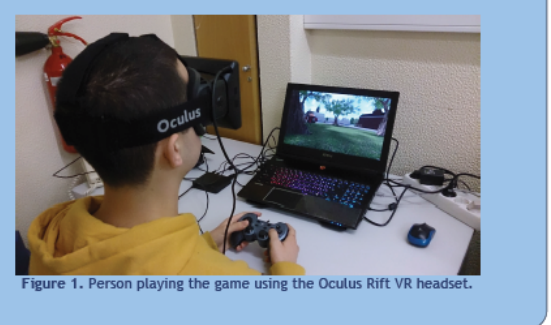

Study supported by the FCT grant SFRH/2011/77044 and the AAC Project N013 SI/2011/HomeTech/QREN - Compete, co-financed by FEDER and Portuguese Foundation for Science and Technology and also the European Project BRAIITRAIN (FP7-HEALTH-2013-Innovation-1-602186-BrainTrain).

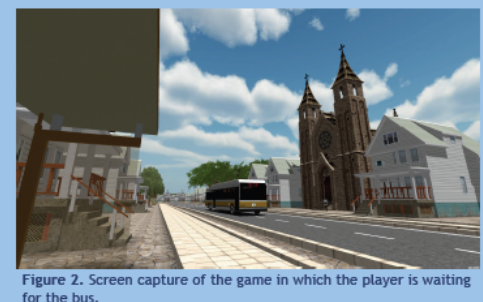

Methodology

This project is divided in three stages:

- The first stage allows the player to freely explore the city and take buses to travel in pre-defined routes. The tasks can be executed in the two levels of difficulty previously mentioned. To help the player navigate in the city, there is a map with all the bus routes, bus stops, buildings, as well as the player's current position and the task's destination.

- In the second stage, the interaction with the buses is not limited to entering and leaving operations - the player can also validate the ticket, choose a place to sit, and press the stop button. The biofeedback system is also implemented in this stage.

The third stage consists mostly of populating the city with people, cars, dogs, etc. Finally, the score system is also implemented.

The game is currently on the first stage and is being developed using the Unity game engine and the Oculus Rift virtual reality headset.

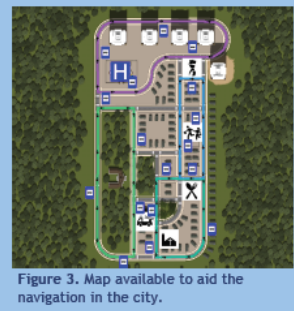

\section{Conclusion}

As this project is still under development, its validation is yet to be conducted. Mevertheless, the results obtained may be useful in understanding how games and virtual reality can improve the adaptive behaviour of individuals with ASD, specifically regarding the task of taking a bus.

\section{Contact}

Miguel Rasteiro Simões Bernardes

Email: mrsimoesथstudent.dei.uc.pt

Figure A.1: Poster presented. 


\section{Appendix B}

\section{Poster presented at ICVR2015}

The Rehab Week 2015 was an event that joined three international conferences: the International Conference on Virtual Rehabilitation (ICVR), the International Conference on Recent Advances in Neurorehabilitation, and the International Neurorehabilitation Symposium. The event took place in Valencia, Spain, between 9th and 12th June. ICVR is a conference that focuses of the use of virtual reality and augmented reality technologies applied to rehabilitation. On January 26, 2015 an extended abstract [103] (please see file attached below) was submitted for the following topics:

- Cognitive Rehabilitation.

- Gaming.

- Regulatory and Educational Efforts to Promote Virtual Rehabilitation.

During the conference, a poster was presented, along with a demo of the game developed. At the end of the conference, the poster was awarded an honourable mention in the category of ICVR2015's "Best Student Poster" (Figure B.1). 


\section{A serious game with virtual reality for travel training with Autism Spectrum Disorder}

\author{
Miguel Bernardes ${ }^{1,2}$ \\ ${ }^{1}$ Institute for Biomedical Imaging and Life Sciences \\ ${ }^{2}$ Centre for Informatics and Systems of the University of \\ Coimbra \\ University of Coimbra \\ Coimbra, Portugal \\ mrsimoes@student.dei.uc.pt
}

\author{
Fernando Barros ${ }^{2}$, Marco Simões ${ }^{1,2}$, Miguel Castelo- \\ Branco $^{1}$ \\ ${ }^{1}$ Institute for Biomedical Imaging and Life Sciences \\ ${ }^{2}$ Centre for Informatics and Systems of the University of \\ Coimbra \\ University of Coimbra \\ Coimbra, Portugal
}

\begin{abstract}
Autism Spectrum Disorder (ASD) is a neurodevelopmental disorder characterized by impairments in social interaction and repetitive patterns of behavior. This article describes the creation of a serious game that prepares individuals with ASD to use buses as a mean of transportation. Virtual reality (VR) support was added, increasing the feeling of presence and the realism of the experience, thus increasing its potential as a learning tool. The game is currently being developed using the Unity game engine and uses the Oculus Rift as virtual reality headset. Preliminary results prove the viability of the experiment and the acceptance from individuals with ASD towards the use of the VR setup. In conclusion, the project aims to understand how games and virtual reality can be used to improve the capabilities of individuals with ASD, and help them live more independently.
\end{abstract}

Keywords-Autism Spectrum Disorder; serious games; travel train; virtual reality; virtual reality therapy

\section{INTRODUCTION}

Autism Spectrum Disorder (ASD) is a neurodevelopmental disorder responsible for impairments in social communication and interaction, and restricted repetitive patterns of behavior, interests, or activities. Currently ASD affects $1 \%$ of the population worldwide [1] and, with a cure yet to be found, individuals rely on therapies and interventions to improve and overcome its impairments. Immersive Virtual Reality (VR) technologies available nowadays are able to present users with experiences realistic enough to trick the mind and create a feeling of presence within the environment [2]. Serious games (games whose objective is learning rather than entertainment [3], regardless of the player's age) have been proven effective in ASD therapies, not only for including game design techniques to keep the players motivated, but also because individuals with ASD are often interested in computer-based activities [4]. This article describes the development and viability testing of a serious game which uses VR to rehabilitate individuals with ASD.

\section{OBJECTIVES AND METHODS}

The purpose of this project is to prepare individuals witllo ASD to use buses for transportation by placing them in a three-

\footnotetext{
Study supported by the FCT grant SFRH/2011/77044 and the AAC
} Project No 13 SI/2011/HomeTech/QREN - Compete, co-financed by FEDER and Portuguese Foundation for Science and Technology and also the European Project BRAINTRAIN (FP7-HEALTH-2013-Innovation-1602186-BrainTrain). dimensional city and setting tasks which involve taking buses to reach specific destinations. The game developed so far provides a safe environment where players can become comfortable with the process of taking a bus. It currently facilitates independence in community travel by training activities such as planning a route and waiting for the right bus, as well as the standard bus procedures: validating the ticket, not sitting on priority seats and timely pressing the stop button. At the beginning of the game, the player can choose which task to attempt and its difficulty, allowing for progression as tasks are completed. Testing sessions were conducted to examine the following factors:

- Technology acceptance - using a Head Mounted Display (HMD) instead of a screen monitor can be overwhelming and cause motion sickness.

- Interface comprehension - interface design standards adopted for desktop applications are often inadequate for HMD as the borders of the screen are blurred and only the center is clear.

- Task performance - difference in task performance between individuals with ASD and controls (individuals without ASD).

Since different participants might need different amounts of time to get used to the game, a tutorial was created. The performance in the tutorial was used to test the interface, while the task performance was used as a first assessment of the participant's capabilities.

\section{A. Participants}

Five individuals with ASD, three males and two females, with a mean age of 32.2 years and standard deviation of 4.0 , and five controls, three males and two females, with a mean age of 30.7 and standard deviation of 6.2 , participated in this testing phase. This study and all the procedures were reviewed and approved by the Ethics Commission of our Faculty of Medicine from University of Coimbra and was conducted in accordance with the declaration of Helsinki. Informed consent was obtained from the parents/guardians of all participants. Participants also gave oral informed consent. 


\section{APPENDIX B. POSTER PRESENTED AT ICVR2015}

\section{B. Procedure}

In the testing sessions the participants received the tutorial and a task. The tutorial consisted of 3 steps: going to an $\mathrm{X}$ marked on the floor, taking the bus number 4 , and leaving in the first stop. Participants were guided step by step by the facilitators through the tutorial. The task consisted of four steps: going to the bus stop signaled in the map, taking the bus number 3, leaving in the stop closest to the police station, and going to the police station. Information about the player's performance was registered for posterior analysis.

\section{RESULTS}

Throughout the testing sessions no participant with ASD reported motion sickness.

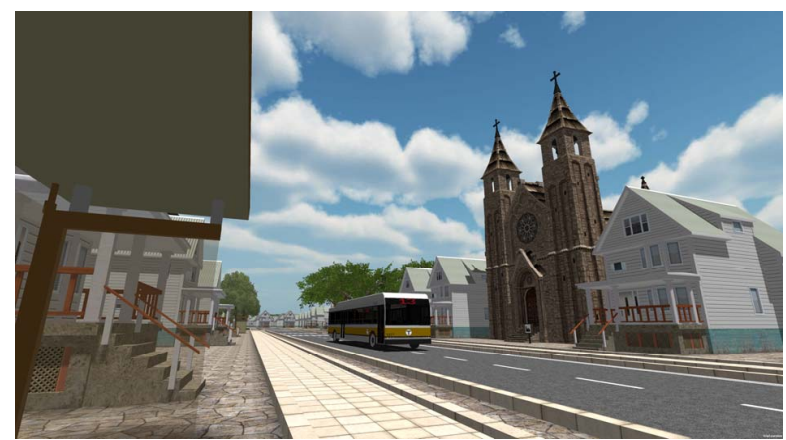

Figure 1. Game screen capture in which the player is waiting for the bus.

During the tutorial participants were asked to read the current objective out loud and identify the location of both player and objective on the map. The results are presented below in Table I and Table II for participants with ASD and controls, respectively. Table III and Table IV indicate the task duration of each participant for each task.

TABLE I. INTERFACE TEST RESULTS FROM PARTICIPANTS WITH ASD

\begin{tabular}{|c|c|c|c|c|c|c|}
\hline & \multicolumn{5}{|c|}{ Participant } & E \\
\hline Observation & A & B & C & D & Percentage \\
\hline Can read the objective & Yes & No & Yes & Yes & Yes & $\mathbf{8 0 \%}$ \\
\hline $\begin{array}{c}\text { Can locate the player on } \\
\text { the map }\end{array}$ & No & No & Yes & Yes & No & $\mathbf{4 0 \%}$ \\
\hline $\begin{array}{c}\text { Can locate the objective } \\
\text { on the map }\end{array}$ & No & No & Yes & Yes & No & $\mathbf{4 0 \%}$ \\
\hline
\end{tabular}

TABLE II. INTERFACE TEST RESULTS FROM CONTROL PARTICIPANTS

\begin{tabular}{|c|c|c|c|c|c|c|}
\hline & \multicolumn{5}{|c|}{ Control Participant } & J \\
\hline Observation & F & G & H & I & Percentage \\
\hline Can read the objective & Yes & Yes & Yes & Yes & Yes & $\mathbf{1 0 0 \%}$ \\
\hline $\begin{array}{c}\text { Can locate the player on } \\
\text { the map }\end{array}$ & Yes & Yes & Yes & Yes & Yes & $\mathbf{1 0 0 \%}$ \\
\hline $\begin{array}{c}\text { Can locate the objective } \\
\text { on the map }\end{array}$ & No & Yes & Yes & Yes & No & $\mathbf{6 0 \%}$ \\
\hline
\end{tabular}

TABLE III. TASK RESULTS FROM PARTICIPANTS WITH ASD

\begin{tabular}{|c|c|c|}
\hline & \multicolumn{2}{|c|}{ Task duration (minutes) } \\
\hline Participant & Tutorial & Task \\
\hline A & 6.58 & 4.47 \\
\hline B & 4.57 & 15.95 \\
\hline
\end{tabular}

\begin{tabular}{|c|c|c|}
\hline C & 4.44 & 3.53 \\
\hline D & 9.70 & 2.42 \\
\hline E & 9.20 & 17.46 \\
\hline Mean & 6.90 & 8.77 \\
\hline Standard deviation & 2.22 & 6.53 \\
\hline
\end{tabular}

TABLE IV. TASK RESULTS FROM CONTROL PARTICIPANTS

\begin{tabular}{|c|c|c|}
\hline & \multicolumn{2}{|c|}{ Task duration (minutes) } \\
\hline Control Participant & Tutorial & Task \\
\hline F & 4.45 & 4.05 \\
\hline G & 2.68 & 2.34 \\
\hline H & 4.39 & 3.29 \\
\hline I & 4.47 & 9.33 \\
\hline J & 4.58 & 4.10 \\
\hline Mean & 4.11 & 4.62 \\
\hline Standard deviation & 0.72 & 2.44 \\
\hline
\end{tabular}

\section{CONCLUSION AND FUTURE WORK}

The results obtained from the interface evaluation show that some components need improvement to become more visible. Statistically comparing performance times, the mean time needed to complete the tutorial was 6.9 minutes for participants with ASD and 4.11 minutes for control participants. Further, the mean time needed to complete the task was 8.77 minutes for participants with ASD and 4.62 minutes for control participants. The difference in performance between participants with ASD and controls reveals a target for the serious game intervention. Due to the high performance dispersion, observable among the individuals with ASD, future stages will include larger study and control groups. In the next stages of development, a system to better measure the player's performance will be implemented. This system will consist of two main components: a score system which focuses on the player's actions, and a biofeedback system, based on electrodermal activity, which measures the anxiety level of the player throughout the task and adapts the environment to it. With these, it will be possible to analyze the impact of practice on both task performance and anxiety reduction. Furthermore, additional elements such as people, animals and cars will be added to increase the complexity of the tasks and travel challenges. Accordingly, results obtained in following stages will allow a more thorough analysis, and may be useful in understanding how games and virtual reality can help individuals with ASD become more independent, specifically regarding to the task of taking the bus.

\section{REFERENCES}

[1] American Psychiatric Association, Diagnostic and Statistical Manual of Mental Disorders, 5th ed. Arlington: American Psychiatric Publishing, 2013.

[2] O. Bimber, “Thinking Virtual," Computer (Long. Beach. Calif)., vol. 47, no. 7, pp. 22-23, Jul. 2014.

[3] D. R. Michael and S. L. Chen, Serious games: Games that educate, train, and inform. Muska \& Lipman/Premier-Trade, 2005.

[4] S. H. A. Chen and V. Bernard-Opitz, "Comparison of personal and computer-assisted instruction for children with autism.," Ment. Retard., 1993. 

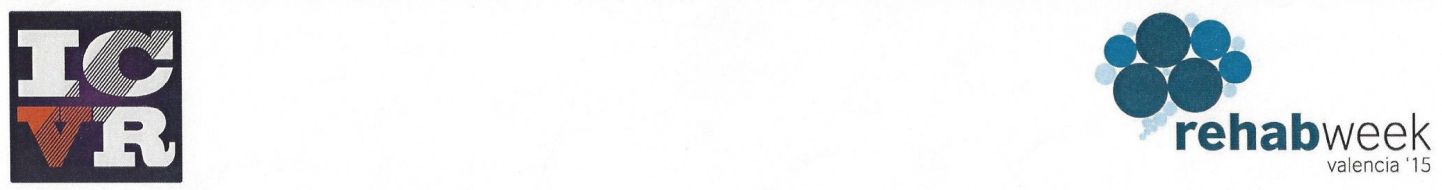

International Conference on Virtual Rehabilitation 2015 June 9-12th, Valencia (Spain)

Best Student Poster - Honorable Mention
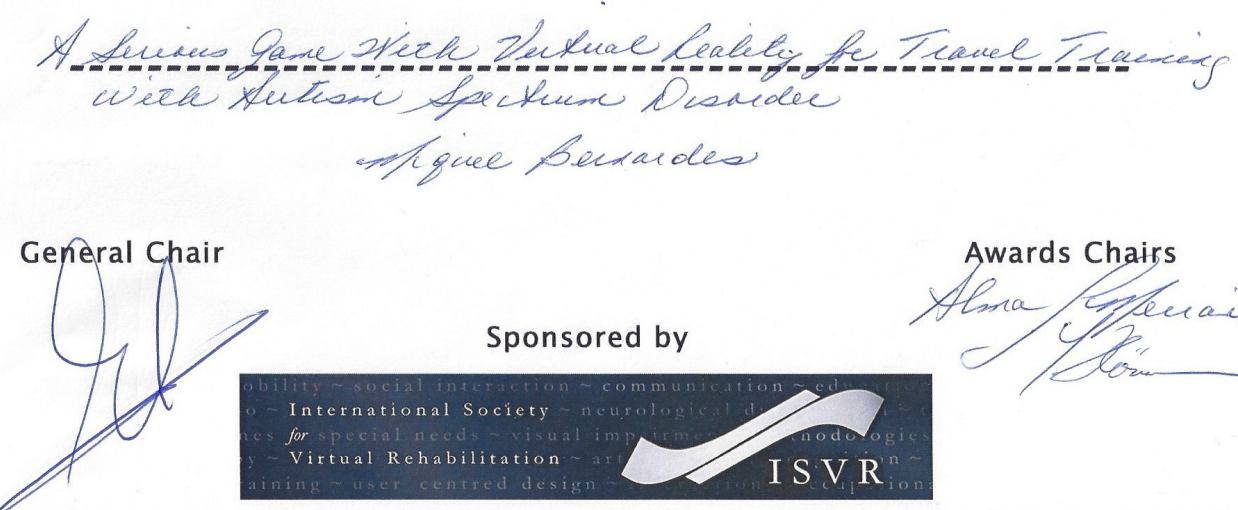

Figure B.1: ICVR2015 award. 


\section{Appendix C}

\section{Unity development}

The purpose of this appendix is to explain the basics concepts of Unity development, along with an example extracted from this project.

Unity [76] is a game engine that can be used to create 2D and $3 \mathrm{D}$ games for a vast array of platforms, from mobile, to PCs and consoles. Games developed in Unity are divided into scenes. Each scene is an independent part of the game, like a level or a menu, which are then built using objects. In its core, an object is merely a set of coordinates, to which components are added. Typically, when adding, for example, a house to a scene, it will be an object with a mesh (the 3D model), a mesh renderer (draws the object in the scene) and a collider (stops the player from walking through the house). However, a house is just a static object in an environment. In order to create behaviours or program the game logic, scripts are created (in C\#, JavaScript or Boo), implemented, and added to objects as components. Even though there is no limit to the number of components that can be added to an object, objects can be added as children of other objects.

The layout of the Unity application can be seen on the image below, on Figure C.1. 


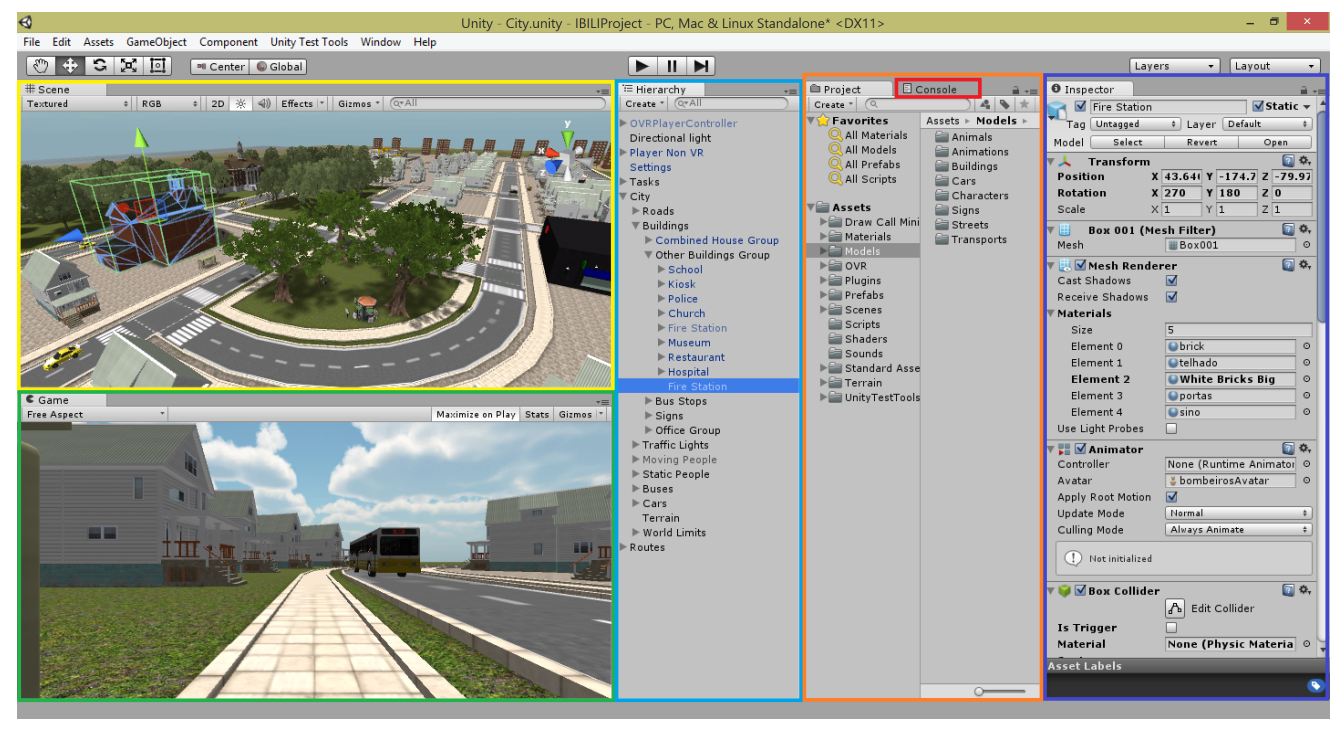

Figure C.1: Unity screen.

Unity's structure is organized in 6 sections:

- Scene view (yellow rectangle) - shows the environment with all the objects of the scene. It offers an editable view of the level, where it is possible to place new objects and organize them.

- Game view (green rectangle) - shows the game as seen by the player.

- Hierarchy (light blue rectangle) - list of all objects in the scene.

- Project (orange rectangle) - list of all assets of the project (e.g. 3D models, scripts, scenes, sounds).

- Console (red rectangle) - shows errors, warnings and other messages.

- Inspector (dark blue rectangle) - shows the properties of any object, asset or setting panel selected.

To better illustrate how the implementation process in Unity works, the creation of a bus can be considered as an example and will be briefly described.

To create a bus, an object was created and given a 3D bus model, and enough colliders to ensure that the player wouldn't be able to go through anything but the entrance and exit. Afterwards, animations and audio (sound of an idle bus) were added. The animator tool in Unity allows the creation of a state machine that controls the animations playing. Accordingly, each state can have an animation associated, and will change to other states whenever specific conditions are met. In 
this case (Figure C.2), whenever the bus stops at a bus stop, it goes from "Idle" (no animation) to "bus@open" (opens the doors). Similarly, right before it leaves the stop, the state switches to "bus@close" (closes the doors), returning, once again, to the "Idle" state.

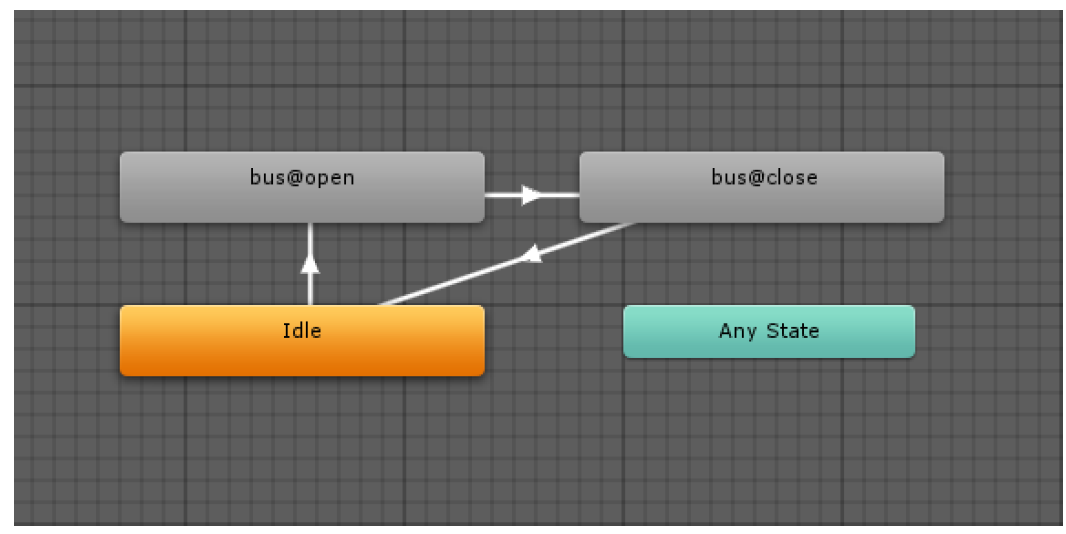

Figure C.2: Unity Animator.

After the basic components of the bus had been added, its inside was filled with 3D models of people, added to each seat, along with a sitting animation (Figure C.3).

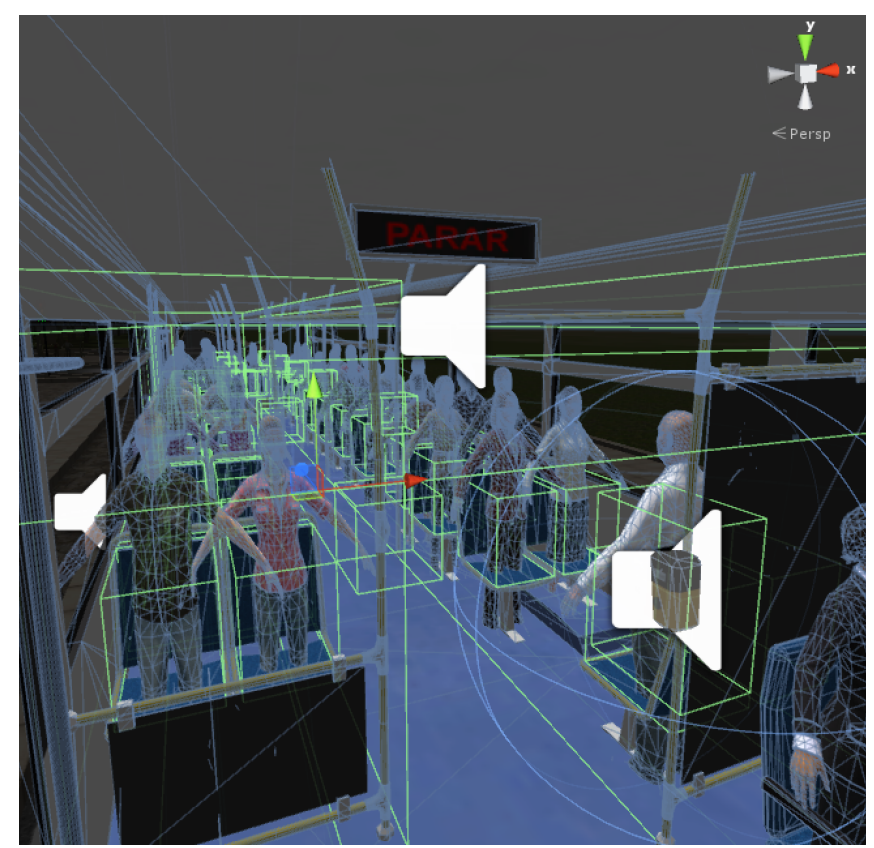

Figure C.3: Bus environment in Unity. 
To make the bus more than a simple, static object, a script was created and added to it that randomizes the presence of people inside the bus, and moves the bus through the city. In order to make different buses move through different routes, four groups of objects were created, each representing a route and associated to a specific bus. These groups contain several empty objects, placed throughout the routes. Furthermore, when the buses move, they drive until the next empty object in its route, and from that one to the next. These objects have specific names, so the bus knows when it matched a bus stop. Finally, to avoid the bus from running over the player in case he/she stood in front of it, a collider was placed in front of the bus. The latter will not act as an obstacle, but as a trigger, and will alert the bus whenever the player is found inside. That way, the bus can stop and honk at the player to leave the road. This trigger can be seen in Figure C.4, as a big green box in front of the bus.

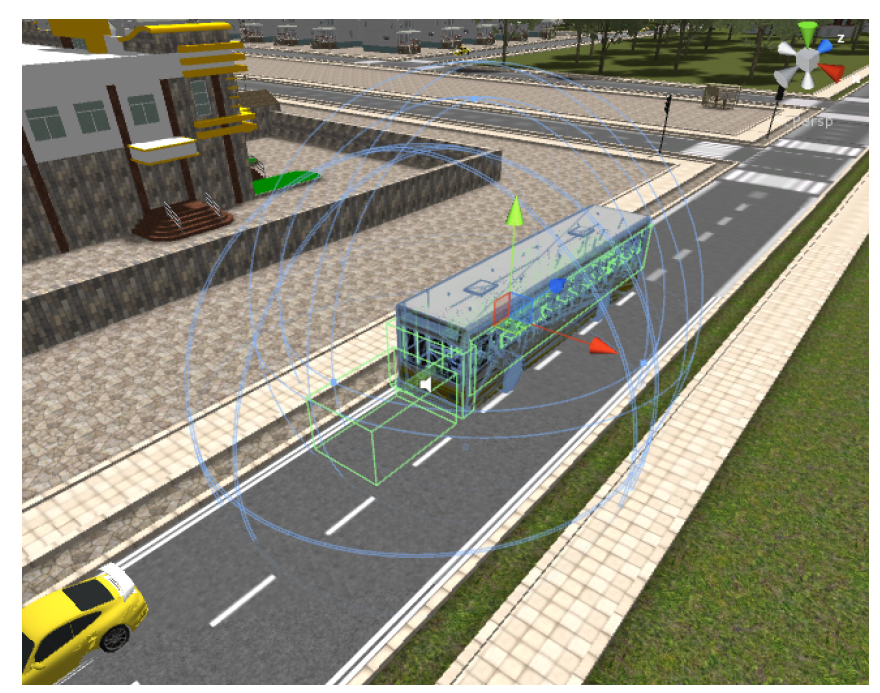

Figure C.4: Bus in Unity.

Most elements within the bus are interactable, from the validating machine, to the stop buttons and seats. The interaction with all these objects is done in the same way, by looking at them and pressing a key to interact. Instead of creating a script for each type of object, which would only differ on what happens upon interaction, $\mathrm{C \#}$ delegates can be used. A delegate is a type of variable whose value is the reference to a function, instead of data. By using delegates, it was possible to use the same script for every interactable element. First of all, the script with a delegate was created, as seen in Figure C.5. 


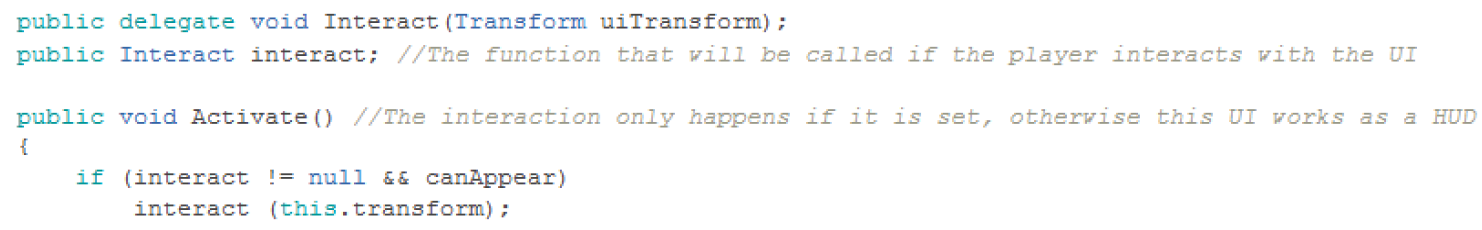

Figure C.5: C\# code segment with the creation of a delegate.

However, if these functions are neither set nor written in the script, they must come from somewhere else. Accordingly, in the bus behaviour script, the three functions for the interaction with the validating machine, stop buttons and seats, are written, as shown in Figure C.6.

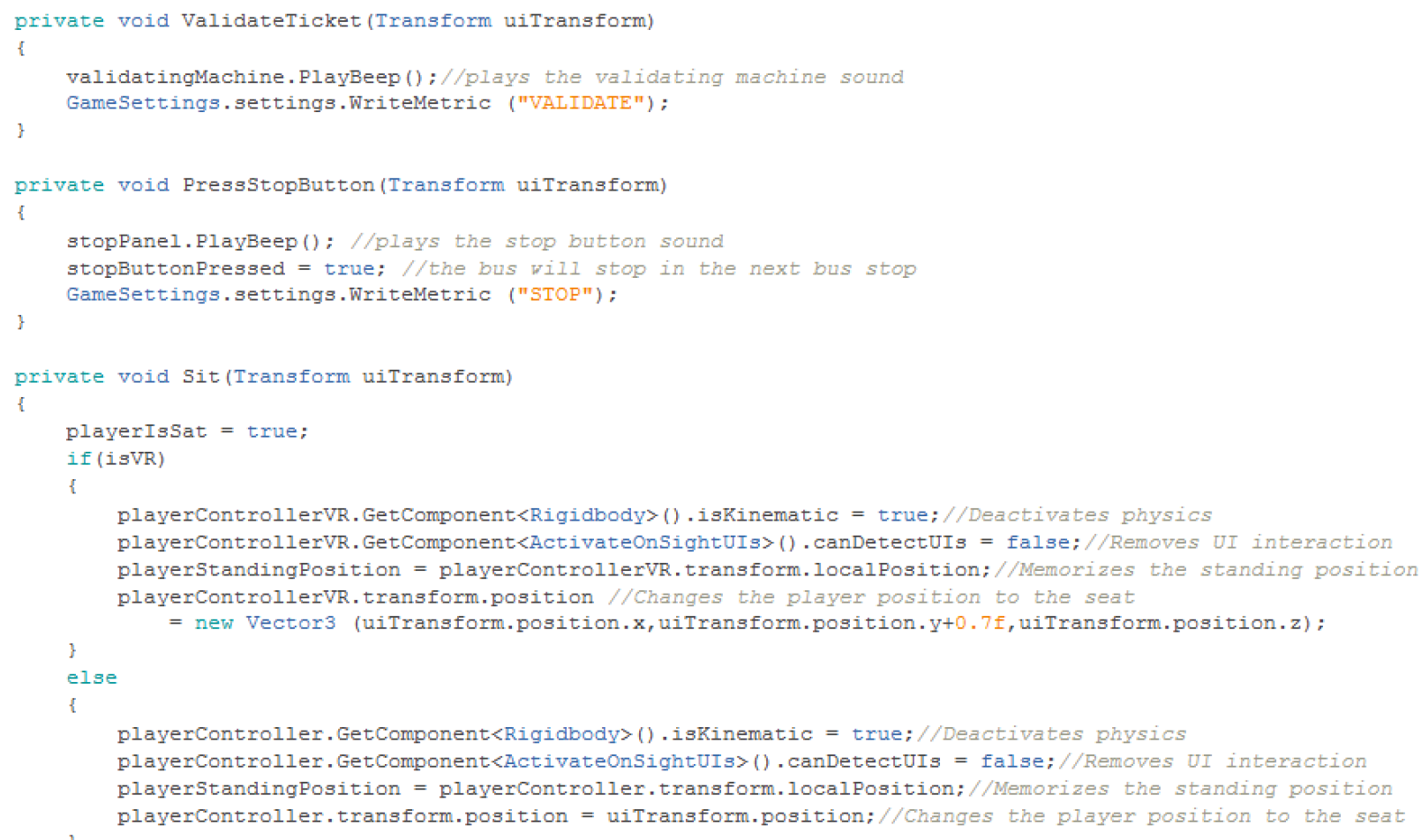

Figure C.6: C\# code segment with the creation of the interaction functions.

With the functions created, they are attributed to each delegate of each interactable object, within the Awake() function of the bus behaviour script (Fig- 
ure C.7)(the Awake() is a function is called, before the start of the game, when the script instance is loaded).

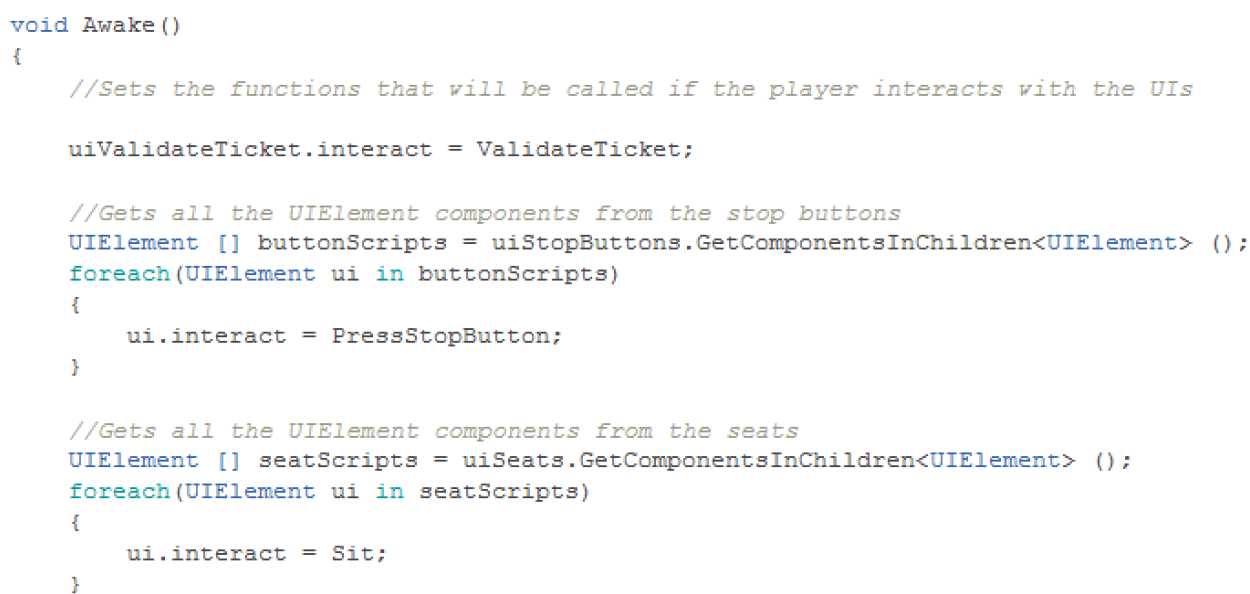

Figure C.7: C\# code segment with the attribution of the interaction functions to the delegates.

This way, whenever the player interacts with the objects, each will be able to call their respective interaction function. More information about Unity development can be found on on-line in the Unity Manual [104].

Despite the potential of Unity as a game engine, the development process is particularly eased thanks to the large community and support offered online. Furthermore, Unity currently has more than 4,000,000 registered developers and $45 \%$ of global game engine market share [94]. This document aimed at delivering a brief explanation of how the Unity development process works. 